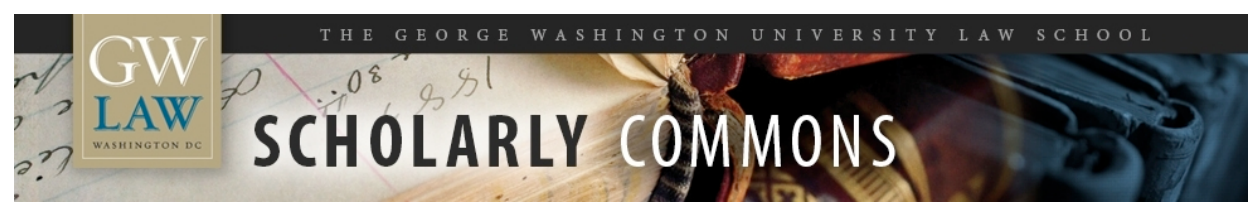

\title{
Murder and the Reasonable Man: Passion and Fear in the Criminal Courtroom
}

\section{Cynthia Lee}

George Washington University Law School, cylee@law.gwu.edu

Follow this and additional works at: https://scholarship.law.gwu.edu/faculty_publications

Part of the Law Commons

\section{Recommended Citation}

Lee, Cynthia, "Murder and the Reasonable Man: Passion and Fear in the Criminal Courtroom" (2003). GW Law Faculty Publications \& Other Works. 27.

https://scholarship.law.gwu.edu/faculty_publications/27

This Book Part is brought to you for free and open access by the Faculty Scholarship at Scholarly Commons. It has been accepted for inclusion in GW Law Faculty Publications \& Other Works by an authorized administrator of Scholarly Commons. For more information, please contact spagel@law.gwu.edu. 


\section{CYNTHIA LEE}

\section{MURDER AND THE REASONABLE MAN}

Passion and Fear in the Criminal Courtroom

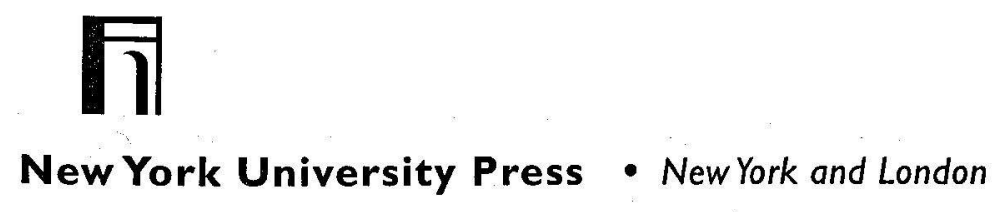




\section{Female Infidelity}

Albert Joseph Berry, a forty-six-year-old cook, and Rachel Pessah, a twenty-year-old woman from Israel, were married on May 27, 1974. Three days after the wedding, Rachel went to Israel by herself. When she returned to the United States on July 13, Rachel told Albert that she had fallen in love with a man she met in Israel, that she thought she might be pregnant by this other man, and that she wanted a divorce.

Nine days later, Albert and Rachel went to a movie. According to Albert, they engaged in heavy petting at the theater. When they got home, Albert expected to have sexual intercourse. Rachel, however, refused, telling Albert that although she had earlier intended to make love with Albert, she decided against it because she wanted to save herself for Yako, the man she had been seeing in Israel. Albert got angry and began to leave. When Rachel started screaming at him, he grabbed her by the throat, and choked her into unconsciousness. Two hours later, Albert called for a taxi to take his wife to the hospital. Albert then spent the night with a woman friend.

Three days later, Albert returned to the apartment. It was 3:00 P.M. and Rachel was not in. She did not return to the apartment that night. Throughout the evening, Albert kept thinking about his wife sleeping with another man, and it made him steam with anger. When Rachel finally came home at 11:00 A.M. the next day, she looked at Albert and said, "I suppose you have come here to kill me." Albert replied, "Yes," then "No," and finally "Yes" again, followed by "I have really come to talk to you." Angry words followed. In an explosion of anger, frustration, and exasperation, Albert grabbed his wife and strangled her with a telephone cord. ${ }^{1}$

Albert Berry was charged with first-degree murder and assault by means of force likely to produce great bodily injury. At trial, Berry's attorney requested a jury instruction on voluntary manslaughter, arguing that Berry was provoked into a heat of passion by Rachel's confession 
of adultery and the ensuing two-week period of sexual taunts and alternating acceptance and rejection. To support this request, Berry's defense attorney called a psychiatrist to the stand who testified that Rachel was a depressed, suicidal girl who sexually aroused Berry and then taunted him into jealous rages by repeated references to her affair with another man in an unconscious effort to provoke Berry into killing her.

The trial court refused to grant the defendant's request for a jury instruction on voluntary manslaughter, and Berry was convicted of firstdegree murder. Berry appealed his conviction to the California Supreme Court. That court reversed Berry's conviction, on the ground that sufficient evidence of provocation existed to warrant a jury instruction on voluntary manslaughter.

The Berry case is a useful vehicle to understand the provocation defense in its various formulations. Provocation or heat of passion is a partial defense ${ }^{2}$ that mitigates a murder charge to voluntary manslaughter. ${ }^{3}$ Ordinarily, if a defendant intends to kill his victim, he acts with the malice aforethought required for a murder conviction. In a successful provocation case, however, the defendant, whose claimed loss of selfcontrol negates the malice aforethought required for murder, is instead convicted of voluntary manslaughter. A voluntary manslaughter conviction makes a huge difference in one's possible sentence. In California, for example, a person convicted of voluntary manslaughter may be sentenced to a term of three, six, or eleven years in the state prison. ${ }^{4} \mathrm{~A}$ person convicted of first-degree murder, in contrast, may be sentenced to a minimum of twenty-five years in prison up to a maximum of life imprisonment. ${ }^{5}$ One convicted of second-degree murder may be sentenced to fifteen years to life. ${ }^{6}$

In order to receive the mitigation from murder to voluntary manslaughter, the defendant must have been incited to violence by "legally adequate provocation" and must not have had a reasonable opportunity to cool off between the time he was provoked and the time he killed the victim. Over the years, American courts and legislatures have embraced three different approaches to provocation. I call these three approaches the early common law or categorical test, the modern or reasonable person test, and the Model Penal Code's extreme emotional disturbance defense. Most jurisdictions today appear to use the modern reasonable person approach, but a significant number of states have in- 
stead adopted the Model Penal Code's extreme emotional disturbance defense.

\section{THE EARLY COMMON LAW'S CATEGORICAL APPROACH}

In the 1700s, courts developed a short list of categories that constituted legally adequate provocation: "(1) an aggravated assault or battery, (2) mutual combat, (3) commission of a serious crime against a close relative of the defendant, (4) illegal arrest, [or] (5) observation by a husband of his wife committing adultery." ${ }^{77}$ Only acts falling within these five categories could trigger the provocation mitigation. ${ }^{8}$

Because the categories were clearly defined, the judge would decide whether legally adequate provocation existed and consequently, whether the issue of provocation would even get to the jury. If the judge decided that legally adequate provocation existed, then the jury could return a verdict of murder, voluntary manslaughter, or acquit the defendant of all charges. If the judge decided that the allegedly provocative conduct by the victim did not fall within one of the narrow categories of legally adequate provocation, the jury would have only two choices: murder or complete acquittal.

One court explained the rationale behind the categorical approach as follows:

To have the effect to reduce the guilt of the killing to the lower grade, the provocation must consist of personal violence. This rule is well established, and we imagine it would not be the part of wisdom to substitute in its place one fluctuating or less rigid, which would require the accused to be judged in each case according to the excitement incident to his natural temperament when aroused by real or fancied insult given by words alone. There must be an assault upon a person, as where the provocation was by pulling the nose, purposely jostling the slayer aside in the highway, or other direct and actual battery. ${ }^{9}$

The personal violence rationale may well explain the reasoning behind the first four categories, ${ }^{10}$ but does not explain the fifth-observation by a husband of his wife in the act of adultery. Sexual betrayal might 
constitute an assault on the husband's ego, but is far from a physical attack upon a person.

If we look carefully at the early common law categories of legally adequate provocation, it becomes apparent that they were created with the hot-blooded man in mind. Men were thought more likely than women to be subjected to an aggravated assault or battery. Men were thought more likely than women to be involved in mutual combat. They were also thought more likely than women to respond with violence to a serious crime committed against a close relative.

The last category of legally adequate provocation, however, was the clearest indication that the early common law categories of legally adequate provocation were created by and for the male half of the population. The husband's observation of his wife having sexual relations with another man was the only category of legally adequate provocation at common law that explicitly applied to male defendants (husbands who killed their wives), and not their female counterparts (wives who killed their husbands). ${ }^{11}$ Moreover, this last category was the only kind of provocation that did not involve violent behavior on the part of the victim toward the defendant. Nonetheless, it was considered the paradigmatic example of legally adequate provocation. ${ }^{12}$

A husband's observation of his wife in the act of adultery was thought to be such a grievous injury and affront to the husband that several states, including Georgia, Texas, Utah, and New Mexico, deemed the husband's killing of an adulterous wife or her lover a justifiable homicide-not a crime at all. ${ }^{13}$ So strong was this sentiment that a New Mexico court gave a jury instruction on justifiable homicide even though the defendant in that case claimed he shot his wife's lover in self-defense, not because he was outraged and wanted to prevent adultery from taking place. In ruling that the trial court did not err in giving a justifiable homicide instruction, the Court of Appeals explained:

The purpose of the law is not vindictive. It is humane. It recognizes the ungovernable passion which possesses a man when immediately confronted with his wife's dishonor. It merely says the man who takes life under those circumstances is not to be punished; not because he has performed a meritorious deed; but because he has acted naturally and humanly. We in New Mexico have enacted [a law], as has been enacted in Texas, that [says], instead of mitigating the homicide to manslaughter, as at common law, such circumstances justify the act. ${ }^{14}$ 
Interestingly, in three out of the four states that recognized justifiable homicide (Georgia, Texas, and Utah), a husband could claim justifiable homicide only if he killed his rival, not if he killed his wife. In these states, if the husband killed his wife after catching her in the act of adultery, the appropriate charge was voluntary manslaughter. In a twisted way, perhaps the legislators who passed these justifiable homicide statutes were trying to protect wives by encouraging husbands to direct their passion and anger against the lover rather than against the wife herself. One court explained that killing the wife's lover was justifiable because such an act was necessary to protect the marriage; killing the wife, by contrast, was not justified because killing her would terminate the marriage. ${ }^{15}$

Why was a husband's observation of his wife in the act of adultery considered so provocative? Assumptions about married women as property belonging to their husbands contributed to the belief that adultery was an extraordinary affront to the husband's sense of self and his manhood. ${ }^{16}$ At marriage, a woman was supposed to become one with her husband. Any property owned by the woman prior to marriage became the husband's property upon marriage. The wife herself was regarded as property of the husband. A wife could not own a credit card in her own name. She could not open an individual checking or savings account. She could not own property separate from her husband, nor could she obtain a home mortgage on her own. In many jurisdictions, a husband could not be convicted of raping his wife because she was considered his property. ${ }^{17}$ Reva Siegel explains:

By law, a husband acquired rights to his wife's person, the value of her paid and unpaid labor, and most property she brought into the marriage. A wife was obliged to obey and serve her husband, and the husband was subject to a reciprocal duty to support his wife and represent her within the legal system. According to the doctrine of marital unity, a wife's legal identity "merged" into her husband's, so that she was unable to file suit without his participation, whether to enforce contracts or to seek damages in tort. ${ }^{18}$

Another reason given for mitigating a killing by a husband who observed his wife in the act of adultery was that sexual infidelity rendered paternity uncertain. If a wife committed adultery with another man, she could then bear that man's child. Given the difficulty of determining the 
true father under such circumstances, a husband might do all he could, including killing his rival, to avoid having to pay the costs of rearing another man's child. Evolutionary psychologists argue that because men alone face this problem of paternity uncertainty, men are naturally more likely than women to respond to sexual infidelity with violence. ${ }^{19}$

The early common law approach was explicitly biased in favor of men. Only a husband could claim provocation at the sight of his wife in bed with another man. A wife who caught her husband having sexual relations with another woman was not permitted to claim she was provoked into a heat of passion. The law expected a dutiful wife to accept her philandering husband's misbehavior. If a wife killed her unfaithful husband or his lover, she was a murderer. Consider the case of Pearl Reed who killed her husband's mistress after catching the woman in a sexual embrace with her husband. Mrs. Reed tried unsuccessfully to come under Texas's justifiable homicide statute.

Pearl Reed, a married woman living in Texas in the 1930s, left her husband to live with her parents because of marital difficulties. Later, she returned to her husband, but their relationship remained rocky.

One evening, Pearl and her husband were helping out at a supper for the benefit of the church. A woman named Margaret Washington sent word to Pearl's husband that she wanted to come to the supper, but needed him to come get her. Pearl's husband left the supper without saying anything to Pearl. Pearl soon noticed that her husband was missing from the supper and suspected that he had gone to meet Margaret. Pearl found a pistol in the drawer of the house where the supper was being held and left the supper in search of her husband. She headed towards Margaret's house. About 300 yards from the house, she found her husband and Margaret in a sexual embrace by the side of the road. Pearl cried out, "Oh Bubba." Hearing Pearl's voice, Pearl's husband and Margaret jumped up and started running away. Pearl pulled out the pistol she'd found at the supper and fired at the two lovers, killing Margaret in the process. ${ }^{20}$

Pearl was charged with and convicted of murder. At the time of the shooting, the Texas Penal Code provided, "Homicide is justifiable when committed by the husband upon one taken in the act of adultery with the wife, provided the killing takes place before the parties to the act have separated." ${ }^{21}$ Appealing her murder conviction, Pearl argued that because a husband had the right to kill his wife's lover if he caught his 
wife in the act of adultery, she too had the right to kill her husband's lover because she had caught the woman in the act of adultery with her husband.

The Texas Court of Appeals could have rejected Pearl Reed's appeal on the ground that she shot her husband's mistress after, not before, the two had separated. Because the statute required the killing to take place "before the parties to the act have separated," Pearl did not meet the requirements of the statute. Instead, the appellate court refused to apply the statute to Pearl on the ground that it was only intended to benefit husbands, not wives, who killed after catching their wives in the act of adultery. The court explained:

We cannot agree with the contention of the appellant. No matter what our opinion might be upon the justice or injustice of article 1220, P.C., which justifies a homicide when committed by the husband upon one taken in the act of adultery with the wife, provided the killing takes place before the parties to the act have separated, it does not give the wife justification for her act if she should kill the woman taken in the act of adultery with her husband. The courts are not vested with the power to make laws but under the Constitution such power is vested alone in the Legislature, and the duties of the courts are to take and enforce them as they are written. If the Legislature in their wisdom has not given equal rights to the wife as they have given to the husband under article 1220, P.C., the courts are without power to do so. ${ }^{22}$

The Texas Court of Appeals deferred to the legislature rather than taking action to rectify the gender inequity reflected in the statute. A court hearing this case today might strike down the Texas statute on Equal Protection grounds because it treats similarly situated men and women differently. ${ }^{23}$

Elizabeth Rapaport explains that the mitigation or justification afforded husbands who killed in response to adultery by their wives was really about protecting the husband's sense of masculinity:

Adultery is sufficient provocation by virtue of being assimilated to assault: The blow administered to the husband is moral, not physical. Adultery derogates from his manhood, which both entitles him and requires him to control his wife, sexually and otherwise. Within the 
patriarchal conception of marriage, any challenge to masculine control-adulterous behavior or inclinations, contesting household authority, leaving -is an assault on both legitimate prerogatives and the very masculinity of the husband. Traditionally, violence to reassert possession or punish defiance has been considered legitimate masculine behavior. It is the rootedness of adultery provocation in patriarchal norms which explains why the extension of this mitigation to women who kill adulterous husbands did not occur until the law began to undergo the transition towards gender egalitarianism. It was not pain and anger at betrayal, which either the husband or wife may feel, that mitigated culpability at classical common law; rather, it was the defense of masculinity and its prerogatives and the legitimacy of violence as a vehicle of male control of the family. ${ }^{24}$

Eventually, the early common law's highly rigid categorical approach to provocation came under increasing criticism, not because it was seen as unfair to women who killed their unfaithful husbands, but because it was thought unfair to male murder defendants who could not meet the early common law's stringent requirements. Joshua Dressler explains:

Only a highly unrealistic belief about passion can explain [the common law] rule in terms of excusing conduct. It is implausible to believe that when an actor observes his or her loved one in an act of sexual disloyalty that actor will suffer from less anger simply because the disloyal partner is not the actor's spouse. Instead, this rule is really a judgment by courts that adultery is a form of injustice perpetrated upon the killer which merits a violent response, whereas "mere" sexual unfaithfulness out of wedlock does not. Thus, it has been said that adultery is the "highest invasion of [a husband's] property," whereas in the unmarried situation the defendant "has no control" over his faithless lover. ${ }^{25}$

Not only was the early categorical approach seen as unfair to unmarried men who claimed they were provoked into killing their unfaithful fiancées or girlfriends, it was also thought to be unfair to married men who learned of their wives' adultery through third parties or through their wives' own confessions. Under the early common law approach to provocation, Albert Berry, although a married man, would not have 
been entitled to argue that he was provoked into a heat of passion by Rachel's adultery because he did not personally discover Rachel in the act of adultery. ${ }^{26}$

\section{THE MODERN APPROACH:}

\section{THE REASONABLE MAN STANDARD}

Given the restricted nature of the categorical approach to provocation, in the late 1800 s many jurisdictions began to abandon it in favor of an approach that employed a reasonableness requirement to determine which types of behavior could be considered legally adequate provocation. ${ }^{27}$ Initially, this approach compared the defendant's actions to those of the hypothetical Reasonable Man. Later, in response to criticism that the Reasonable Man approach favored male defendants over female defendants, jurisdictions began to replace the words "Reasonable Man" with "Reasonable Person."

In modern jurisdictions, legally adequate provocation exists if the hypothetical reasonable person in the defendant's shoes would have been provoked into a heat of passion. For a defendant to receive the provocation mitigation, the jury must find that (1) the defendant was actually provoked into a heat of passion, (2) the reasonable person in the defendant's shoes would have been so provoked, (3) the defendant did not cool off, and (4) the reasonable person in the defendant's shoes would not have cooled off between the provocative event and the act or acts that led to the victim's death. ${ }^{28}$ Because the defense of provocation is considered a case-in-chief defense attacking the existence of malice aforethought, the mental state required for a murder conviction, the state has the burden of disproving at least one of the above elements beyond a reasonable doubt. ${ }^{29}$ In sending the case back to the jury to decide whether Berry's reaction was reasonable, the California Supreme Court's opinion in the Berry case reflects the modern approach to provocation.

Unlike the early common law approach which allowed a defendant to claim provocation only if he was responding to something that fell within one of the strictly defined categories of legally adequate provocation, the modern test adopts a context-sensitive approach that permits more defendants to claim provocation as a defense. The defendant 
need not be married to claim partner infidelity as legally adequate provocation, nor must the defendant personally discover his or her partner in flagrante delicto (in the act) in order to assert the defense. Moreover, the defendant doesn't have to be correct in his belief. Even perceived infidelity can constitute legally adequate provocation under the modern test. As long as the fact finder finds that the reasonable man (or woman) in the defendant's shoes would have been provoked into a heat of passion, the defendant may receive the mitigation to voluntary manslaughter.

Another difference between the early common law and the modern approach to provocation lies in who (or which body) gets to decide whether legally adequate provocation exists. As a general rule, judges decide questions of law while juries decide questions of fact. Under the early common law approach, the judge determined whether legally adequate provocation existed because the categories of legally adequate provocation were clearly delineated as a matter of law. In modern jurisdictions, while the judge plays an initial gatekeeper function, deciding whether there is sufficient evidence of provocation to permit defense argument on provocation, the jury ultimately decides whether the thing that provoked the defendant constitutes legally adequate provocation. ${ }^{30}$ Legally adequate provocation exists if the Reasonable Person in the defendant's shoes would have been provoked into a heat of passion, and reasonableness is considered a mixed question of law and fact best left to a twelve-person jury reflecting the community's norms and values, rather than a single judge.

The modern approach to provocation appears to establish gender equality by giving men and women equal access to the defense. ${ }^{31}$ In practice, however, the modern approach still ends up benefiting men more than women because more men than women kill their partners, and thus have the opportunity to use the provocation defense. According to statistics compiled by the U.S. Department of Justice, nearly 52,000 men and women were killed by someone with whom they shared an intimate relationship between 1976 and $1996 . .^{32}$ Almost 30 percent of all female homicide victims were killed by husbands, former husbands, boyfriends, or former boyfriends, while less than 6 percent of all male homicide victims were killed by wives, former wives, girlfriends, or former girlfriends. ${ }^{33}$ In 1996, approximately 2,000 intimate partner homicides were committed..$^{34}$ Of these 2,000 homicides, three out of every four victims were women. ${ }^{35}$ 
When women kill their male partners, they are not necessarily treated unfairly by the criminal justice system. Government studies indicate that female defendants in spouse murder cases are more likely to be acquitted than male defendants. ${ }^{36}$ Additionally, female defendants convicted of killing their husbands tend to receive shorter prison sentences than male defendants convicted of killing their wives. ${ }^{37}$ The average sentence for a convicted wife in a spouse murder case is six years. The average sentence for a convicted husband is 16.5 years. ${ }^{38}$ While these numbers suggest the system is biased in favor of women and against men, the gender differential may also be due to the fact that grounds for claiming self-defense (e.g., being attacked by one's husband) are more often present in wife defendant cases than in husband defendant cases."

The factors motivating intimate partner homicide are different for men than they are for women. Studies have found that most women who kill their male partners do so after suffering tremendous physical and psychological abuse ${ }^{39}$ In contrast, men charged with killing their female partners more often than not are motivated by sexual jealousy. ${ }^{40}$ Even if these men are initially charged with first-degree murder, the majority end up being convicted of some lesser offense. ${ }^{41}$ Because killing in response to female infidelity is seen as a mitigating factor, men who kill their female intimates are rarely charged with or convicted of capital murder. Elizabeth Rapaport calls this the "domestic discount"-a discount given only to men who claim they were provoked into killing their female domestic partners. ${ }^{42}$

Men who kill their wives were not always viewed so favorably. Carolyn Ramsey notes that during the 1800 s, more than half of all defendants convicted of capital murder in New York County were men who had killed their wives or female lovers. ${ }^{43}$ According to Ramsey, prosecutors were more likely to seek the death penalty for domestic murderers who failed to live up to then prevailing masculinity norms than men who killed male rivals. In Ramsey's view, the District Attorney had an incentive to sate the public's desire for harsh punishment by trying

* Patrick A. Langan and John M. Dawson, U.S. Dept of Justice, Spouse Murder Defendants in Large Urban Counties 21 (1995) (noting that grounds for claiming self-defense are more often present in wife defendant cases than in husband defendant cases). 
marginal figures, such as unemployed drunks who killed their wives, on capital charges.

Donna Coker observes that many men who kill in response to actual or perceived female partner infidelity have a history of violence that is overlooked or downplayed. Coker observes:

Contrary to "[t]he popular image of the model citizen who one day goes beserk and kills a family member[,]" police studies have consistently found that men who kill their female partners have a history of violent behavior. Roughly $70 \%$ to $75 \%$ of domestic homicide offenders have been previously arrested and about $50 \%$ have been convicted [of] violent crimes. ${ }^{44}$

Moreover, according to Coker, men who kill their female partners in response to actual or perceived infidelity and those who abuse their female partners share much in common. Both blame the female victim for causing them to react violently. The man who kills his female partner maintains that her infidelity caused him to lose his self-control. The man who abuses his female partner blames her for failing to act the way a good wife, fiancée, or girlfriend should act. ${ }^{45}$

Coker points to several reasons to question the male abuser's claimed loss of self-control. First, abusive men in heterosexual relationships tend to direct their violence only against current or former wives, girlfriends, or children. ${ }^{46}$ They may have similar feelings of frustration and rage in other settings, but do not respond with violence. ${ }^{47}$ Coker explains that " $[t]$ his is likely the result of differentially perceived risks as well as social learning that justifies violence against female partners (e.g., 'If I hit my boss, I would get fined and maybe arrested; but my wife is supposed to do what I say')." 48

Second, men who beat their wives, but stop short of killing, often explain that the violence was not more severe because they did not want to seriously injure their partner, suggesting a level of control over the degree of violence which is inconsistent with the abuser's claim of loss of self-control. ${ }^{49}$ In Stiffed: The Betrayal of the American Man, Susan Faludi recounts one convicted batterer's confession to his domestic violence counseling group:

"I denied it before," he said of the night he pummeled his girlfriend, who had also worked on the base. As he spoke, he studied his massive, 
callused hands, lying uselessly on his lap. "I thought I'd blacked out. But looking back at that night, when I beat her with an open hand, I didn't black out. I was feeling good. I was in power. I was strong. I was in control. I felt like a man." But what struck me most strongly was what he said next: that moment of control had been the only one in his recent life. "That feeling of power," he said, "didn't last long. Only until they put the cuffs on. Then I was feeling again like I was no man at all." 50

Like the man who batters his female partner, one who kills his female partner because of infidelity, real or imagined, asserts he could not control himself, excusing his violent action as the result of an understandable loss of self-control. The same factors that cause us to question the abuser's claimed loss of self-control should make us question the man who claims his female partner made him do it. Moreover, often a significant period of time elapses between the event which triggers the claimed loss of self-control and the killing, suggesting the killing was deliberate and planned rather than spontaneous and uncontrolled.

In light of these patterns, Wendy Keller challenges us to answer a number of questions:

It should be asked, however, why there exists such a large discrefancy between the number of men as opposed to the number of women claiming the killing committed was in response to this scenario of infidelity. Are husbands simply not committing adultery? Or, are women ignorant of their adulterous husbands? Or, alternatively, are women merely choosing not to confront their husbands in a deadly manner? If so, then perhaps manslaughter is just an embodiment of men's excuses and experiences. ${ }^{51}$

Some argue that the reason for the relatively small number of female defendants who kill their male partners in response to infidelity is biological-men have hormones that make them more physically aggressive than women. ${ }^{52}$ Supporters of the biological explanation for male violence suggest that women respond to infidelity by turning their anger inward and becoming depressed, whereas men express their jealous anger by lashing out. ${ }^{53}$ Moreover, fear of paternity uncertainty may encourage men to react more negatively and more aggressively than women in response to sexual infidelity. ${ }^{54}$ 
Biological anthropologists explain female passivity in response to male infidelity as a function of the fact that men are more likely than women to commit adultery. ${ }^{55}$ According to this view, "the male tendency to commit adultery is caused by the Darwinian drive to produce offspring. " ${ }^{\text {"56 }}$ Miller explains, "Under this interpretation, men must fight instinct in order to remain faithful." ${ }^{15}$.

In suggesting that men who kill in response to female infidelity are not responsible for their actions because their genes made them lose their self-control, the biological explanation obscures the role of socialization in encouraging male violence and aggression in response to sexual infidelity. "[A] man who commits adultery is less aberrant than a woman who does so; a wife who discovers that her husband has strayed is therefore socialized to be less surprised by such behavior." 58 Male infidelity is a common theme in our movies, television shows, and even (real world) politics (Gary Condit, Bill Clinton, Rudy Giuliani, and Gary Hart). Some studies, such as the Hite Report on Male Sexuality, report that as many as 72 percent of married men have committed adultery, feeding the perception that male infidelity is something to be expected. ${ }^{59}$

The acceptance of male infidelity as part of human nature is in stark contrast to the condemnation of women with whom these married men stray. Though less so today, many place most of the blame for an extramarital affair between a married man and an unmarried woman on the woman. The "other woman" is considered a homewrecker, even if the house she is accused of wrecking would probably be in a state of disrepair with or without her.

Female infidelity, in contrast, is not expected. Women are supposed to be monogamous. Monogamy as such is very much a matter of male entitlement. The words used to describe female infidelity (she was "cheating" on me, she was sleeping around, she was whoring) suggest the man's entitlement to his female partner's sexuality. Therefore, when a man finds out that his female partner has been unfaithful, his violent reaction is understandable.

The biological explanation for male violence in response to female infidelity fails to account for the growing number of women who, like their male counterparts, are sexually unfaithful. The same report that found up to 72 percent of married men have committed adultery also found that 70 percent of all married women have had at least one extramarital affair. ${ }^{60}$ If both men and women are unfaithful sexual part- 
ners, then it seems there must be some other reason why we think it is reasonable or at least understandable when a man reacts violently to the discovery of sexual infidelity, but not when a woman does so.

Despite evidence that both men and women can and do cheat on their partners, we continue to assume that men, but not women, have a natural tendency to be sexually promiscuous. This assumption finds its roots, at least in part, in social attitudes and beliefs about what it means to be a man in today's society. As early as junior high school, young boys learn that scoring with as many girls as possible gives them the positive image of being a stud. Although the current directors of the James Bond film series have tried to be more responsive to a female audience that does not want to see women depicted only as sex objects, for many years James Bond (007) was portrayed as a ladies' man, an eligible bachelor who successfully lured into bed all the beautiful women he encountered. In short, Bond was a playboy and it was desirable to be a playboy. Former President Bill Clinton at least at one time was viewed as an extremely sexy and charismatic man. Even though he was caught lying under oath about an extramarital affair with a White House intern, his public approval ratings remained high during his impeachment trial because he was just being a bad boy and well, boys will be boys.

In contrast, consider the things that are said about women who "play around." Women with numerous sexual partners are considered promiscuous and immoral. Women who sleep around are called sluts and whores. The virtuous woman, the kind a man wants to bring home to meet his parents, loves only one man. She controls her sexual desires.

Given these assumptions, when a man finds his female partner in bed with another man, his sense of outrage and betrayal is supported by a society that disapproves of her behavior. A man in this situation who kills his female partner or her lover can appeal to societal expectations to show that his use of violence was a reasonable response to his female partner's infidelity. A woman who finds her man in a compromising position is supposed to either accept his philandering as an expression of human nature or leave him. She is not supposed to kill him.

\section{THE "MERE WORDS" RULE}

Most modern courts have retained the "mere words" rule, a vestige of the early common law approach. Under this rule, words alone can 
never constitute legally adequate provocation. ${ }^{61}$ The "mere words" rule is based on the idea that a reasonable person should be able to tolerate verbal insults rather than respond with physical violence. ${ }^{62}$

Under the early common law approach, the "mere words" rule made sense. Only things included in the short list of categories of legally adequate provocation were sufficient to mitigate a homicide that would otherwise be considered a murder down to manslaughter. Anything off the list was insufficient. Words were not on the list, so they couldn't constitute legally adequate provocation.

The mere words rule makes less sense under the modern formulation of the provocation doctrine. Under the modern test, the jury is charged with determining whether a reasonable person in the defendant's shoes would have been provoked. This means that in most cases the judge defers to the jury on the question of whether the defendant was reasonably provoked into a heat of passion and whether there was a reasonable amount of time for the defendant to cool off. Arguably it would be logical to permit the jury to consider any and all claims of provocation, including claims that extremely insulting or inflammatory words provoked the defendant into a heat of passion. The mere words rule, however, precludes the jury from deciding these issues.

The Berry case could have been, but was not, interpreted as a mere words case. Berry never actually observed his wife in the act of adultery. What provoked him was his wife's confession that she had committed adultery. Despite the mere words rule, the California Supreme Court held that Berry should have been given the opportunity to argue to the jury that he was reasonably provoked into a heat of passion because his wife not only confessed to adultery, she also tormented him for two weeks by feigning sexual interest and then rejecting him. ${ }^{63}$ The Berry case is not the only case of its kind. Other courts have permitted male murder defendants to argue they were reasonably provoked by their wives' confessions of adultery, creating an exception to the rule that mere words do not constitute legally adequate provocation. ${ }^{64}$

Some have tried to explain this inconsistent treatment of words, noting that some courts draw a distinction between informational words (i.e., words that convey information that, if observed directly, would provoke the reasonable person into a heat of passion) and insulting words. ${ }^{65}$ Under this distinction, informational words such as confessions of adultery are considered more provocative than verbal insults. 
It is not necessarily true that informational words are more provocative than insulting words. Depending on the context, a racial insult can be just as provocative as a confession of adultery. For example, a Black man who has suffered from racial discrimination all his life may be particularly sensitive to being called the $\mathrm{N}$ word. In contrast, a man who knows that his wife sees other men may not be outraged by a confession of adultery. If courts are going to permit some defendants to argue they were reasonably provoked into a heat of passion by words uttered by the victim, they should allow other defendants to make the same claim.

\section{THE MODEL PENAL CODE APPROACH:}

\section{EXTREME MENTAL OR EMOTIONAL DISTURBANCE}

It appears that at least twenty states have adopted the Model Penal Code's approach to provocation. ${ }^{66}$ Under the Model Penal Code, a person who would otherwise be guilty of murder is guilty of manslaughter if he killed another person while suffering from an "extreme mental or emotional disturbance for which there is a 'reasonable explanation or excuse."'67 Section 210.3(1)(b) of the Code provides:

(1) Criminal homicide constitutes manslaughter when:

(b) a homicide which would otherwise be murder is committed under the influence of extreme mental or emotional disturbance for which there is reasonable explanation or excuse. The reasonableness of such explanation or excuse shall be determined from the viewpoint of a person in the actor's situation under the circumstances as he believes them to be. ${ }^{68}$

While the burden of proving or disproving the elements of this defense can be placed on either the government or the defendant, many states that have adopted the Model Penal Code's extreme emotional disturbance defense place the burden of proving the elements of this defense on the defendant. ${ }^{69}$ 
Like modern formulations of the provocation defense, the Model Penal Code version lets the jury, rather than the judge, decide whether the defendant ought to receive the mitigation..$^{70}$ Apart from this one similarity, the two approaches are significantly different. Unlike the modern test, the Model Penal Code does not require proof of legally adequate provocation triggering the defendant's loss of self-control. ${ }^{71}$ Rather than focus on the nature of the provocation, the Model Penal Code approach focuses on the defendant's subjective state of mindwhether the defendant was suffering from an extreme mental or emotional disturbance. Additionally, the Model Penal Code does not require the absence of a cooling off period. ${ }^{72} \mathrm{~A}$ defendant may receive the partial mitigation even if the killing took place after a long period of tension-building. ${ }^{73}$ Finally, the Model Penal Code rejects categorical restrictions on the defense of provocation still viable in many modern jurisdictions, such as the mere words rule and the misdirected retaliation rule. $^{74}$

Under the Model Penal Code formulation of the heat of passion defense, the defendant must have actually (or subjectively) suffered from an extreme mental or emotional disturbance for which he or she has a reasonable explanation or excuse. Because the reasonableness of the defendant's explanation or excuse is determined from the viewpoint of a person in the defendant's situation under the circumstances as the defendant believes them to be, the Code subjectivizes the reasonableness inquiry to a greater extent than permitted by the modern approach. The drafters explained that they were purposely introducing more subjectivity into the reasonableness determination while attempting to retain the determination's objective character:

There is a larger element of subjectivity in the standard than there was
under prevailing law, though it is only the actor's "situation" and "the
circumstances as he believes them to be," not his scheme of moral val-
ues, that are thus to be considered. The ultimate test, however, is ob-
jective; there must be "reasonable" explanation or excuse for the
actor's disturbance.

Although the drafters of the Code may have intended to retain the objective nature of the reasonable person standard, any objectivity gained by using the term "reasonable" is undermined by requiring a subjective evaluation of the defendant's explanation or excuse. By stat- 
ing that the reasonableness of the explanation or excuse for the actor's extreme mental or emotional disturbance must be "determined from the viewpoint of a person in the actor's situation under the circumstances as he believes them to be, ${ }^{\prime 76}$ the Code allows the defendant's subjective perspective to control the outcome. Subjectivizing the reasonableness standard is almost as good as getting rid of it altogether. ${ }^{77}$

The subjective Model Penal Code approach has led to some shocking verdicts. ${ }^{78}$ In a few cases, juries have rejected murder charges in favor of manslaughter when the provocation consisted of a female partner dancing with another man.

January 16, 1979. Little Rock, Arkansas. Randall Dixon and Rebecca Newman went to a bar to celebrate their engagement to marry. Randall became jealous when Rebecca asked a male friend to dance with her. Randall stormed off and went home. He returned to the bar only after his sister asked him to return. Upon entering the bar, Randall saw that his fiancée was still dancing and having a good time with her male friend. Randall charged onto the dance floor and knocked Rebecca down. He then hit her so hard that a waitress said it could be heard all over the bar. By this time, it was almost 2:00 A.M. Randall was ejected from the bar. Randall insisted that Rebecca come home with him to his apartment. Once there, he continued to beat her. Randall's thirteen-year-old niece and her girlfriend were at the apartment and testified that Rebecca had bruises all over her face. Her eyes were black, her jaws were swollen, and her nose was bleeding. Rebecca begged Randall to stop hitting her, and then passed out. Subsequently, Rebecca died of cranial cerebral injuries. ${ }^{79}$

Dixon was charged with murder in the second degree. At trial, he claimed that he should be found guilty of manslaughter rather than murder because at the time of the incident, he was suffering from an extreme emotional disturbance. Dixon explained that the reason he became so emotionally distraught was because Rebecca had asked another man to dance with her. Dixon felt Rebecca was not acting the way a fiancée ought to behave. When he came back to the bar and saw Rebecca laughing and dancing with the same man, he simply lost his selfcontrol. Instructed to decide the reasonableness of Dixon's explanation from his perspective, the jury returned a verdict of manslaughter.

Because the only information about this case appears in a short three-page court opinion, little is known about Dixon except that he 
was a man living in Arkansas at the time of the killing. It is unlikely that he belonged to a religious group that frowns upon drinking and dancing, given that he was celebrating his upcoming marriage in a bar. We do not know his class status or race. We only know that this incident took place in the South.

Place seems to play a role both in terms of an individual's propensity toward violence upon taking offense and the jury's willingness to excuse such violence. In Culture of Honor: The Psychology of Violence in the South, ${ }^{80}$ Richard Nisbett and Dov Cohen seek to explain why homicide rates are higher for White males in the South than they are for White males in the North. After examining Southern and Northern male attitudes toward violence and their comparative behavioral responses to insult, Nisbett and Cohen found that Southern men are more likely than their Northern counterparts to approve of the use of force in response to insults. In the South, "[i]nsults cannot be ignored, because a man's reputation for strength and toughness is compromised until he proves himself through violence, or at least through dominant or aggressive behavior signaling a capacity for violence." 81 In laboratory experiments, Southerners actually experienced physiological changes when they were insulted. Their cortisol and testosterone levels increased more than their Northern counterparts, and they were more likely to end the incident with verbal or physical aggression. Nisbett and Cohen's work on the psychology of violence in the South suggests that individuals from that region tend to take offense more easily than individuals from other parts of the country, and have a greater tendency to resort to violence in response to insults to honor. ${ }^{82}$ This may help explain why Dixon felt that his outrage upon seeing his fiancée dancing with another man was reasonable and why his jury agreed with him.

Place, however, only goes so far in explaining why juries sometimes accept claims that seem patently unreasonable. In a similar case arising in Connecticut, a man became distraught at the sight of his former girlfriend dancing with another man. This man stalked his former girlfriend for two weeks, watching her apartment to see who visited her and who spent the night. After two weeks of stalking, this man accosted his former girlfriend at her apartment and then killed her.

June 21, 1987. 4:00 A.M. Bridgeport, Connecticut. Forty-four-year-old Hipolito Martinez waited outside Esther Grajalez Perez's house at 407 Nichols Street. She wasn't home. What was she doing out this late? Who 
was she going out with at four o'clock in the morning? As he waited, Hipolito became increasingly agitated. Even though he was a married man, Hipolito had gone out with Esther for approximately four years. The last year-and-a-half of their relationship. Hipolito stayed at Esther's place on the weekends and the YMCA during the week. In November 1986, Esther told Hipolito she wanted to break up. He moved out after a loud argument. He was bitter and angry about the breakup. He had wanted so much for the two of them, but Esther had only wanted him on the weekends. She just wanted to party. After Esther broke up with him, she dated other men. This bothered Hipolito tremendously.

The first weekend in June, Esther called Hipolito and asked him if he wanted to go dancing. They met at the Calypso. There, another man asked Esther to dance. Hipolito was furious. The way the two were dancing made Hipolito think they were dating. In fact, the man dancing with Esther was Leonardo Mieles, Esther's brother. Hipolito told Esther that he would shoot her one day.

After the incident at the Calypso, Hipolito started hanging around Esther's apartment building. He wanted to find out who was spending the night with her. He was also agitated because Esther telephoned his wife and told her that Hipolito wanted to get back together with her, that he had made trouble for her at the Calypso, and that she didn't want Hipolito because she had a new boyfriend. At midnight on June 20, Hipolito stood outside Esther's apartment and threw rocks at her window.

June 21. 4:00 A.M. Hipolito waited for Esther in front of her apartment. His .32 caliber gun was in a holster on his belt. Finally, a car pulled up. Hipolito saw Esther in the passenger's seat. Esther spotted Hipolito and asked her brother, Leonardo, who had just taken her and her sons to the airport, to come up with her to her apartment. As she approached her front door, Hipolito grabbed her arm and pointed a gun at her. Leonardo tried to separate the two, but Hipolito turned the gun on Leonardo and said, "This isn't between you and me, it's between her and me." Leonardo backed off and went to the car to call the police. Hipolito dragged Esther from her doorway, and forced her to walk across the street, muttering repeatedly, "You made me do this." He then struck Esther in the face and shot her five times. Shortly after the shooting, Hipolito told police, "I shot her and I hope she dies." ${ }^{\prime \prime 3}$

Martinez was charged with murder. At trial, he argued he was suffering from an extreme emotional disturbance. The sight of his former 
girlfriend dancing with another man was Martinez's "reasonable" explanation for his emotional disturbance even though this observation took place two weeks before he killed her. The jury returned a verdict of manslaughter, agreeing with Martinez that, from his perspective, his explanation was reasonable.

The Model Penal Code's subjective approach, permitting mitigation whenever a defendant can show he (or she) was actually suffering from an extreme mental or emotional disturbance at the time of the homicide, is extremely problematic because it provides an excuse to almost any defendant who appears credible on the stand. The requirement that the defendant's explanation or excuse be reasonable does not provide much of a check on the defendant's subjective showing, since the Code directs the trier of fact to determine the reasonableness of the defendant's explanation from the viewpoint of a person in the defendant's position viewing the circumstances as the defendant believed them to be.

A third case, also from Connecticut, highlights the problematic nature of the Model Penal Code approach to provocation.

Mark Chicano and Ellen Babbit were involved in a romantic relationship that had deteriorated by the end of 1986 . At approximately 2:00 A.M. on February 28, 1987, Mark went to Ellen's home in East Windsor, Connecticut. While outside the house, Mark saw Ellen's new boyfriend, Raymond Arnold, arrive and enter the house. Mark then walked around the house and stood outside Ellen's bedroom where he could hear Ellen and Raymond making love. After thirty minutes of standing outside the bedroom window, Mark quietly entered the house and hid in the bathroom for an hour. Once he was certain Ellen and Raymond were asleep, Mark crept into the bedroom and struck Raymond on the head with a crowbar. Ellen cried out and tried to protect Raymond. This only enraged Mark who continued to strike Raymond with the crowbar until Raymond was lifeless. Mark then started kicking and punching Ellen. Because she was resisting so fiercely, Mark tried to tie Ellen's hands. At this point, Ellen's eleven-year-old son entered the room and started screaming. Mark turned to the boy, grabbed him by the throat to quiet him, and then strangled him to death. Mark turned back to Ellen and struck her on the head twice with the crowbar, killing her almost instantly. ${ }^{84}$

Chicano was charged with three counts of murder, felony murder, 
and other crimes. At trial, he intimated he was acting under an extreme emotional disturbance caused by hearing his former girlfriend Ellen and her new boyfriend making love. One heavily contested issue was where Chicano got the crowbar which he used to kill two of the three victims. The government contended that Chicano brought the crowbar with him in his car to Ellen's house. If this were the case, Chicano likely planned to kill his former girlfriend. A planned killing usually constitutes first-degree murder. The defense, however, claimed Chicano found the crowbar in Ellen's home and used it because it was handy. Of course, even if it were true that Chicano used a crowbar which he found in the house, it still would have taken some thought and effort on his part to locate and use it in the fatal attack. A three-judge panel, however, focused on whether Chicano brought the crowbar with him to Ellen's home and found insufficient evidence that he did. After concluding that Chicano met the requirements of the affirmative defense of extreme emotional disturbance, the panel found Chicano guilty of three counts of manslaughter in the first degree, rather than murder. ${ }^{85}$

As these cases illustrate, the Model Penal Code's subjective approach permits the mitigation in many cases in which the early common law approach and the modern approach would not. In a Model Penal Code jurisdiction, as long as the jury believes the defendant was acting under an extreme emotional disturbance for which there is a "reasonable" explanation or excuse (from the defendant's perspective), the jury may return a manslaughter verdict. When killing a former girlfriend or a fiancée for dancing with another man is partially excused, the law sends a message that men who react violently, even fatally, to such activity deserve sympathy rather than condemnation for their actions.

\section{POST-MODEL PENAL CODE ATTEMPTS TO ADDRESS PROBLEMS WITH THE DOCTRINE OF PROVOCATION}

Some jurisdictions are changing their laws to make it more difficult for men who kill in response to female infidelity to assert that they acted in a heat of passion. These reforms have taken one of two forms. First, in what appears to be a return to the early common law's categorical approach, some states are adopting categorical exclusions. Unlike the early common law which named categories of legally adequate 
provocation, these states identify categories of inadequate provocation. ${ }^{86}$ Second, at least one state has attempted to abolish the defense of provocation. ${ }^{87}$

In an example of categorical exclusion, the Maryland legislature in 1997 added a statutory provision to Maryland's Penal Code. Section 387A of the Annotated Code of Maryland (Criminal Law) provides, "The discovery of one's spouse engaged in sexual intercourse with another person does not constitute legally adequate provocation for the purpose of mitigating a killing from the crime of murder to voluntary manslaughter." ${ }^{\prime 8}$ In essence, Maryland has ruled that as a matter of law the discovery of one's spouse in the act of adultery is not legally adequate provocation. ${ }^{99}$ The Kenneth Peacock case was probably the motivating force behind this change.

February 8, 1994. Towson, Maryland. 5:00 P.M. Kenneth Peacock, a thirtysix-year-old truck driver, called his thirty-one-year-old wife Sandy to let her know that the roads were icy and he wouldn't make it home that night. An outgoing, fun-loving spirit, Sandy decided to go to a new bar in the town of Maryland Line where she ran into her friend Bruce Leslie Morgan. Sandy and Bruce both had a lot to drink before leaving the bar and going to Sandy's home. According to Bruce, Sandy promptly took off all her clothes and jumped into bed. Bruce was so drunk, he passed out before climaxing.

Midnight. Bruce was knocked awake by an angry Ken Peacock, who had come home earlier than expected and was pointing a rifle at him. Ken yelled at Bruce to get out of his house. He then shouted to his sobbing wife, "Shut up, bitch. I can't believe you did this to me." Still drunk, Bruce stumbled out of the house.

Once alone, Ken and Sandy proceeded to argue. At a lull in the argument, Sandy called her mother and told her she was moving out. Ken grabbed the phone and told his mother- in-law, "She's lucky if I let her live to leave." Ken, still holding onto his rifle, was so upset that he proceeded to drink a gallon of wine and four beers.

February 9, 1994. 4:00 A.M. Ken leveled his rifle at his wife who was lying on the sofa. A shot rang out. Ken dialed 911 and told the police that he shot his wife in the head because she was sleeping around on him..$^{90}$

Peacock was initially charged with first-degree murder. Later, prosecutors permitted him to plead guilty to voluntary manslaughter be- 
cause they believed his claim that he was provoked into a heat of passion by finding his wife in bed with another man. At Peacock's sentencing hearing, prosecutors argued for a sentence of three to eight years. The defense asked for probation on the ground that Peacock did not intend to shoot his wife. Peacock maintained he pointed his rifle at Sandy merely to frighten her and the gun accidentally discharged. Undermining Peacock's claim of an accidental shooting was a history of domestic violence. According to Sandy's mother, her daughter spent one night in a motel with a guard outside her door because she was so afraid of her husband.

On October 17, 1994, Judge Robert Cahill sentenced Peacock to eighteen months in prison and fifty hours of community service. ${ }^{91}$ Because Peacock received credit for time served, he was out of jail within two weeks. Judge Cahill explained that he was reluctant to give any jail time at all to Peacock, explaining, "I seriously wonder how many men married five, four years would have the strength to walk away without inflicting some corporal punishment. I am forced to impose a sentence only because I think I must do it to make the system honest."

Judge Cahill's remarks provoked an angry response from many women. Baltimore District Court Judges Teaette Price and Sandra Gray noted that Judge Cahill's comments reflect "a stereotypical view of the proper or expected behavior of a husband who finds his wife engaged in infidelity." 93 Melinda Towne, Maryland Chapter President for the National Organization for Women, criticized the characterization of the event as a heat of passion killing:

Most people might be angry and upset [if they found their spouse in bed with someone else], but we have to remember that this man waited [four hours] before going back and killing his wife. This was not a spur-of-the-moment emotional response. We don't think a woman would have been treated the same way if she went back and killed her husband the same way. ${ }^{94}$

Kim Gandy, Executive Vice President for the National Organization for Women, echoed these sentiments, commenting, "The sentencing reflects the judge's attitude toward this woman, that she was [her husband's] property, that he had the right to be judge, jury and executioner." ${ }^{\prime 95}$ The public outrage following Judge Cahill's remarks likely led the Maryland legislature to add section 387A to the Maryland penal 
code, providing that the observation of a spouse in the act of adultery does not constitute legally adequate provocation. ${ }^{96}$

One might think that disallowing the provocation defense only in sertain situations, such as the observation of a spouse in the act of adultery, does not go far enough, and that the best way to deal with the gender bias inherent in the doctrine is to completely abolish provocation as a defense to murder. ${ }^{97}$ The state of Texas attempted to do something of this sort in the mid-1990s. In September 1994, the Texas legislature revised its penal code to eliminate heat of passion as a partial defense to nurder. ${ }^{98}$ Under Texas law, sudden passion no longer acts to mitigate a nurder down to manslaughter and may only be considered at the senalty phase of the trial. If the jury finds sudden passion in the penalty shase, the defendant will be convicted of second- rather than first-dezree murder. ${ }^{99}$

Despite this change, a Texan who shot and killed his wife in De:ember 1998 because she had invited her lover into the family home vas able to receive a sentence of probation because the jury found he rad acted in a sudden heat of passion:

December 1998. Fort Worth, Texas. Jimmy Watkins, a thirty-three-year-old supervisor of a waste disposal company, and his thirty-year-old wife, Nancy, were married in 1984. In 1997, the couple began having marital problems. Nancy, who worked at a Wal-Mart store, began seeing one of her coworkers, Keith Fontenot. On December 21, 1998, Nancy kicked Jimmy out of the house after he sexually assaulted one of her relatives. Keith Fontenot moved in the same day. Following his removal from the house, Jimmy started calling Nancy using his cellular phone every few minutes. He called her at 11:25 P.M., 11:29 P.M., 11:30 P.M., 11:31 P.M., 11:37 P.M., and 11:43 P.M. He stopped calling her for about three hours, then called her again at 3:24 A.M. on December 22. Later that day, he called his wife three more times. The last time he called, it was 3:30 P.M. Jimmy called Nancy from his cellular phone while he was just outside the family home. He asked his wife where she was in the house. When she told him she was in the kitchen, he kicked in the kitchen door, burst in, and shot her in the head with a 9 millimeter handgun while their ten-year-old son watched. He then turned his gun on Keith, shooting him twice. The third time he pulled the trigger, the gun didn't go off. Thinking he was out of bullets, Jimmy fled in his green GMC pickup truck. While driving, Jimmy discovered he still had bullets left. His gun had simply jammed. He pulled over to the side of the 
road to fix his gun, then headed back to the house. While his wife was on the phone with 911 dispatchers pleading for help, Jimmy shot her five more times, killing her. ${ }^{100}$

Watkins was charged with murder. At trial, he argued that he was distraught over his wife's affair and simply snapped when he found out that his wife's lover had moved into the family home. The jury found Watkins guilty of murder, but then recommended a sentence of probation because he killed his wife in a sudden heat of passion. ${ }^{101}$ In October 1999, Judge Robert Gill sentenced Watkins to ten years of probation. As a condition of probation, Watkins was ordered to serve four months in custody and pay a $\$ 10,000$ fine.

Watkins did not walk in on his wife while she was in bed with another man. He shot her in the kitchen of the family home in front of their ten-year-old son. Watkins stopped shooting only because his gun jammed. After he fixed the jam, he returned to the house to finish the job, pumping five more bullets into his wife while she was on the phone with 911, pleading for help. Watkins's probationary sentence for murdering his wife is a reminder that even today, some people think a man's violent reaction to female partner infidelity is normal or reasonable.

\section{REVISITING THE BERRY CASE}

The story told at the beginning of this chapter was largely Albert Berry's story, the one he told when he testified at trial and the one his attorney told when he appealed Berry's murder conviction to the California Supreme Court. Berry asserted that Rachel was screaming at him before he choked her into unconsciousness the first time and before he strangled her with a telephone cord several days later. Yet how do we know whether Rachel was actually screaming? Perhaps Albert heard screaming when Rachel was trying to talk to him. Perhaps Albert remembered screaming when there was only noise and confusion. Perhaps Albert made up a screaming Rachel to support his assertion that he was provoked into a heat of passion. Rachel Pessah, the only other person to witness the events preceding her death, can't tell us what happened because she is dead. Her side of the story was never heard. Yet Berry's version of what happened was the only one represented in the California Supreme Court's opinion. 
If one digs beneath the surface and goes beyond the facts as reported in the California Supreme Court opinion, as law professor Donna Coker did by reviewing the transcripts of the trial testimony, one discovers that Berry had a history of prior violence against his other female partners. Before he married Rachel Pessah, Berry stabbed his second wife eleven times in the abdomen with a butcher knife after she called out the name of another man while she and Berry were having sex. ${ }^{102}$ In other relationships, Berry destroyed property and threatened physical violence against his female partners to keep them in line. ${ }^{103}$ In Berry's statement to the police, he admitted, "I deliberately waited to kill [Rachel]. No pretense, no bullshi[t], no nothing. "104 With this additional information, Berry's claim that he was reasonably provoked by Rachel's behavior is disingenuous.

The Berry case is often cited for its "extremely elastic interpretation of the cooling-off requirement." 105 The "no time to cool off" requirement in the modern test is intended to ensure that the defendant truly acted in a heat of passion, not as the result of premeditation and deliberation. As Donna Matthews and Caroline Forell note, "Most courts require that a relatively short interval-usually only a few minutes-occur between the provocation and the killing. However, like the expanded scope of provocation ... many courts stretch the cooling-off time when men kill their intimates." ${ }^{106}$ Even though Albert Berry found out about his wife's infidelity two weeks before he killed her, and waited in Rachel's apartment for twenty hours before strangling her with a telephone cord, the California Supreme Court thought a rational jury could find that a reasonable man in Berry's shoes would not have cooled off during this time period.

Under the Model Penal Code approach, not only would Berry be permitted to argue extreme emotional disturbance to the jury, most likely he would be successful in receiving a manslaughter verdict. Arguably, only an extremely disturbed individual would strangle his wife to death with a telephone cord. Berry's excuse would be Rachel's confession of adultery and her subsequent behavior, teasing him sexually and then rejecting him. Because the reasonableness of this explanation would be determined from Berry's perspective, the trier of fact would likely conclude that this was a reasonable explanation for Berry's extreme emotional disturbance.

Of course, not all claims of provocation are so unsympathetic. The Berry case may be included in most criminal law casebooks and taught 
to first-year law students precisely because it is so outrageous. The case makes us question the modern approach to provocation. It makes us question the desirability of an open-ended reasonableness requirement that permits defendants like Berry to argue they were reasonably provoked by a confession of marital infidelity.

Finding out that one's partner, male or female, has been unfaithful is a devastating experience. The infidelity reflects a profound betrayal of trust and in most cases damages the relationship beyond all hope of repair. Discovering one's partner in bed with another person only multiplies the feelings of anger, outrage, betrayal, and profound sadness that accompany the information conveyed. It is thus understandable why lawmakers, judges, prosecutors, and jurors sympathize with the man who lashes out in anger in response to his female partner's infidelity. The provocation defense allows the jurors to translate their sympathy for the defendant into a verdict that relieves the defendant of murder liability. The defense also allows jurors to register their disapproval of the act of killing by returning a verdict of voluntary manslaughter.

While the provocation defense offers the benefit of allowing the law to reflect gradations of culpability, unfairness can result when certain defendants and not others are able to bolster their claims of reasonableness by relying on commonly held beliefs and attitudes about what it means to be a man in today's society. The reasonableness requirement, while providing a useful and necessary check on the defendant's subjective emotional distress, opens the door to inconsistent treatment of similar claims. What is reasonable to an American jury is a function of what is considered typical or normal in America. As we shall see, normality in America has an overlooked gender, race, and sexual orientation. 


\section{Gay Panic}

March 1, 1995. Pontiac, Michigan. Jonathan Schmitz, a twenty-four-yearold employee at the Fox and Hounds restaurant in Pontiac, Michigan, was looking forward to his upcoming appearance on the Jenny Jones Show. The nationally televised show was airing a segment on "Secret Admirers" and John had been invited to Chicago to appear as a guest. John hoped that his secret admirer would be his former girlfriend, Kristen. John wanted to resume a relationship with his ex and had told friends that if Kristen was his secret admirer, he would propose to her.

March 6, 1995. Chicago, Illinois. Showtime. John sat on stage, waiting to see his former sweetheart. Then Scott Amedure appeared. John was taken aback. What was his friend Scott doing on the show? Then he realizedScott was his secret admirer. John managed a smile and hugged Scott for the sake of the cameras. He even laughed when Scott recounted a fantasy that involved John, whipped cream, strawberries, and champagne.

On his way back to Michigan, John told his friend Donna Riley, who had worked with Scott Amedure to arrange the taping, that he could get angry about his appearance on the Jenny Jones Show if he thought about it. On the plane, John struck up a conversation with Patricia Cielinski, who was sitting next to him. John told her about his experience on the show and said he was disappointed that his friends Donna and Scott had set him up. He told Patricia that he had spent $\$ 600$ on new clothes and other things, thinking that his secret admirer would be his ex-girlfriend or another woman. John repeated that he could get angry about Scott's appearance on the show if he thought about it. Yet after returning to Michigan, John went out for drinks with Scott and Donna.

March 9, 1995. Pontiac, Michigan. John came home from work to find a flashing construction light and an anonymous note in front of his apartment. The note read, "John, if you want it off, you'll have to ask me. P.S. It takes a special kind of tool. Guess Who." Believing the note was a crude sexual come-on from Scott, John drove to his bank and withdrew $\$ 350$. He 
then went to two different gun stores where he purchased a 12-gauge pump-action shotgun and ammunition. Next stop, Scott's trailer home, seven miles away. Leaving the gun in his car, John walked up to the trailer and knocked on the door to make sure Scott was home. Scott answered the door. He let John in. John told Scott he needed to go back to his car because he had left the engine running, and promised to come right back. Then John went to his car, got his shotgun, and came back into the trailer. Scott saw the shotgun and tried to hide behind a wicker chair, but it was an ineffective shield. The first bullet tore through the chair and into Scott's chest. Scott fell to the ground. Scott's roommate came out into the front room and watched in horror as John walked up to Scott, who was writhing on the floor and screaming in pain, manually racked the shotgun, and fired again. ${ }^{1}$

When a heterosexual man kills a gay man and is charged with murder, a common defense strategy is to use the concept of "gay panic" to explain the killing. ${ }^{2}$ As one court has explained, "homosexual panic" is "the idea that a latent homosexual-and manifest 'homophobe' - can be so upset by a homosexual's advances to him that he becomes temporarily insane, in which state he may kill the homosexual." ${ }^{3}$ Although the term has appeared several times in recent popular literature, gay panic is not an officially sanctioned criminal law defense. Gay panic nonetheless is used by criminal defendants to bolster many different criminal law defenses, including temporary insanity, diminished capacity, provocation, and self-defense.

The Jonathan Schmitz case, also known as the Jenny Jones case because the initial incident which triggered Schmitz's panic was his appearance on the Jenny Jones Show, is unusual because Schmitz used the idea of gay panic first to bolster a claim of diminished capacity, a mental defect defense which essentially admits the unreasonableness of the defendant's actions, and later a claim of provocation, a defense which rests upon an assertion of reasonableness. ${ }^{4}$ Because diminished capacity and provocation rest upon inconsistent claims regarding the reasonableness or normalcy of the defendant, defendants usually will choose one defense or the other, but not both. Schmitz used a diminished capacity defense at his first trial to reduce his first-degree murder charge to second-degree murder. He successfully appealed and his second-degree murder conviction was vacated because the trial court had refused to allow the defense to remove a juror they found problematic. On re- 
trial, Schmitz was not able to reassert the diminished capacity defense that had helped him at his first trial because Michigan law only permits diminished capacity as a defense to first-degree murder. Schmitz's attorney instead argued that Schmitz was reasonably provoked into a heat of passion by Amedure's actions and therefore should be found guilty of manslaughter rather than murder. This time, Schmitz's attempt to use a gay panic argument was unsuccessful. Schmitz was again convicted of second-degree murder, and sentenced to twentyfive to fifty years in prison.

In this chapter, I start by examining the historical origins of the concept of gay panic. I discuss the use of gay panic to bolster claims of mental defect. I then discuss the use of gay panic to support claims of reasonableness through the defenses of provocation and self-defense. I conclude by returning to the Jonathan Schmitz case, examining the ways in which masculinity, race, and sexual orientation interacted to produce the outcome in that case.

\section{"HOMOPHOBIA"-A MISNOMER}

Many use the term "homophobia" to describe anti-homosexual attitudes. I too use the term for this purpose, but try to do so sparingly because of its problematic nature. Attaching the prefix "homo" to the word "phobia" suggests that individuals with negative attitudes about homosexuality are fearful of homosexuals, although anti-homosexual sentiments are often driven more by prejudice than fear. ${ }^{5}$ Colleen Logan warns that "the continued use of homophobia as a descriptor for antihomosexual response may be seen by society as implicit permission to continue the oppression of homosexuals, excused by its being the result of inescapable fear." Similarly, Gregory Herek remarks, "Characterizing hostility toward homosexual persons in terms of a phobia implies that those attitudes are based upon an irrational fear, similar to the fear some people experience when confronted with snakes, spiders, or open spaces."7 Stephanie Shields and Robert Harriman note, "The great difference between the unreasonable fear of spiders (or mutilation, snakes, etc.) and fear of homosexuality lies in the assignment of responsibility for such acquired pathologies. Whereas spider phobics typically accept responsibility for their fear and even seek treatment, homophobics do not. To the homophobic, it is homosexual men who are sick." 8 


\section{HOMOSEXUAL PANIC DISORDER}

The use of gay panic in murder cases has its roots in theories about latent homosexuality as a mental disorder. The term "homosexual panic" was coined by Dr. Edward Kempf, a clinical psychiatrist, in $1920 .{ }^{9}$ After treating several hundred patients who exhibited similar characteristics, Kempf came to the conclusion that certain troubled individuals who thought of themselves as heterosexual were actually latent homosexuals. These individuals suffered from an internal conflict between their feelings of attraction to individuals of the same sex and societal views of such feelings as perverse. They also experienced a heightened sense of anxiety in same-sex environments, caused by this tension between their true feelings of attraction to members of the same sex and what they perceived as the socially acceptable feelings they were supposed to have-attraction to members of the opposite sex. ${ }^{10}$

According to Kempf, Homosexual Panic Disorder was marked by two factors: (1) a patient's terror of his attraction to homosexuality, and (2) his or her fear of heterosexuality. ${ }^{11}$ Interestingly, a panic state was typically precipitated by separation from an individual of the same sex to whom the patient was emotionally attached, not by a sexual advance. $^{12}$

Homosexual Panic Disorder was listed in the 1952 edition of the Diagnostic and Statistical Manual of Mental Disorders, the official list of psychiatric disorders published by the American Psychiatric Association. It has not appeared in that manual since 1952. ${ }^{13}$ Even then, Homosexual Panic Disorder was not recognized as an existing psychiatric disorder by many of the standard psychiatric and psychological dictionaries. ${ }^{14}$

Some modern support for Dr. Kempf's theory exists. In 1996, Henry Adams conducted a study to find out whether heterosexual men who exhibited strong anti-gay sentiments would be aroused by homosexual erotica. Adams started by measuring sixty-four Caucasian self-described heterosexual male participants' feelings toward gays. After evaluating their responses, he divided the participants into two groups which he labeled "homophobic" (those who were hostile toward gays) and "not homophobic" (those who were not hostile toward gays). He then placed a sensor on the penises of all the participants, and measured penile response to erotic videotapes involving heterosexual, female homosexual, and male homosexual activity. Only the men in 
Adams's homophobic category, those who had earlier expressed strong anti-gay sentiments, showed an increase in penile erection in response to male homosexual erotic stimuli. ${ }^{15}$ Like Kempf's patients, the homophobic men in Adams's study generally were not aggressive toward others.

Even if self-identified straight men who express strongly negative feelings about homosexuality are actually latent homosexuals repressing their own homoerotic desires, the idea that gay panic should excuse the killing of a gay man is problematic for several reasons. First, treating gay panic as a mental disorder can lead to the assumption that homophobia stemming from latent homosexuality is a mental illness. ${ }^{16}$ However, many individuals who are of sound mental ability believe that homosexual activity is immoral and deviant. Studies indicate that negative attitudes about homosexuality tend to come from two sources: sexual conservatism and prejudice against those who are different. ${ }^{17}$ Sexually conservative individuals and prejudiced individuals are not necessarily mentally ill.

Second, the idea that homosexuality itself is a mental illness has long been discredited. In December 1973, after a review of the scientific literature and consultation with experts in the field, the Board of Trustees for the American Psychiatric Association deleted homosexuality from the Diagnostic and Statistical Manual of Mental Disorders, Second Edition (DSMII), its official list of mental disorders. ${ }^{18}$ The Board recognized that a significant proportion of the gay and lesbian population were "clearly satisfied with their sexual orientation and showed no signs of psychopathology."19 The American Psychological Association followed suit in January 1975, adopting the following resolution:

Homosexuality per se implies no impairment in judgment, stability, reliability, or general social and vocational capabilities; [f]urther, the American Psychological Association urges all health professionals to take the lead in removing the stigma of mental illness that has long been associated with homosexual orientations. ${ }^{20}$

Even though more than twenty-five years have passed since both the American Psychiatric Association and the American Psychological Association rejected the characterization of homosexuality as a mental illness, the idea that it might be normal for someone to be sexually 
attracted to another person of the same sex still arouses controversy today. In November 1999, a coalition of medical, mental health, educational, and religious organizations announced that it would be sending school superintendents across the country a booklet entitled "Just the Facts about Sexual Orientation and Youth." Among other things, the booklet informed readers that mental health and health professional organizations do not support the idea that homosexuality is abnormal or mentally unhealthy. ${ }^{21}$ Negative reaction to the booklet was strong and swift. Janet Parshall, spokeswoman for the conservative Family Research Council, stated, "If they're going to talk about 'the facts,' here's a fact: All the major religions of the world consider homosexuality wrong." 22 John Paulk, a "homosexuality and gender analyst" for Focus on the Family, a Christian group based in Colorado, commented, "They're saying they want to present factual information on homosexuality, but we believe that they're presenting propaganda."23

Negative attitudes about homosexuality are not limited to the private sector. The U.S. military's "don't ask, don't tell" policy forces gays and lesbians who wish to join or remain in the military into the closet. Until as recently as 1990, federal law barred gays and lesbians, along with convicted felons, epileptics, and drug addicts from immigrating to the United States. ${ }^{24}$ In 1996, Congress passed the Defense of Marriage Act (DOMA) which declared that marriage is the union of man and woman. ${ }^{25}$ Implicit in the Act is the idea that marriage is not the union of man and man nor of woman and woman.

A third problem with using gay panic to support a mental defect defense in a murder case is that the psychological profiles of the defendants in these cases seem very different from the patients Dr. Kempf diagnosed. ${ }^{26}$ Men who kill gay men often appear to be quite normal, whereas Kempf's patients tended to have a history of psychological problems. ${ }^{27}$ Moreover, Kempf's patients were not aggressive toward others. If physical at all, they tended to inflict punishment upon themselves, not on others. ${ }^{28}$ As Adrian Howe observes:

[T]here was a considerable discrepancy between cases reported in the psychiatric literature and the cases involving immediate reaction or sudden panics described in the legal defenses. Patients diagnosed with acute homosexual panic demonstrated "a helplessness, passivity, and inability to be aggressive" far removed from the picture of the explosively violent man constructed by lawyers deploying a HPD 
[Homosexual Panic Disorder] defense. The legal argument that this disorder was likely to result in extreme violence therefore had no psychiatric basis. ${ }^{29}$

A fourth problem with the use of gay panic as a mental disorder is the gendered nature of its use. The murder defendants who claim that Homosexual Panic Disorder made them do it are almost exclusively male. ${ }^{30}$ According to Kempf, however, Homosexual Panic Disorder is a mental disease that afflicts both male and female patients. Gary Comstock, one of the nation's leading authorities on violence against gays and lesbians, questions why we should accept claims of gay panic made by men who kill in response to gay male sexual advances when women apparently do not kill in response to lesbian sexual advances:

[I]f the homosexual panic defense is premised on the disorder's causing murderous behavior in those it afflicts, why have female patients not been driven to kill? The soundness of the defense's premise should be challenged according to its inability to reflect the behavior of the universe of those who suffer from the disorder. If only some are driven to murder, the defense should be pressed to present a scientific, medical explanation for the differential behavior. To be used convincingly as a cause for killing, the disorder would have to be documented with evidence that both male and female patients have killed. ${ }^{31}$

While it is not inconceivable that a woman might panic and respond violently to a lesbian sexual advance, a search for lesbian panic homicide cases turned up no such cases. The lack of such cases suggests that gay panic is the product of a specific construction of masculinity, one that values heterosexism and violence as traits of the masculine.

\section{GAY PANIC AND MENTAL DISORDER}

A defendant claiming mental defect in the form of an insanity defense or a diminished capacity defense typically argues that the victim's (homo)sexual advance caused him to lose control over his mental abilities. ${ }^{32}$ Insanity, a complete defense which results in a not guilty by reason of insanity (NGI) verdict, requires proof that the defendant, because of a mental disease or defect, lacked the ability to determine right from 
wrong or the ability to control his conduct to conform to the law. Diminished capacity, a partial defense to murder which results in a manslaughter conviction, generally requires proof that the defendant was acting under the influence of a mental disease or defect which affected his capacity to premeditate and deliberate or form the intent to kill required for murder. ${ }^{33}$ Two high-profile cases illustrate how the concept of gay panic and mental disorder can be deployed in the courtroom.

\section{Matthew Shepard}

October 6, 1998. Laramie, Wyoming. Around 10:30 P.M. Matthew Shepard, a twenty-two-year-old openly gay political science student at the University of Wyoming, arrived at the Fireside Bar and ordered a beer. Around midnight, Shepard met Russell Henderson and Aaron McKinney, two high school dropouts also in their early twenties, who were sharing a pitcher of beer. Henderson and McKinney pretended they were gay and invited Shepard to join them for a drive in McKinney's truck.

Once McKinney and Henderson had Shepard alone in their truck, McKinney pulled out a gun and told Shepard, "We're not gay, and you're getting jacked." He then ordered Shepard to hand over his wallet. Shepard complied, but this did not end the incident. McKinney proceeded to hit the 5 foot 2,102 pound Shepard repeatedly on the head with the butt of his .357 Magnum pistol. During this time, Henderson drove the truck to a deserted field about one mile outside of Laramie. Once there, McKinney ordered Shepard out of the truck. McKinney asked Shepard whether he could read the license plate on the truck. Shepard replied, "Yes, I can read it," and then recited the license plate number. McKinney responded by kicking Shepard between his legs and striking him over the head, causing Shepard to lose consciousness. Then McKinney and Henderson stripped Shepard of his shoes and tied him to a wooden fence.

Shepard remained tied to the fence in near-freezing weather for approximately eighteen hours before Aaron Kriefels, a freshman at the University of Wyoming, found him. Shepard, who was so badly beaten that he was recognizable only by a distinctive bump on his ear, died five days later. $^{34}$

After leaving Shepard tied to the fence, Henderson and McKinney headed back into town. There, McKinney picked a fight with two Latino 
youths, Emiliano Morales and Jeremy Herrera. McKinney threw the first punch, hitting Morales in the head. He proceeded to pummel Morales until Herrera intervened, striking McKinney with a stick. According to one police officer, if Herrera had not intervened, Morales might have ended up a homicide victim like Shepard. ${ }^{35}$ Police officers who responded to a 911 call about the fight found Henderson and McKinney in McKinney's truck. They also found the bloody gun used to beat Shepard, Shepard's credit card, and one of Shepard's shoes. ${ }^{36} \mathrm{Hen}-$ derson and McKinney were arrested and charged with first-degree murder, felony murder, kidnapping, and aggravated robbery. ${ }^{37}$ On the eve of trial, Henderson pleaded guilty to murder to avoid the death penalty. McKinney, however, decided to take his chances with a jury, hoping for an outright acquittal or mitigation of the charges.

Initially, McKinney denied that Shepard made any sexual advances toward him. ${ }^{38}$ Later, McKinney told several people that Shepard placed his hand on McKinney's crotch and stuck his tongue in McKinney's ear while in McKinney's pickup truck. ${ }^{39}$ In a letter McKinney sent from prison to the wife of a fellow inmate, McKinney described the events of the evening as follows:

When we got out to where he was living, I got ready to draw down on his ass, and all of the [sic] sudden he said he was gay and wanted a piece of me. While he was "comming [sic] out of the closet" he grabbed my nuts and licked my ear! Being a verry [sic] drunk homofobic [sic] I flipped out and began to pistol whip the fag with my gun, ready at hand. ${ }^{40}$

It is hard to believe that an unarmed Shepard, who was much smaller than McKinney and Henderson, would attempt a sexual advance upon a man with a gun who had just announced that he wasn't gay and that Shepard was getting robbed.

McKinney's murder trial began on October 25, 1999. Despite McKinney's initial denial that Shepard made any sexual advances, Jason Tangeman, McKinney's attorney, used a gay panic argument before the jury of seven men and five women. ${ }^{41}$ During his opening statement, Tangeman argued that Shepard made a (homo)sexual advance upon McKinney and that this sexual advance was particularly upsetting to McKinney because of his past history with unpleasant homosexual encounters. According to Tangeman, when McKinney was five years old, 
he was forced to perform oral sex on a neighborhood bully. As a teenager, McKinney engaged in homosexual acts with a cousin, and at the age of twenty, McKinney was traumatized when he accidentally entered a gay and lesbian church in Florida. ${ }^{42}$ These "sexually traumatic events" combined with his use of alcohol and methamphetamine ${ }^{43}$ caused McKinney to lose his self-control.

Tangeman's opening statement was somewhat of a surprise. McKinney's attorneys had not mentioned plans to use a gay panic defense in any of the pretrial hearings. ${ }^{44}$ Judge Barton Voigt quickly called a hearing to decide whether the defense attorneys should be permitted to introduce evidence of gay panic in support of a mental disorder defense. After hearing arguments from both sides, the judge ruled against the defense. First, Judge Voigt observed that despite their protests to the contrary, the defense attorneys were in fact trying to assert what he called a "homosexual rage" defense. He explained:

Defense counsel have tried valiantly to convince the Court that their defense is not a homosexual rage defense. But what they hope to do is to present testimony that, because of homosexual experiences in the Defendant's past, he flew into a rage and killed Matthew Shepard, without specific intent to kill, but voluntarily in a sudden heat of passion. This is the homosexual rage defense, nothing more, nothing less. The fact that the Defendant attempts to raise it through lay witnesses, rather than through experts, is inconsequential. ${ }^{45}$

The judge then ruled that McKinney's prior homosexual experiences could not be considered by the jury on the issue of provocation because provocation is supposed to be based upon an objective Reasonable Person standard and McKinney's personal experiences bore only upon his subjective state of mind. The judge also ruled that the defenses of temporary insanity and diminished capacity were not recognized by Wyoming law, and accordingly were unavailable to the defense. ${ }^{46}$

Despite the judge's attempts to limit the defense's use of gay panic, Tangeman called two witnesses to the stand whose testimony was used to convey the idea that Matthew Shepard was sexually aggressive and deserved the beating he got, playing on stereotypical images of gay men as sexual deviants and sexually aggressive predators. ${ }^{47}$ One witness testified that he was at the Fireside Lounge Bar the night Shepard was killed. According to this witness, Shepard approached him, whis- 
pered something in his ear, and licked his lips in a sexually suggestive manner. ${ }^{48}$ After he agreed to let Shepard sit with him, this witness testified that he "began to feel really uncomfortable. I didn't like the thoughts I was having about the motives for him sitting with me." ${ }^{49}$

A second witness testified that Shepard was sexually aggressive toward him when they went on a trip to a lake with others in the summer of 1998. According to this second witness, Shepard tugged on his shirt and asked him to go for a walk. He responded by punching Shepard twice, knocking him out. ${ }^{50}$

These two witnesses were used by the defense not only to give credibility to McKinney's otherwise hard to believe claim that Shepard had made a sexual advance upon him, but also to suggest that it was reasonable for McKinney to be offended by Shepard's advance and for him to respond to the alleged homosexual advance with violence. During closing arguments to the jury, Tangeman again argued that Shepard's sexual advance upon McKinney triggered the subsequent beating.

Some have speculated about the role of class in the murder of Matt Shepard. Henderson and McKinney were seasonal roofers who brought home about $\$ 900$ a month after taxes. ${ }^{51}$ Both were frequent users of methamphetamine, the drug of choice for drug users without a lot of money. ${ }^{52}$ Shepard, on the other hand, was a student at the University of Wyoming who reportedly wore stylish leather shoes and could afford to drink imported beer. ${ }^{53}$ Henderson and McKinney could have been hostile to Shepard because of his higher class and wealth. According to University of Wyoming professor Beth Loffreda, however, most residents of Laramie did not believe class resentment caused McKinney to kill Shepard. One resident told Loffreda that he believed class resentment was not a factor contributing to Shepard's beating, because most people in Laramie are not wealthy and those who are don't flaunt it.

Even if class did not motivate McKinney to kill Shepard, race and class together may have influenced the public's perception of the case. Shepard was young, White, and middle class. Henderson and McKinney, in contrast, were working class or unemployed, high school dropouts, and methamphetamine users-viewed as "White trash" by some. According to Jay, a gay Shoshone-Northern Arapahoe-Navajo American Indian from the Wind River Reservation in Wyoming, people were outraged by the killing of Matt Shepard because "it was as if white, middle-class America finally had its own tragedy." Jay continued, "If that was me hung on the fence, they'd just say, oh, another 
drunk Indian." ${ }^{54}$ Jay's intuition about public sentiment may be accurate. That McKinney brutally beat a Latino shortly after beating Shepard was barely reported in the press. Had Morales, a young Latino with a criminal record, died of his injuries, one wonders whether middle America would have been as outraged as they were following Shepard's murder.

At the end of the trial, the jury had to decide whether to convict McKinney of first-degree murder (which requires proof of premeditation and intent to kill), second-degree murder (which requires proof that the defendant purposefully killed the victim), or felony murder (which merely requires proof that a killing occurred during the commission or attempted commission of a felony). The jury found McKinney guilty of two counts of first-degree felony murder (one based on the underlying felony of kidnapping and the other on the felony of robbery) and one count of second-degree murder. ${ }^{55}$ Despite repeated attempts to use gay panic as a mitigating factor, McKinney was not able to escape liability for murder.

\section{Billy Jack Gaither}

A gay panic argument was used in another high-profile case by a man named Charles Butler who was charged with murder in the death of Billy Jack Gaither, an openly gay man. Butler and his friend, Steven Mullins, beat Gaither and then set his body on fire atop a pyre of tires, claiming they did so because Gaither propositioned them.

February 19, 1999. Coosa County, Alabama. Steven Mullins asked Billy Jack Gaither, a thirty-nine-year-old textile worker, to pick him up and take him to the Tavern, a local bar which both men frequented. Mullins was unemployed and often asked Gaither for rides and money. Mullins told Gaither that his friend Charles Butler was interested in a sexual threesome and that they were supposed to meet Butler at another bar. In fact, Mullins and Butler had no intention of having a sexual threesome with Gaither. As Mullins later explained, he decided to kill Gaither for propositioning him two weeks earlier, and invited Butler to join him because he knew how much Butler despised homosexuals. Gaither and Mullins picked up Butler, and drove to a secluded place in the woods.

The three men got out of the car, and started drinking beer. Butler was the first to hit Gaither, claiming he did so only after Gaither talked about 
his interest in a sexual threesome. Butler told sheriff's investigator Kelley Johnson, "Well, sir, he started talking, you know, queer stuff, you know, and I just didn't want no part of it. That's when I kicked him, and he went down. I kicked him maybe two or three more times, then he got up, and then I went to use the bathroom, and that's when Steve jumped on him."

As Butler was relieving himself at the front of the car, Mullins grabbed. Gaither, threw him on the ground, and slashed his throat with a pocket knife. He then stabbed Gaither in the ribs. Mullins told Butler to pop the trunk of Gaither's car, then ordered Gaither to climb in.

With Gaither in the trunk of the car, Mullins and Butler drove to a trailer where they picked up tires, kerosene, a box of matches, and an ax handle. The two men then got back in the car and drove to Peckerwood Creek. Once there, Mullins and Butler took the tires out of the trunk and propped the ax handle against the car. Butler started to light the tires. Mullins dragged Gaither out of the trunk and left him on the ground. While Mullins's back was turned, Gaither managed to get up and knock Mullins down the embankment. Gaither crawled back to the car and tried to escape. Mullins got up, followed Gaither, and dragged him out of the car. He then grabbed the ax handle and beat Gaither in the face until his face collapsed. In the meantime, the tires had caught fire. Mullins dragged Gaither's body into the flames and he and Butler watched Gaither's body burn. ${ }^{57}$

That night, Butler confessed to his father, "Daddy, we kicked a queer's ass." Butler's father told this to a friend, and within a week Butler and Mullins were in custody. The two men were each charged with capital murder. In June 1999, Mullins pleaded guilty to capital murder and agreed to testify against Butler in exchange for a life sentence without the possibility of parole.

At his arraignment, Butler pleaded not guilty by reason of mental disease or defect. ${ }^{58}$ Before trial, however, Butler withdrew his mental defect defense, 59 arguing instead that he should be found not guilty of murder because it was Mullins who actually killed Billy Jack Gaither.

Even though Butler formally withdrew his mental defect defense, gay panic was prominently featured at his trial. Butler claimed he hit Gaither only after Gaither told him he was interested in a sexual threesome with Butler and Mullins. Mullins too asserted that the reason he killed Gaither was because Gaither had propositioned him two weeks earlier. 
Gaither's friends, however, said it was highly unlikely that Gaither would proposition either man. According to one friend, "[Billy Jack] didn't walk around acting, looking, or talking gay. If anybody was asking for sex, it wasn't him-it was them. We've got a lot of rednecks in here. You don't make advances with them around." 60 Marian Hammonds, owner of The Tavern, a straight bar which Gaither frequented, described Gaither as a likable man who, while never denying he was gay, "made a point of never doing the gay thing when he was at our place. ... My husband, Larry, didn't even know he was gay until about a year ago, and I had to tell him." 61 Hammonds further remarked, "He [Gaither] never put anybody in [an awkward] position." 62

Mullins may have had a different reason for wanting Gaither dead. Friends of Gaither have asserted that Mullins and Gaither had a sexual relationship which Mullins didn't want anyone to know about, and that Mullins killed Gaither in order to ensure that he never would tell anyone about their homosexual affair. At Butler's trial, Mullins adamantly denied having sex with Gaither or any other man. Yet Butler's attorneys presented several witnesses who testified that Mullins had a secret gay sex life. One man, Jimmy Lynn Dean, testified that he and Mullins had oral sex about four months before Billy Jack Gaither was killed. ${ }^{63}$

In Butler's case, neither gay panic nor the "it wasn't me" argument worked. The jury convicted Butler of capital murder. Even though this made Butler eligible for the death penalty, Gaither's family requested that Butler be spared capital punishment. Butler was sentenced to life in prison without the possibility of parole.

It is comforting that attempts to link gay panic to mental disorder in these two very high-profile cases did not work. In large part, the gay panic argument probably failed in both cases because the facts clearly demonstrated a premeditated and deliberate intent to kill. Additionally, gay and lesbian activists focused media attention on these cases, which helped to delegitimize defense attempts to blame the victim.

Over time, the use of mental defect defenses in gay victim homicide cases has fallen out of favor for a number of reasons, not the least of which is the difficulty of securing a favorable jury verdict with a mental defect defense. ${ }^{64}$ Jurors are often skeptical of defense claims of insanity. ${ }^{65}$ Additionally, a verdict of not guilty by reason of insanity (temporary or otherwise) does not mean the defendant goes free. The defendant who is found insane is usually committed to a mental institution for an indefinite period of time. This period of confinement 
can exceed the length of the prison sentence the defendant would have received if he or she had been convicted. Many individuals would rather serve a definite prison sentence than endure the stigma and uncertainty of an indefinite period of commitment in a mental institution. Moreover, asserting a mental defect defense is often seen as an unacceptable admission of mental deficiency.

Another reason for the shift away from mental defect defenses is the unavailability of those defenses in certain jurisdictions. At least three states do not recognize the defense of insanity. ${ }^{66}$ A number of states have either abolished the defense of diminished capacity or substantially restricted its use. For example, diminished capacity is not officially recognized as a defense in California ${ }^{67}$ or Wyoming. ${ }^{68}$ In some states, such as Michigan, diminished capacity is only allowed as a defense to first-degree murder. ${ }^{69}$

\section{GAY PANIC AND CLAIMS OF REASONABLENESS}

Because of the above-described difficulties associated with mental defect defenses, male defendants charged with murder may claim instead that they were provoked into a heat of passion by the victim's homosexual advance. ${ }^{70}$ Alternatively, they may claim they acted in self-defense. Both defenses require a showing of reasonableness. The defendant will not succeed unless the jury finds that a reasonable man in the defendant's shoes would have been provoked or would have used deadly force in self-defense.

The idea that a homosexual advance constitutes legally adequate provocation is almost as deeply rooted in Anglo-American law as the idea that the observation by a husband of his wife in the act of adultery constitutes legally adequate provocation. At early common law, one of the categories of legally adequate provocation was a serious crime committed against a close relative. Some courts limited this category to cases in which a father discovered someone committing sodomy on his son..$^{71}$ The discovery by a father of someone committing sodomy on his son and the observation by a husband of his wife in the act of adultery were the only two categories of legally adequate provocation which did not involve actual violence by the deceased victim against the defendant. Both these categories involved observations of offensive sexual behavior. 
Not all observations of sexually offensive behavior are considered legally adequate provocation. In one case, a man named Stephen Carr, charged with first-degree murder for killing a woman after watching her engage in lesbian lovemaking, tried unsuccessfully to assert a provocation defense. ${ }^{72}$ Carr encountered Claudia Brenner and Rebecca Wight on May 13, 1988, as they were hiking on the Appalachian Trail. Carr decided to follow the two women, and watched from a hidden vantage point as they began to engage in lovemaking. For no apparent reason, Carr aimed his single-gauge shotgun at the two women and shot eight bullets, killing Wight and injuring Brenner. He was charged with first-degree murder.

In defense of his actions, Carr argued that he was provoked into a heat of passion after observing the two women engage in nude lesbian lovemaking. ${ }^{73}$ To support his heat of passion argument, Carr argued that he had a history of constant rejection by women, starting with his mother who was involved in a lesbian relationship. Prior to trial, the prosecutor filed a motion in limine, arguing that the defendant should be precluded from arguing he was provoked by the women's lovemaking. At the hearing on this motion, defense counsel argued that Carr should be permitted to introduce evidence of his personal, psychologi$\mathrm{cal}$, and sexual history to support his claim of provocation. The Honorable Oscar Spicer found such evidence irrelevant, and granted the prosecution's motion. ${ }^{74}$ After a non-jury trial, the judge found Carr guilty of first-degree murder. Carr appealed his conviction, arguing that Judge Spicer erred in disallowing evidence of his psychosexual history to show that he was provoked into a heat of passion. The appellate court affirmed Carr's conviction, explaining that "The sight of naked women engaged in lesbian lovemaking is not adequate provocation to reduce an unlawful killing from murder to voluntary manslaughter. It is not an event which is sufficient to cause a reasonable person to become so impassioned as to be incapable of cool reflection. A reasonable person would simply have discontinued his observation and left the scene; he would not kill the lovers." 75

Unlike Carr who killed a lesbian woman after merely observing her engage in lovemaking, heterosexual men who have killed gay men in response to unwanted nonviolent sexual advances have had much better luck arguing that they were reasonably provoked into a heat of passion. Perhaps this is because the argument that a nonviolent homosexual advance constitutes legally adequate provocation conforms to dom- 
inant norms of masculinity. A male-on-male sexual advance threatens a heterosexual man's sense of identity as a man in several ways. First, men in this society are supposed to be interested in women, not men. Second, men are supposed to be the sexual aggressors, not the ones aggressed upon. ${ }^{76}$

Masculinity norms also bolster the heterosexual male's claim that he was reasonably outraged by the nonviolent homosexual advance. Roy Scrivner notes that men in this society are supposed to be "fearful and disdainful of homosexuals," and "are taught to reject any personal same-gender sexual feelings."77 James Harrison observes that many heterosexual men are so terrified of being perceived as gay that they avoid expressing qualities that they think seem feminine, like being loving, caring, gentle, and nurturing, and enjoying beauty. ${ }^{78}$

Finally, dominant masculinity norms legitimize the use of physical violence in response to nonviolent homosexual advances. Men in this society who are physically strong, aggressive, and willing to use force when necessary are admired by women and other men. ${ }^{79}$ When a heterosexual man finds his masculinity threatened by a homosexual advance, aggression and violence are considered appropriate ways to respond. ${ }^{80}$ The feeling of threat in such cases is analogous to the threat to male identity and honor that arises when a wife is unfaithful.

The perceived threat to male identity may be heightened if the advance occurs in front of other people, rather than in a private setting. JoAnn Wypijewski recounts the following conversation she had with a young man from Laramie, Wyoming, the town where Matthew Shepard was killed:

"If a guy at a bar made some kind of overture to you, what would you do?"

"It depends on who's around. If I'm with a girl, I'd be worried about what she thinks, because, as I said, everything a man does is in some way connected to a woman, whether he wants to admit it or not. Do I look queer? Will she tell other girls?"

"If my friends were around and they'd laugh and shit, I might have to threaten him."

"If I'm alone and he just wants to buy me a beer, then okay, I'm straight, you're gay-hey, you can buy me a beer." ${ }^{81}$ 
In both the Matthew Shepard and Billy Jack Gaither cases, however, the alleged sexual advance occurred in private (in a pickup truck or out in the woods) when the defendant was with the victim and only one other man, yet the alleged sexual advance still triggered a violent response. Perhaps the private nature of these encounters encouraged the juries in these cases to see the defendants' actions as unreasonable.

The claim of reasonableness linked to anti-gay violence is very much the product of a culture that privileges heterosexual male violence over other types of violence. A man who responds to a (homo)sexual advance with violence resulting in death claims he acted as any ordinary (i.e., heterosexual) man would have acted. A woman who tries to make a similar claim would find it pretty difficult to succeed. A woman who responds with deadly force to a man who whistles at her, tries to kiss her, grab her buttocks, or fondle her breasts is quite unusual, not at all typical. Ordinary or reasonable women are supposed to accept a certain amount of unwanted male attention, and while they might frown, struggle, or protest, they are not supposed to use lethal violence to dissuade or thwart men who suggest sexual interest. Moreover, women are taught to believe that a man who expresses his sexual attraction to a woman is merely behaving the way a man is supposed to behave. The woman who is the target of male attention is supposed to be flattered. Even if the woman is a lesbian, and is just as offended by a male sexual advance as a heterosexual male might be, she is unlikely to convince the average juror that a violent response to a nonviolent heterosexual advance is reasonable, because women are not supposed to be violent. David Wertheimer, former Executive Director of the New York City Gay and Lesbian Anti-Violence Project, wryly points out, "If every heterosexual woman who had a sexual advance made to her by a male had the right to murder the man, the streets of this city would be littered with the bodies of heterosexual men." 82

The heterosexual man's claim of reasonableness does more than privilege men over women. It privileges heterosexual men over gay men. If a heterosexual man responds violently to a homosexual advance, he enjoys a presumption of reasonableness. A heterosexual man is supposed to be disgusted and outraged when another man attempts a sexual advance. If, however, a gay man responds violently to a heterosexual female's sexual advance, he will have a difficult time convincing anyone that he was reasonably provoked into a heat of passion even if a heterosexual woman's sexual advance is just as disgusting to 
him as a gay man's sexual advance might be to a heterosexual man. Men in this society are supposed to be happy if a woman shows she is sexually attracted to him by taking off her clothes, kissing him on the mouth, or grabbing his crotch. If a man, however, shows his sexual interest in another man by acting in a similar manner, he is asking for a violent response.

Charles Butler, the man convicted of capital murder for his part in the slaying and burning of Billy Jack Gaither on a pyre of tires, admitted he would have reacted differently had Gaither been a woman. In an interview with Frontline, Butler admitted that Billy Jack did not attempt to grab him or touch him in any way. Billy Jack's verbal suggestion of a sexual threesome made Butler feel disrespected and led him to beat Billy Jack. Butler admitted that had a woman made a similar suggestion, he would not have viewed her remarks as disrepectful. Because the verbal come-on came from a man, Butler felt he had to react with physical violence.

Race and age also play a part in gay homicide cases. Sixty-seven percent of the perpetrators of anti-gay/lesbian violence are White and 94 percent are male. ${ }^{83} \mathrm{~A}$ majority of the perpetrators are in their teens or twenties. These young, White, male defendants are often described at trial as well-liked, normal young men. ${ }^{84}$ In many cases, the victim is much older than the defendant. Stereotypes about gay men as sexual deviants who prey on young boys and cannot be trusted to work in positions of supervisory authority, the message of both the Religious Right and the Boys Scouts, might lead jurors to feel that a young male defendant's violent response to an older male's sexual advance is reasonable. Even though the concept of reasonableness is usually associated with reason and calm deliberation, the opposite of violence driven by emotion, a young heterosexual man nonetheless is considered reasonable if he responds violently to an older male's nonviolent homosexual advance.

\section{Randy Eklund}

One problem that arises in murder cases in general is the absence of the victim's testimony. Since the victim is dead, the jury often hears only the defendant's account of what happened. This is particularly true in cases in which the defendant and the victim were alone at the time of the homicide. 
February 26, 1991. Rockford, Illinois. Johnny Mangum, a thirty-year-old ex-convict and former Golden Gloves boxer, met Randy Eklund, a gay man twelve years his senior, at Pribby's Tavern in Rockford. The two men began talking, and Eklund bought a number of drinks for Mangum. Eventually, Eklund invited Mangum to come home with him. Mangum accepted the invitation. The two continued drinking in Eklund's kitchen. After several more drinks, Eklund reached over, placed his hand on Mangum's crotch, and squeezed. Mangum pushed Eklund's hand away and told him to stop. Eklund retorted, "I bought you all those drinks, and I want to suck your dick." In response, Mangum began to hit Eklund. When Eklund tried to escape, Mangum followed Eklund and continued to beat him until he fell to the ground. Mangum then forced Eklund to lie face down and tied Eklund's hands and feet together behind his back. With Eklund disabled, Mangum took Eklund's car keys, filled a garbage can with bottles of Eklund's liquor, loaded the garbage can and Eklund's microwave into Eklund's car, and drove it away. Later that evening, Mangum bragged to a friend that he had "robbed a faggot and beat the guy up." ${ }^{85}$

After Ecklund's dead body was discovered, Mangum was charged with first-degree murder. At trial, he claimed that Eklund's homosexual advance provoked him into a heat of passion. According to Mangum, when Eklund grabbed his crotch and said he wanted to suck his penis, he got so angry that he couldn't stop himself from the brutal beating that followed. ${ }^{86}$

Mangum's claim that he killed Eklund in a heat of passion was partially successful. The jury found him guilty of murder in the second degree, implicitly acquitting him of first-degree murder. ${ }^{87} \mathrm{~A}$ journalist who sat through the trial looked over at the jury when the verdict was read and noticed that several of the jurors looked at Mangum with sympathy. After the trial, this journalist interviewed several of the jurors to ask about their decision. One male juror called the deceased victim a "deviate," and added, "I think anyone of his sexual persuasion invites a certain amount of grief." ${ }^{\prime \prime 8}$ Another male juror said he would have clobbered any guy who hit on him. ${ }^{89}$

Mangum's class likely had some influence on his verdict. Jurors are not usually sympathetic to poor defendants with criminal records. In this case, however, at least some of the jurors were sympathetic to Mangum even though he was a transient and convicted criminal who apparently "hung out with alcoholics and drug users along a strip of 
seedy bars in one of Rockford's two 'red light' districts." 90 The jurors may have felt it was particularly believable that a lower-income man like Mangum would panic and respond violently to a (homo)sexual advance.

Mangum's status as a convicted felon may have worked against him as well, encouraging the jury to return a conviction for seconddegree murder rather than the lesser offense of voluntary manslaughter. Studies indicate that lower- and working-class men convicted of assaulting or killing gay men tend to receive more severe sentences than middle- and upper-class men convicted of similar crimes. ${ }^{91}$ If Mangum had been an upper-middle-class or wealthy man, the jury might have returned a more favorable verdict, such as a manslaughter conviction.

Mangum's story may have sounded credible to his jury because it resonated with stereotypes about gay men as sexual deviants and predators. However, in this case as in most homicides, the only version of the facts the jury heard was the defendant's version. Mangum claimed that Eklund grabbed his crotch and started squeezing. Mangum claimed that Eklund threatened to "suck his dick," but we will never know what really transpired the night Randy Eklund was beaten to death. Eklund is not alive to contest Mangum's version of events and no eyewitnesses saw the homicide.

At Mangum's sentencing hearing, Mangum's former wife testified that Mangum did not like homosexuals. She also testified that Mangum told her that before he met her, he used to go into the Seventh Avenue area of Rockford and walk the streets on a regular basis, posing as a homosexual in order to encourage gay men to pick him up. After being picked up, Mangum would wait until the gay stranger made a sexual advance, then he would beat and rob him. ${ }^{92}$ Given this history, Mangum may have pretended interest in Eklund to encourage some kind of sexual advance from Eklund, so that he would have an excuse to beat him. Mangum not only beat Eklund to death, he also stole his belongings. If Mangum was as out of control as he claimed to have been, it is unlikely that he would have had the presence of mind to steal Eklund's liquor, microwave, and car.

For some reason, the jury seemed to ignore Mangum's history as a former boxer who had fought in a "Golden Gloves" competition. Given this history, one might have concluded that Mangum was capable of leaving Eklund's home as soon as the situation got uncomfortable 
for him. Even if Eklund had made some kind of sexual advance, Mangum could have gotten out of the situation without beating him to death.

\section{Stephen Lamie}

August 6, 1988. Lafayette, Indiana. Seventeen-year-old Timothy Schick went out with friends to drink and look for women. After his friends asked to be dropped off, Schick continued to drive around. His car broke down, so he stuck out his thumb and tried to hitchhike a ride. Thirty-eight-yearold Stephen Lamie saw Schick and offered him a lift. Schick climbed in Lamie's car and asked him if he knew where they could find some loose women. Lamie said he couldn't help him. Schick then asked Lamie if he knew where one could get a blow job. Lamie told Schick he could handle that request. Lamie drove to a local high school baseball field and told Schick this was where he would get his blow job. As the two were walking toward the field, Lamie pulled down his own shorts and underwear, grabbed Schick around the waist, and reached for Schick's penis. Shocked by Lamie's forwardness, Schick kneed Lamie in the stomach and hit Lamie in the face. Lamie fell to the ground without fighting back, but Schick continued to kick and beat Lamie. When he heard gurgling sounds coming from Lamie's throat and chest, Schick removed Lamie's watch, some cigarettes from Lamie's pocket, and $\$ 26$ from Lamie's wallet. He raced back to Lamie's car and wiped the dashboard and seat to get rid of his fingerprints, then ran away. ${ }^{93}$

Schick was charged with murder and other offenses. At trial, Schick claimed he was provoked into a heat of passion by Lamie's sexual overture and therefore should be convicted of manslaughter rather than murder. The jury agreed, and found Schick guilty of voluntary manslaughter.

In analyzing the jury's verdict, it is important to consider several factors besides the gender and sexual orientation of the parties. The relative ages of the defendant and victim may also influence the jury's decision as to reasonableness. More than 50 percent of the perpetrators of anti-gay and anti-lesbian violence are under the age of twentyeight. ${ }^{94}$ Given the stereotype of the gay man as a sexual predator who preys on young boys, Lamie's status as a gay man more than twice Schick's age may have influenced the jury to see Schick's violent reac- 
tion as reasonable. Additionally, Lamie's explicit sexual advance (as described by Schick) may have convinced the jury that Schick's violent acts were necessary to protect himself from a sexual assault. If an older man pulled down his underwear, exposed his penis to a teenage girl, grabbed her around the waist, and tried to grab her breasts or crotch, we would probably sympathize with the girl if she used nonlethal violence (a kick or a punch) to escape the older man's sexual advance.

The problem is that even under Schick's version of events, Schick did more than simply use nonlethal violence to escape Lamie's alleged sexual advance. After Lamie was down on the ground with his underwear around his ankles, Schick proceeded to punch, kick, and stomp Lamie to death. If Schick had been a teenage girl, it is doubtful that a jury would find such a response ordinary or reasonable, although they might grant her leniency out of sympathy. Moreover, Schick's claim that the alleged homosexual advance provoked him into such a heat of passion that he completely lost his self-control must be called into question, given that Schick had sufficient presence of mind to take Lamie's watch, cigarettes, and cash, and wipe his fingerprints from Lamie's car before fleeing the scene.

\section{Billy Francis Brinkley}

July 13, 1973. Mecklenburg, North Carolina. Seventeen-year-old David Mills met forty-three-year-old Billy Francis Brinkley at a bar. According to Mills, Brinkley offered to pay Mills $\$ 20$ if Mills would "commit a homosexual act" with Brinkley. Mills agreed, and the two men drove to Paw Creek Cove in Brinkley's car. Once there, according to Mills, Brinkley proceeded to grab Mills's privates. Mills demanded his $\$ 20$, but Brinkley said he didn't have $\$ 20$ with him. Because Brinkley did not have the money he had promised, Mills fought Brinkley off. When Brinkley persisted, Mills pushed Brinkley out of the car. Mills then chased Brinkley, knocked him down, kicked him, and pulled Brinkley's clothes down to hinder his escape. Mills then took Brinkley's jewelry and fled in Brinkley's car. Brinkley's body was later found in a cove in Mecklenburg County, North Carolina. Brinkley had died from head injuries and a massive crushing injury to his chest consistent with having been kicked and then thrown against rocks. Mills was found a few hours after Brinkley's death with Brinkley's automobile, watch, ring, and bracelet. ${ }^{95}$ 
Mills was charged with second-degree murder. Mills maintained he was reasonably provoked by the older man's attempt to have sex with him. The jury agreed that Mills was reasonably provoked, and convicted him of voluntary manslaughter.

Mills's voluntary manslaughter verdict is troubling for several reasons. First, it suggests that the jury believed it was reasonable for Mills to become enraged at Brinkley's conduct (grabbing Mills's private parts and making a pass at him), even though Mills had previously agreed to engage in sexual activity with Brinkley. Mills willingly accompanied Brinkley to Paw Creek Cove, knowing that the purpose of the trip was sex. Generally speaking, the criminal law does not excuse a defendant who creates the conditions of his own defense.

Second, the verdict suggests the jury believed Mills's claim that he was genuinely afraid of being sexually assaulted by Brinkley, even though Mills's behavior-pushing Brinkley out of the car, chasing Brinkley, knocking Brinkley down, kicking him, and pulling his pants down to hinder Brinkley's escape-seems more consistent with the behavior of someone who intends to seriously injure than the behavior of one who is afraid. If Mills had been afraid of Brinkley, he might have tried to get away by driving off in Brinkley's car as soon as he pushed Brinkley out of the car. Instead, Mills chased after Brinkley, knocked him down, and kicked him repeatedly. Once Brinkley was down, he no longer posed an immediate threat to Mills. Nonetheless, Mills proceeded to pull down Brinkley's clothes to hinder Brinkley's escape. He then either pushed or threw Brinkley onto the rocks in the cove where the body was later found.

Finally, Mills's claim that the alleged sexual advance by Brinkley so provoked him that he lost his ability to control his actions is belied by his having the presence of mind to take several items of value belonging to Brinkley, including his watch, ring, bracelet, and car.

One pattern that emerges from gay homicide cases is that the perpetrator who claims he was provoked into a heat of passion often takes money or other items of value from the victim after killing him. Stealing the victim's belongings suggests an economic motivation for the killing, rather than panic or fear. Johnny Mangum took off with Randy Eklund's liquor, microwave oven, and car after beating him to death. Timothy Schick took Steven Lamie's watch, cigarettes, and money, then wiped off his fingerprints from the dashboard of Lamie's car in an attempt to avoid detection and arrest. David Mills took Billy Francis 
Brinkley's watch, ring, bracelet, and car. As one observer of gay panic killings has noted, "the number of cases where [gay] murders have been accompanied by robbery suggests that criminal opportunism is a frequent motive for these killings." 96

Also undermining claims of provocation in gay homicide cases is the fact that the defendant often places himself in a situation in which a homosexual advance is likely. Johnny Mangum accepted Randy Eklund's invitation to come home with him. Timothy Schick hitched a ride from Stephen Lamie, a total stranger, and stayed in the car even after Lamie suggested he could handle a blow job for Schick. David Mills agreed to have sex with Billy Francis Brinkley in exchange for $\$ 20$. Yet in case after case, jurors seem to overlook these facts undermining the defendant's claim that he was actually and reasonably provoked when they give the defendant the manslaughter conviction he seeks.

Less common, but sometimes successful, are claims of gay panic and self-defense. Just as in the provocation cases discussed above, the defendant claiming self-defense draws upon masculinity norms, heterosexuality norms, and stereotypes about gay men to bolster his claims of reasonableness.

\section{Kenneth Brewer}

September 30, 1997. Oahu, Hawaii. After an afternoon and evening of drinking beer and bar hopping, Stephen Bright, a thirty-year-old construction worker, decided to check out Hula's, a gay bar on Kuhio Street. There he met Kenneth Brewer, a retired fifty-eight-year-old former hotel executive. Brewer offered to buy Bright some drinks and the two men chatted. After midnight, Brewer invited Bright to spend the night at his Hawaii Kai condominium. Bright agreed to accompany Brewer back to his condo. Once they arrived, the two men went to Brewer's bedroom where they had a few gin and tonics.

After several drinks, Brewer excused himself. According to Bright, Brewer came back into the bedroom, completely naked with an erection, approached Bright, and told him he wanted to "fuck." Then Brewer grabbed Bright's throat with one hand and his crotch with the other, saying, "Take your clothes off. I want to suck your cock." Bright punched Brewer to get him off of him. He then beat Brewer until Brewer was a bloody mess at the foot of the bed. ${ }^{97}$ 
Bright was charged with second-degree murder. At trial, Bright claimed he acted in self-defense, beating Brewer to ward off a sexual assault. Self-defense as a defense to murder requires proof that the defendant honestly and reasonably believed it was necessary to use deadly force to protect against an imminent threat of death or serious bodily injury. If the defendant could have avoided the threatened harm by taking less fatal action, the defendant cannot claim self-defense. Self-defense doctrine also requires proportionality. An individual cannot use deadly force to counter nondeadly force.

Interestingly, Bright's attorney, Deputy Public Defender Jack Tonaki, did not argue that his client's fear of sexual assault was somehow worse because his attacker was a man. Instead, in a sophisticated appeal to the women on the jury, Tonaki argued that fighting back in self-defense against the threat of sexual assault is the same whether by a man or a woman. Engaging in a bit of veiled gender- and sexual orientation-switching, Tonaki further argued that it makes no difference whether the sexual assailant is gay or straight, because an individual has the right to fight off an unwanted sexual attack. ${ }^{98}$ The jury, encouraged to imagine Bright as a woman being sexually attacked by an older man, sympathized with Bright.

It is true that a woman threatened with imminent rape or other forcible sexual assault is generally justified in using deadly force in selfdefense. However, the woman is justified only if deadly force is necessary to avoid being killed or seriously injured. Use of deadly force to protect against death or serious bodily injury is considered proportionate force. It is doubtful that Stephen Bright had to kill Kenneth Brewer in order to avoid the alleged sexual advance. Bright was younger by almost thirty years and much stronger than Brewer. According to Wayne Tashima, the prosecutor who tried the case, Bright's body was muscular and stocky. It was obvious that he worked out, and his job as a construction worker required him to lift heavy objects. Brewer, in contrast, was overweight and weak. Bright did not have to beat Brewer to death in order to avoid a sexual assault.

Further undermining Bright's claim of self-defense was that Brewer's blood was found on the inside of Bright's jeans, suggesting that Bright had his pants off during the beating and may have engaged in some form of consensual sexual activity before the killing. Bright, however, denied taking off his pants during the evening. His attorney suggested Brewer's blood could have gotten on the inside of Bright's 
jeans after he took off his clothes and threw them together in a laundry basket. According to the prosecutor, however, Bright did not remove his clothes until at least four hours after the killing. Any blood from the beating probably would have dried by that time, and would not have transferred from one piece of clothing to another.

The blood on the inside of Bright's jeans suggests Bright may have allowed Brewer to orally or manually copulate him before he beat Brewer to death. If so, Bright's claim that he was afraid of Brewer and only beat him to ward off a sexual attack is suspect. It seems more plausible that Bright went to Brewer's home knowing that Brewer expected some kind of sexual activity in exchange for all the drinks he had purchased for Bright that evening. The two may have started to engage in sexual activity. Then Bright may have started feeling disgusted with himself and took his feelings of shame and guilt out on Brewer. Alternatively, Bright may have engaged in consensual sex in order to make it easier for him to kill Brewer. The brutality of the beating suggests a rage that far exceeds the force needed to protect oneself from a sexual assault.

The jury deliberated for three-and-a-half days before acquitting Bright of murder, finding him guilty of only third-degree assault, a misdemeanor. The maximum punishment for third-degree assault was one year in jail." Because Bright had already been in jail for one year pending trial, he was released from jail the same day he was convicted. ${ }^{99}$

\section{REVISITING THE JENNY JONES CASE}

Heterosexism, racism, and sexism often work in tandem, privileging White (race) heterosexual (sexual orientation) males (gender) over others who are seen as different from the norm. ${ }^{100}$ One of the goals of this project is to highlight the ways in which masculinity, race, and sexuality norms work in tandem to privilege certain claims of reasonableness over others. To the extent possible, I have tried to engage in what Peter Kwan calls a cosynthetic analysis, one that takes into account differing axes of subordination. ${ }^{101}$ In like vein, Darren Hutchinson calls upon service.

* Bright was sentenced to time served and four hundred hours of community 
legal scholars to apply a "multidimensionality" approach, recognizing the interrelationships between racism, patriarchy, and heterosexism. ${ }^{102}$

It is often difficult to perform a multidimensional analysis because the written accounts of most cases focus on only one axis of discrimination, if any. ${ }^{103}$ For example, court opinions in gay panic cases rarely identify the race of the defendant or victim because the court is focused on sexual orientation. Similarly, court opinions in racialized self-defense cases rarely identify the class status or sexual orientation of the parties.

How might a cosynthetic or multidimensional analysis be applied to the Jenny Jones case? Such analysis would evaluate how norms of heterosexuality, masculinity, and race interacted to support Schmitz's claim that appearing on the Jenny Jones Show with a gay secret admirer was deeply humiliating. For example, Jonathan Schmitz's claim of outrage and embarrassment by a gay secret admirer makes sense only if we accept as reasonable his expectation that his secret admirer would be a woman. A gay man wouldn't necessarily expect a woman to be his secret admirer. But in this society, heterosexual orientation is the norm and therefore most people think it reasonable for a man to expect that a secret admirer will be a woman.

Schmitz's resort to violence as an expression of outrage at Amedure's expression of sexual interest could also be seen as reasonable given the masculinity norm of violence and aggression. Men in this society are socialized to respond to threats to masculinity with force. A boy who turns the other cheek when hit is considered a sissy. ${ }^{104}$ Because men are not supposed to be anything like women, the fact that women rarely resort to violence when they are confronted with unwanted sexual attention from male admirers does not detract from the male claim of reasonableness. Scott Amedure, however, did not make an unwanted homosexual advance upon Schmitz, unless we stretch the meaning of sexual advance. There was no attempted kiss, no grabbing or stroking of a private part. Schmitz's response to the note he received on his doorstep, which he assumed was a crude come-on from Amedure, was grossly disproportionate, which was probably why Schmitz's second jury rejected his claim of reasonable provocation.

The racial implications of the Jenny Jones case are less apparent. Both Schmitz and Amedure were White men, so the case seems devoid of racial content. Race most likely had an effect on public perception in the negative. Because Schmitz was a White male, his resort to violence 
was not attributed to all White males as a class. Had Schmitz been a Black man or a foreigner, his resort to violence might have been seen as typical of all Black men or all men from his particular country. Instead, Schmitz's resort to violence was viewed as the act of a distraught individual.

In the end, the jury rejected Schmitz's claim of provocation. Apparently, they did not believe Schmitz's claim that being taped on the Jenny Jones Show with a male secret admirer would cause a reasonable man to be provoked. The legal hook that helped Schmitz reduce his murder charge from first degree to second degree was diminished capacity, a mental defect defense. Given that Schmitz clearly met the requirements for first-degree murder-he intended to kill and premeditated and deliberated on how to do so-Schmitz was lucky to receive a second-degree murder conviction. 


\section{Culture and Crime}

In 1986, Dong Lu Chen immigrated to the United States from mainland China with his wife, Jian Wan Chen, and their three children. Dong Lu, fifty-three years old at the time, had been a farmer in China, but was only able to find work as a dishwasher in Maryland. Dong Lu lived in Maryland. His wife and three children lived in New York where Jian Wan worked part-time at a garment factory. On his days off, Dong Lu would travel to New York to be with his wife and family. During one visit, Jian Wan refused to have sex with Dong Lu. Dong Lu began to suspect that his wife was having an affair.

In June 1987, Dong Lu decided to move back to New York to live with his family. He noticed that his wife seemed cold and distant. Dong Lu continued to suspect his wife of infidelity. Finally, on August 25, Dong Lu asked Jian Wan whether she was seeing another man. Jian Wan confessed that she was. Dong Lu walked away without saying anything more. Two weeks later, on September 7, Dong Lu tried to have sex with his wife. According to Dong Lu, Jian Wan refused, telling him, "I won't let you hold me because I have other guys who will do this." This retort angered Dong Lu who grabbed his wife and pressed her down. "How long has this been going on?" he shouted in Chinese. Jian Wan, who could barely breathe, gasped, "For three months." Her honesty only enraged Dong Lu further. Dong Lu went into the next room, grabbed a claw hammer, came back to the bedroom, and struck his wife eight times on the head. ${ }^{1}$

Dong Lu Chen was charged with second-degree murder in the death of his wife. At trial, Chen's attorney argued that Chen should be found not guilty of murder because he was temporarily insane at the time of the crime. Chen's attorney further argued that Chen's cultural background negated his culpability in two ways. ${ }^{2}$ First, according to the defense, any reasonable or ordinary Chinese man would have reacted the way Chen did when he learned of his wife's infidelity. Second, 
Chen's attorney argued that if Chen had been in China when he found out about his wife's infidelity, his family would have stopped him from killing his wife. Because he was here in America, without his usual base of familial support, Chen had no one to hold him back when he lost his self-control. ${ }^{3}$

Chen's attorney relied primarily upon the testimony of Burton Pasternak, an American anthropologist who had studied Chinese culture, to make these points. Pasternak explained that in Chinese culture adultery by a wife was a stain on the husband, indicating that the husband had only minimal control over his wife. ${ }^{4}$ According to Pasternak, Chen's behavior "would not be unusual at all for [a] Chinese in that situation, for a normal Chinese in that situation. ... If it [sic] was a normal person, it's not the United States, they would react very violently. . . . I've witnessed such situations myself." ${ }^{5} \mathrm{He}$ continued, "In general terms, I think that one could expect a Chinese [man] to react in a much more volatile, violent way to those circumstances than someone from our own society."6

While Pasternak testified on direct examination that he had witnessed similar incidents in China, suggesting personal knowledge of incidents in which other Chinese men had killed their adulterous wives, he later admitted on cross-examination that he could not recall a single instance during the six years in which he had lived in China where a Chinese man had killed his wife for being unfaithful. ${ }^{7}$ Nonetheless, Brooklyn Supreme Court Justice Edward Pincus found Chen guilty of second-degree manslaughter, rather than murder, and sentenced him to five years of probation and no additional jail time. Explaining his decision, Justice Pincus wrote:

Were this crime committed by the defendant as someone who was born and raised in America, or born elsewhere but primarily raised in America, even in the Chinese American community, the Court would have been constrained to find the defendant guilty of manslaughter in the first degree. But, this Court cannot ignore ... the very cogent forceful testimony of Doctor Pasternak, who is, perhaps, the greatest expert in America on China and interfamilial relationships. ${ }^{8}$

Justice Pinkus continued, "[Dong Lu Chen] was the product of his culture. ... The culture was never an excuse, but it is something that made him crack more easily. That was the factor, the cracking factor. ${ }^{\prime \prime}$ 


\section{THE MEANING OF CULTURE}

When we talk about culture, what do we mean? In 1871, Edward B. Tylor defined culture as "that complex whole which taken [together] includes knowledge, belief, art, morals, law, custom, and any other capabilities and habits acquired by man as a member of society."10 According to Madhavi Sunder, this traditional definition "conceived of culture as a 'thing' that survives and is imposed on generation after generation."11 The traditional view was that culture was something "static, homogeneous, bounded, and distinct." 12

Sunder notes that most anthropologists today "dismiss Tylor's view as mistaken in its characterization of culture as a static, unchanging set of beliefs that is imposed upon individuals generation after generation." ${ }^{13}$ Modern anthropologists see culture as "increasingly fluid, heterogenous, and contingent."14 Postmodernists have redefined the term culture as reflecting "a discourse or a set of social relations between individuals and groups attempting to define and redefine themselves in relation to one another and within a social context." 15

One thing missing from these attempts to define culture is recognition that culture is something we Americans tend to ascribe to others, namely immigrants and racial minorities, not to ourselves. As Leti Volpp explains:

[B]ehavior that we might find troubling is more often causally attributed to a group-defined culture when the actor is perceived to "have" culture. Because we tend to perceive white Americans as "people without culture," when white people engage in certain practices we do not associate their behavior with a racialized conception of culture, but rather construct other non-cultural explanations.... Thus, we consider early marriage by a Mexican immigrant to reflect "Mexican culture." In contrast, when a white person commits a similar act, we view it as an isolated instance of aberrant behavior, and not as reflective of a racialized culture. Under this schema, white people are individual actors; people of color are members of groups. ${ }^{16}$

Think about it. When someone says, "I'm going to talk about the role of cultural norms in the criminal courtroom," as I've said often enough when describing this book project, the first thing one thinks about is a foreign immigrant defendant or other defendant of color attempting to 
excuse a criminal act by saying what he did would have been okay in his country or community. Dong Lu Chen's claim that what he did was normal for an ordinary Chinese man in his situation is believable because we think of China as a patriarchal society where men can do whatever they want and women are killed for the slightest transgression. Popular films contribute to our vision of China as a patriarchal society. For example, the film Raise the Red Lantern, ${ }^{17}$ set in China during the 1920s, depicts the life of a self-centered, wealthy, Chinese man with several wives, including one about his age and several who are much younger. The husband sleeps with a different wife every night. The wife he chooses to sleep with is treated to extra special attention from the servants that day in preparation for the big night, while the other wives are ignored or treated like second-class citizens. Instead of recognizing the unfairness of the situation and getting angry at the husband, the women compete for his nightly attentions. Tired of being left alone night after night while her husband enjoys the company of other women, one of the younger wives decides to take on a lover herself. When the husband discovers her adultery, he has her killed. The China depicted in Raise the Red Lantern is the China in the American imagination. We Americans tend not to think of China as a place where men and women both work and share domestic responsibilities, even though this state of affairs is more reflective of modern-day China.

Even though numerous American men have killed their wives for committing adultery, we don't think of America as a patriarchal society. We think our country is progressive, especially compared to countries in Asia and Africa. ${ }^{18}$ We don't think American men who beat their wives are representative of American culture, even though domestic violence is a serious problem that affects a significant number of American women. We don't see the actions of White, heterosexual, American men who kill their unfaithful wives as reflecting the cultural norms of American society. The irony is that while we see men who kill their female partners as aberrant individuals, not cultural icons, we also find credible their claims of normality or reasonableness.

\section{THE ROLE OF CULTURE IN THE CRIMINAL COURTROOM}

Although it is common to hear the term "the cultural defense," there is no separate cultural defense per se. Typically, a defendant will offer lay 
or expert testimony regarding her cultural background to support a traditional defense, such as insanity, provocation, or self-defense. Cultural evidence may also be offered as a mitigating factor during plea negotiations or at sentencing.

It is difficult to assess the extent to which cultural information influences criminal cases. No nationwide database keeps track of criminal cases in which cultural evidence is presented and it is virtually impossible to independently track all the criminal cases in which cultural evidence helped secure an acquittal, a reduction in the charges, or a lighter sentence. Nonetheless, it appears that most attempts to use culture to exonerate or mitigate are not successful. ${ }^{19}$ According to Holly Maguigan, defendants who are not from the dominant culture are convicted more frequently and sentenced more severely than dominantculture defendants. ${ }^{20}$

Attempts to use culture in the criminal courtroom may fail because judges and jurors have difficulty placing themselves in the shoes of the other. It is hard for someone who is not part of a given community to understand that community's beliefs and customs. Moreover, a defendant who comes from a different country or a minority community in the United States does not fit mainstream America's vision of the average ordinary person.

Judges may also exclude cultural evidence because they believe it is irrelevant. Judges may assume that Americans have a shared understanding of what reasonable people think and do. Admitting evidence regarding a defendant's cultural background would muddy the otherwise clear waters of reasonableness.

To a large extent, these judges are correct in thinking that Americans have shared understandings. Some attitudes and beliefs are so pervasive in American society that they influence the way all of us see things. Nonetheless, Americans are not a homogeneous group. People who are exposed to the same testimony and evidence can and do come to vastly different conclusions. O.J. Simpson's double murder trial was televised and watched by thousands of Americans, each of whom interpreted the evidence in a different way. Even though exposed to the same testimony, the same DNA evidence, and the same arguments by the attorneys, Americans disagreed over Simpson's culpability as if they had seen two different trials.

Reasonableness is a vague, open-ended standard. In many cases, jurors will not agree that the defendant acted reasonably or unreasonably. 
In such cases, jurors should be guided by more than simply the influence of dominant American cultural norms which are likely to lead to one result. Information about the defendant's cultural background may be useful to help jurors understand why the defendant acted the way he did. Jurors don't have to agree that the defendant's actions were reasonable, but they should at least hear what the defendant has to offer in his defense. When the defendant is American, the jurors already understand the defendant's cultural background because the jurors are part of the same culture. The American defendant doesn't have to ask for special consideration because he already gets it.

Culture is sometimes thought to be less relevant than gender. For example, Yvonne Wanrow tried unsuccessfully to present evidence of her Native American background in support of her claim of self-defense. ${ }^{21}$ Wanrow, charged with killing a man she believed had molested her child, wanted to show that because Native American culture places heavy emphasis on the importance of family and abhors unnatural sex acts, it was reasonable for her to be startled and afraid when she found the man she believed had engaged in unnatural sex acts with her child directly behind her. ${ }^{22}$ The trial judge excluded Wanrow's proffered evidence on the ground that it was not relevant. Although Wanrow was later able to get her conviction reversed because of the trial court's erroneous use of the male pronoun when describing the Reasonable Person, ${ }^{23}$ both the intermediate court of appeals and the Washington Supreme Court agreed that the trial court acted properly in excluding evidence of Wanrow's Native American culture.

Other Native Americans have attempted unsuccessfully to persuade judges that their beliefs or actions were reasonable in light of their cultural background and experiences. In State v. Williams, for example, a Native American couple charged with manslaughter in the death of their infant baby tried unsuccessfully to argue that their failure to take their baby to a doctor was due to a reasonable fear that the doctor would tell governmental authorities that they were bad parents, and then the government would come and take away their child. ${ }^{24}$ Surveys of states with large Native American populations, conducted by the Association on American Indian Affairs around the time of the trial, indicated that approximately 25 to 35 percent of all Native American children were separated from their families and placed in foster homes, adoptive homes, or institutions. ${ }^{25}$ In some states, the rate of adoption and foster placement for Native American children was even higher. In 
Minnesota, Native American children were placed in foster or adoptive homes at a per capita rate five times greater than non-Native American children, and nearly one in every four Native American children under one year old was adopted. ${ }^{26}$ In Montana, the ratio of foster-care placement for Native American children was at least thirteen times greater than that for non-Native American children. ${ }^{27}$ In South Dakota, 40 percent of all adoptions made by the State's Department of Public Welfare were of Native American children, even though Native Americans made up only 7 percent of the entire state's juvenile population. ${ }^{28}$ Given these statistics, the Williamses argued that their fear that their infant would be taken away from them was reasonable. The trial judge was not persuaded by this argument and found the parents guilty of manslaughter.

In affirming the convictions, the appellate court explained that the crime of manslaughter is committed by one who fails to exercise ordinary caution and thereby causes a death. According to the court, "Ordinary caution is the kind of caution that a man of reasonable prudence would exercise under the same or similar conditions." ${ }^{29}$ Focusing on whether a "man of reasonable prudence": would have failed to take the baby to the doctor, rather than on whether the Native American parents' fear that their baby would be permanently taken away from them was reasonable, the appellate court found that the parents acted unreasonably. ${ }^{30}$

When I teach State v. Williams in my criminal law classes, my students generally defend the appellate court's decision. ${ }^{31}$ Many will argue that all individuals should be held to the same (i.e., American) standard of reasonableness. In their view, the "reasonable parent" would have taken the baby to the doctor. Because the Williamses failed to do so, they acted negligently and therefore satisfied the conditions for conviction. Like the trial and appellate courts, many students do not think the Native American parents' fear of having their baby taken away is relevant. Perhaps the parents' fear is not considered relevant because most Americans never have to worry about the government permanently taking their young children away from them. 


\section{PROBLEMS WITH THE USE OF CULTURE}

\section{IN THE CRIMINAL COURTROOM}

Although cultural evidence is often excluded, it is sometimes allowed under problematic circumstances. We've seen how courts sometimes privilege gender over race. When courts admit evidence of culture, the opposite occurs. Race (or the defendant's culture) is privileged over gender. As Dana Chiu notes, "When we privilege the voices of Asian men, who rely on their cultures' traditions of beating and killing their wives to excuse their acts, women are silenced. ${ }^{\prime 32}$ Dong Lu Chen's sentence of probation with no jail time created concern in the Asian Pacific American community that other Asian immigrant men would view the verdict and sentence as a license to beat and kill their wives. Sharon Hom, commenting upon the Chen case, notes, "This kind of thinking reinforces patriarchal and racial stereotypes-which don't even exist in China today. This is like saying, 'My goodness, Americans lynch blacks, let's let them do it,' just because lynchings have happened in the past." ${ }^{\prime 33}$

A second, related, problem is that culture is often presented as uncontested or one-dimensional. The Asian immigrant male defendant claims he comes from a culture that condones male violence against women. Asian immigrant women from the same country, however, might contest his depiction of their culture. Leti Volpp explains how this occurred in the Dong Lu Chen case:

Pasternak's perspective was "male," obviating the possibility that a woman, and specifically a Chinese immigrant woman, might describe divorce, adultery, and male violence within "Chinese culture" very differently... . Thus, the "cultural defense" served in this case to legitimize male violence against women by glossing over the gendered aspects of Pasternak's testimony. ${ }^{34}$

Volpp further notes that the defense strategy in the Chen case turned the tables by portraying Dong Lu Chen, the husband, as the victim, thus rendering the real victim, Jian Wan Chen, invisible:

But where was Jian Wan Chen in this story? The defense strategy rendered her invisible. She was most notably present in the testimony as a dead body and as a reputed "adulteress," bringing a "stain" upon 
her husband. Jian Wan Chen did not exist as a multi-faceted person but was instead flattened into the description "adulteress." Any discussion of her at trial was premised upon her characterization as a woman who provoked her husband into jealousy. How should this flattening be interpreted? This invisibility and erasure of the woman, Jian Wan Chen? ${ }^{35}$

A third problem is the assumption that the culture of others is fixed and static. Cultural practices, however, are not fixed, but change over time. ${ }^{36}$ At one time, Chinese women had their feet bound so they could barely walk. Small feet were considered pretty, delicate, childlike. Women in China no longer follow this practice. Similarly, American women once wore corsets with "whalebone or metal stays that were laced so tightly the wearer could barely breathe". so they could achieve the "perfect" sixteen-inch waist. ${ }^{37}$ While American women today do other things to their bodies to look beautiful, including breast augmentation and plastic surgery, they no longer commonly wear the unbearably tight corsets that once were popular. ${ }^{38}$

That cultural norms are in a constant state of flux is evident if we look at our own evolving attitudes about men and masculinity in American society. At one time, being a man in American society meant being in control, being physically strong, being the breadwinner, not exhibiting anything that might be seen as feminine, and not showing one's emotions. In the 1970s, Deborah David and Robert Brannon identified the four primary elements of the "male sex role" in America:

No Sissy Stuff: The stigma of all stereotypical feminine characteristics and qualities, including openness and vulnerability.

The Big Wheel: Success, status, and the need to be looked up to.

The Sturdy Oak: A manly air of toughness, confidence, and self-reliance.

Give 'Em Hell? The aura of aggressiveness, violence, and daring. ${ }^{39}$

Today, what it means to be a man is much less clear. Ronald Levant notes, "To many [American] men, particularly mid-life men, the question of what it means to be a man today is one of the most persistent unresolved issues in their lives. ${ }^{\prime 40}$ American men today feel pressure from their female partners to be more emotional and sensitive. Many (though, unfortunately, not all) have begun to help with the domestic 
chores of cooking and cleaning, tasks previously delegated to the female partner. Men are no longer the sole breadwinners in many households. The reality of women in the workplace and the need for dual incomes to afford a comfortable standard of living have made some of the traditional traits of masculinity obsolete. Accordingly, young American men today do not endorse many of the traditional norms of masculinity. ${ }^{41}$

Some masculinity norms, however, have survived even the passage of time. According to Levant, most young American men still endorse the norm of male aggression. ${ }^{42}$ Susan Faludi, who agrees with Levant that the meaning of manhood is much less clear today than it was eighty years ago, opines that the current prevailing norm of masculinity is the man in control of his environment. The man in control sounds a lot like "The Big Wheel" and "The Sturdy Oak" male sex role norms described by David and Brannon. According to Faludi:

The man controlling his environment is today the prevailing American image of masculinity. A man is expected to prove himself not by being part of society, but by being untouched by it, soaring above it. ${ }^{43}$

In China, as in America, masculinity norms have likely changed over time. Even if a cultural practice of killing one's wife for being unfaithful once existed in China, it is doubtful that this practice was in force in 1986 when Dong Lu Chen emigrated to the United States from mainland (communist) China.

Another problem with the way culture is deployed in the criminal courtroom is the perpetuation of negative stereotypes. Cultural evidence which is used to help a particular criminal defendant often ends up hurting others from the defendant's community by creating or reinforcing negative stereotypes. The Dong Lu Chen case, for example, sent the message that it is normal for Chinese men to be more volatile and violent than American (or, more precisely, non-Chinese) men. Recall Burton Pasternak's testimony: "In general terms, I think that one could expect a Chinese [man] to react in a much more volatile, violent way to those circumstances than someone from our own society." 44 Even if untrue, individuals who heard about the case might have been left with the impression that all Chinese men are extremely jealous and prone to physical violence. The problem is compounded when other Asian immigrant men are able to use culture to excuse their acts of violence against women. ${ }^{45}$ 
Anthony Alfieri argues that defense attorneys should be sensitive to the risk that when they assert "deviance" defenses such as "Black Rage" or mob contagion, on behalf of their Black criminal defendant clients, they hurt the entire African American community by sending the message that all African Americans are deviants who cannot control their impulse toward violence. ${ }^{46}$ For example, attorneys for Damian Monroe Williams and Henry Keith Watson, who were charged with attempted murder, aggravated mayhem, torture, and second-degree robbery arising from their assault upon Reginald Denny, ${ }^{47}$ argued that their African American clients lacked the specific intent to kill Denny (a necessary element of attempted murder) because the beating of Denny was the result of Black Rage and mob contagion. ${ }^{48}$ Williams was acquitted of attempted murder and convicted of mayhem, a felony, and four misdemeanor assaults. ${ }^{49}$ Watson was also acquitted of attempted murder and convicted of a misdemeanor assault. The jury deadlocked on the other charges against Watson, leading the judge to declare a mistrial on those counts..$^{50}$

Being sensitive to the defendant's community, while a good idea in theory, may conflict with the practical realities of criminal defense practice and the ethical duty to zealously represent the client. All attorneys owe a duty of loyalty to their clients, but criminal defense attorneys, more so than other attorneys because of the stakes involved (the client's life or liberty), must put their clients' interests above all other interests. Abbe Smith points out that lawyers are not supposed to forsake their clients for larger causes. ${ }^{51}$ Attorneys, civil and criminal, are not supposed to place restrictions on their advocacy based on their own personal moral values. ${ }^{52}$ Criminal defense attorneys have a special duty to use "all means and expedients ... at all hazards and costs to other persons" to save their clients. ${ }^{53}$ Smith concludes that if criminal defense attorneys were to follow Alfieri's advice and refrain from advancing defenses which could help their clients, they would not only breach their ethical duty of loyalty to the client, but also contribute to the problem of massive incarceration of young Black men.

Criminal defense attorneys, however, can be sensitive to racialized narratives without selling out their clients. ${ }^{54}$ For example, the attorneys for Damian Williams and Keith Watson could have advanced the Black Rage and mob contagion arguments while acknowledging that not all young Black males are violent criminals. Making such an admission likely would have enhanced the defense attorneys' credibility with the 
jury. It isn't clear from the press accounts whether the prosecutor made any effort to educate jurors about the dangers of racial stereotyping, but such education certainly would have been worth the effort. Prosecutors in other cases have successfully rebutted defense attempts to use racial stereotypes to their client's advantage. Holly Maguigan points out that the rape trial of African American boxer Mike Tyson is one example of "successful prosecutorial response to stereotyped cultural information presented and argued by a defense lawyer." 55 In that case, the defense tried to depict the complainant, Desiree Washington, an African American woman, as a "lascivious, hot-blooded, willing young thing who could not wait to screw the savage. ${ }^{\prime 56}$ As Joan Morgan notes, Tyson's attorneys "used a characterization of African American female sexuality that has plagued [Black women] since slavery." 57 The defense attorneys also depicted Tyson as an out-of-control Black sex maniac, hoping that the jury would think Washington was asking for it when she accompanied Tyson to his hotel room at 2:00 in the morning. Instead, the jury convicted Tyson of rape. ${ }^{58}$

\section{THE DEBATE OVER ADMISSIBILITY OF CULTURAL EVIDENCE}

No universal rule governs the admissibility of cultural evidence in the criminal courtroom. ${ }^{59}$ Some judges admit cultural evidence while other judges view it as irrelevant. This has led Deirdre Evans-Pritchard and Alison Dundes Renteln to opine that "whether a defendant can invoke a cultural defense depends almost entirely on the luck of the draw, that is, on who the judge is." 60

Whether cultural evidence should be admitted at trial is hotly contested. Those who oppose the admission of cultural evidence argue that the behavior of individuals who choose to live in the United States should conform to the laws and customs of this country. Ignorance of the law generally is not an excuse, and a person who lives in this country shouldn't be excused simply because what he or she did would not be a crime in his or her country.

Proponents argue that cultural information should be admitted at trial if relevant. A person's cultural background might be relevant in many different ways. Culture might inform the question of whether the defendant acted with the requisite mental state. If, for example, the defendant believed she was helping the victim, she may not have acted 
with an intent to kill or inflict grievous bodily injury. ${ }^{61}$ Some Southeast Asians believe that coining, rubbing a serrated coin about the size of a quarter on the skin of a child until mild bruising occurs, is a way to cure the flu and other ailments. ${ }^{62}$ When a Southeast Asian parent is charged with child abuse or child endangerment because of coining, evidence of this cultural belief may demonstrate a lack of intent to harm.

If the defendant asserts a defense with a reasonableness requirement, such as provocation, self-defense, mistake of fact, or consent as a defense to rape, his or her criminal liability will turn upon whether the jury thinks a reasonable person in the defendant's shoes would have believed or acted the way the defendant did. Ordinarily, factors such as the defendant's age, height, weight, and gender are taken into account when determining whether the defendant acted reasonably. Arguably, a defendant's cultural background is an equally important consideration.

Holly Maguigan notes that the debate over admissibility of cultural evidence has sometimes pitted multiculturalists against feminists. ${ }^{63}$ Multiculturalists believe in the importance of cultural difference and critique the idea that assimilation into the dominant culture is always best. They "argue that the old 'melting pot' social metaphor, which privileges the erosion of cultural distinctiveness in the dominant cultural stew, is obsolete and at times discriminatory." ${ }^{164}$ Multiculturalists believe that admitting cultural evidence in criminal cases is necessary "to counteract the injustice of applying the dominant culture's legal standards to defendants from other countries." ${ }^{65}$

In contrast, some feminists argue against the admission of cultural evidence, especially in cases involving male violence against women, because admission "condones such violence."66 Feminists who oppose the admission of cultural information find themselves in an awkward situation. Feminists generally believe in the importance of individualized and contextualized adjudications. They are generally supportive of social framework evidence, evidence which helps the jury understand the context in which the defendant was acting. For example, feminists have generally supported battered women's attempts to introduce expert testimony regarding the effects of battering on an abused victim's state of mind. Yet when a male immigrant defendant attempts to introduce expert testimony about the effects of his cultural upbringing on his state of mind, some feminists argue that such evidence should be excluded because it reinforces patriarchal practices and the subordination of immigrant women. 
Some feminists have argued that it is unfair to give immigrants and members of minority communities in America a special defense that is unavailable to members of the dominant culture. For example, Doriane Coleman argues that recognition of a cultural defense violates the antidiscrimination principle by treating immigrant defendants more favorably than dominant culture defendants. ${ }^{67}$

The special treatment argument is misguided for two reasons. First, courts generally do not recognize a separate cultural defense. Cultural evidence is usually introduced to provide support for a traditional criminal defense. Second, as Holly Maguigan notes, the special treatment argument "ignores the work of scholars who explain that the standards of the dominant culture operate now as a cultural defense." ${ }^{68}$ Americans who commit crimes don't have to specially argue that their cultural background influenced their actions because dominant social norms already support their claims of reasonableness. Moreover, there is no risk of inadequate translation because all the relevant decision makers-the judge, jury, and prosecutor-are part of the same culture.

Coleman calls the question of how to resolve the competing values of respect for cultural difference and the protection of women and children the "Liberals' Dilemma" because liberals, who generally respect both cultural difference and feminist concerns, have to choose one over the other when it comes to the question of whether cultural evidence should be admitted in criminal cases. ${ }^{69}$ Several scholars have contested Coleman's characterization of the issue, arguing that the values of multiculturalism and feminism are not hopelessly conflicted. Leti Volpp, for example, notes that the reason Coleman is able to pit multiculturalism against feminism is by depicting feminism as "Euro-American" and non-European culture as patriarchal. ${ }^{70}$ Volpp points out that feminism is not exclusively Euro-American, and Euro-American culture is also patriarchal. ${ }^{71}$ Volpp argues that Coleman's "bifurcation of race and gender leads to the mistaken conclusion that the goals of multiculturalism and feminism are antithetical. ${ }^{\prime 72}$ Andrew Taslitz argues that permitting immigrant defendants, such as Hmong men charged with rape, to offer cultural evidence is actually consistent with the values of feminism and multiculturalism. ${ }^{73} \mathrm{He}$ explains:

Postmodern multiculturalists view objective truth in the law as a fiction, with the law and its products merely reflecting the drafters' 
voices. Anglo-American law thus embodies dominant white male culture, rather than some grander truth. Because all cultures deserve respect, postmodern multiculturalists argue that we cannot judge those of another culture without at least giving their culture's perspective a voice in the judgment process. Cultural evidence serves that purpose. Indeed, at their most extreme, postmodern multiculturalists conclude that a culture's people can be judged only by that culture's standards. Evidence of Hmong marriage-by-capture customs should thus be relevant not only to show that Hmong men believed that the captured women were consenting, but also to show that their belief was reasonable. Emphasizing respect for the disempowereds' voices and for their cultural differences from the mainstream is consistent with some branches of feminism. Some feminists have thus endorsed the cultural defense in selected contexts. ${ }^{74}$

\section{CULTURE ISN'T LIMITED TO FOREIGNERS AND MINORITIES}

Contrary to popular perception, immigrant and racial minority defendants are not the only ones who try to mitigate their criminal charges by relying on cultural norms. Every time a White heterosexual male murder defendant argues he was reasonably provoked into a heat of passion by his female partner's infidelity or by a gay man's sexual advance, he seeks to mitigate his charges by relying on cultural norms. The White heterosexual male defendant, however, has an advantage over the defendant of color because the cultural norms he relies upon are dominant social norms. These norms are so embedded in American culture that we Americans do not perceive them as cultural per se.

Why is it so easy to see the culture in immigrant and minority defendant claims of reasonableness, and so difficult to see the culture in similar claims asserted by Americans, especially White heterosexual American men? Leti Volpp explains that when White people engage in criminal behavior, we tend to see their acts "as an isolated instance of aberrant behavior, and not as reflective of a racialized culture. ${ }^{\prime 75}$ To illustrate her point, Volpp compares and contrasts the way we view dowry murders in India with the way we view domestic violence homicides in the United States. "Dowry murders are thought of as a peculiar indicator of the extreme misogyny of India, ${ }^{276}$ while an American man 
who beats his wife to death is seen as an individual acting wrongfully. His acts are his own, not a reflection of U.S. culture. Volpp explains:

We identify sexual violence in immigrants of color and Third World communities as cultural, while failing to recognize the cultural aspects of sexual violence affecting white mainstream women. This is related to the general failure to look at the behavior of white persons as cultural, while always ascribing the label of culture to the behavior of minority groups. ${ }^{77}$

Government action in the wake of two of the most devastating acts of terror on American soil provides support for Volpp's theory that we Americans tend to see the culture in others while failing to see the culture in ourselves. On April 19, 1995, the Alfred P. Murrah Federal Building in Oklahoma City was destroyed by a bomb blast that left 169 dead and more than 600 injured. ${ }^{78}$ Initially, the public thought the bombing was the work of an Arab terrorist group..$^{79}$ When law enforcement officials discovered that the bombing of the Oklahoma City federal building was the work of White supremacist Timothy McVeigh, McVeigh's act of terror was not attributed to all White men with right-wing supremacist ideas. The FBI did not round up all the known White supremacists and detain them for months on end. McVeigh and his alleged coconspirator Terry Nichols were seen as individuals with extreme ideas rather than as representatives of the entire White American male population.

In contrast, when nineteen men from Saudi Arabia, Egypt, and other Middle Eastern countries hijacked three American planes on September 11, 2001, and flew them into the World Trade Center and the Pentagon, killing close to three thousand people, the government rounded up more than a thousand men, most of whom were of Arab and South Asian descent, and detained them for months with little or no evidence that these men were actually linked to the attacks on September 11. The government was able to detain these men with little public protest at least in part because the September 11 attacks were seen as the product of a foreign culture and religion and the men who were detained were believed to be part of that other culture.

Another example of the American tendency to perceive the criminal actions of immigrants as representative of their culture occurred 
shortly after an Egyptian immigrant shot and killed two people while waiting in line at the El Al Airlines ticket counter at the Los Angeles International Airport on July 4, 2002. After the incident, Governor Gray Davis told Maher Hathout, senior adviser to the Muslim Public Affairs Council, that he was concerned that members of the Muslim community were not clearly condemning the Egyptian man's actions. ${ }^{80}$ The Muslim Public Affairs Council quickly sent a letter to Israel's consul general, calling the shooting heinous and offering condolences to the families of the victims. ${ }^{81}$

When Caucasian Americans commit criminal acts, predominantly White organizations are not called upon to issue words of condemnation and apology, because the actions of White criminals are not attributed to all Whites. ${ }^{82}$

\section{INTEREST CONVERGENCE THEORY}

Given the general resistance to the use of cultural evidence in criminal cases, how can we explain the exceptional cases in which immigrant defendants and nonimmigrant defendants of color have been able to use culture to their benefit? One possibility is that immigrant and minority defendant claims which serve the dominant culture are more likely to succeed than claims that do not serve dominant interests. ${ }^{83}$

Derrick Bell first announced the principle of interest convergence in a Harvard Law Review article published in 1980. In that article, Bell responded to Herbert Wechsler's criticism of the Supreme Court's Brown v. Board of Education decision to end racial segregation in the public schools. ${ }^{84}$ Wechsler complained that the Brown decision lacked a neutral and principled basis. ${ }^{85}$

Bell provided two responses to Wechsler's assertion that the Brown decision lacked a neutral and principled basis. First, Bell noted that racial equality provided "the neutral principle which underlay the Brown opinion," at least on a normative level (i.e., as a description of the way the world ought to be) ${ }^{86}$ At the time Brown was decided, however, racial equality was not yet viewed as a legitimate principle by large segments of the American people. Therefore, racial equality could not be the real reason why the Court acted the way it did. Bell posited that interest convergence was the actual driving force behind the Brown decision. Interest convergence provided a neutral, positivist 
(i.e., how the world actually is), explanation for the Supreme Court's generosity.

According to Bell, the principle of interest convergence is the notion that "the interest of blacks in achieving racial equality will be accommodated only when it converges with the interests of whites. ${ }^{187}$ Bell argued that Brown is best understood as a decision which served the interests of powerful Whites in America. It did so in three ways. First, the decision helped the United States in its foreign relations by providing it with almost immediate credibility regarding America's commitment to racial equality. ${ }^{88}$ Segregation had damaged the reputation and prestige of the United States as a nation truly committed to the principle of equality and undermined its efforts to convince communist countries to convert to democracy. By ending racial segregation in the public schools, the Supreme Court gave a much needed boost to America's flagging reputation in the world community. Second, the Brown decision served to convince Blacks at home that America was a place where they were welcome. Blacks who had fought in World War II on behalf of the United States were returning home and encountering widespread racial discrimination and violence. Powerful elites worried that if there was another war, pervasive racial discrimination might discourage Blacks from again volunteering to fight for America. The Brown decision helped majority interests by conveying to Blacks the message that America was committed to treating them equally. ${ }^{89}$ Finally, Bell argued, ending segregation served the interests of White Southerners trying to industrialize the South..$^{00}$

\section{ASIAN IMMIGRANT MEN WHO KILL THEIR FEMALE PARTNERS}

Just as interest convergence helps us understand the Brown v. Board of Education decision, it may also help us understand why some cultural claims are more successful than others. ${ }^{91}$ A good number of the cases in which cultural evidence is used successfully involve Asian immigrant men who kill their Asian immigrant wives for some kind of infidelity, whether actual or merely imagined. Dong Lu Chen, for example, killed his Chinese wife after she rebuffed his sexual advances and confessed to seeing another man. Chen was permitted to introduce evidence that 
cultural factors caused him to react the way he did, and received a light sentence of probation and time served.

It is interesting that Chen's attorneys advanced a temporary insanity defense, a defense that requires a finding that the defendant was suffering from a mental disease or defect at the time of the act that caused him not to be able to tell right from wrong or to control his actions. No evidence was presented suggesting that Chen didn't know it was wrong to kill his wife, and the argument that family members would have stopped him if this had happened while he was in China, suggesting a lack of ability to control his actions, borders on the ludicrous. The presence of family members in the home (his wife's two sisters) certainly didn't stop another Asian immigrant defendant, May Aphaylath, from stabbing his wife to death for talking on the telephone with a former boyfriend, ${ }^{92}$ and it is doubtful that family members present somewhere in the Chen house would have been able to stop Chen, who killed his wife in the privacy of their bedroom.

The evidence presented by Chen's attorneys, and on which the judge relied, is much more supportive of a claim of reasonable provocation. Chen's attorneys essentially argued that any ordinary Chinese man would have cracked from the strain of learning that his wife had been unfaithful. According to the defense, Chen's reaction was reasonable because a wife's adultery is a stain on the Chinese husband's honor. As James Sing notes, "[a]lthough neither the defense nor the court made any mention of the provocation doctrine, this crucial element of cultural sameness [that Chen acted the way other reasonable men in China would have acted] reveals that the court in essence ruled that Dong Lu Chen was provoked into killing his wife and that the crime was therefore excusable." 93

Chen's claim of reasonableness is very similar to claims of reasonableness made by American men charged with murdering their wives. ${ }^{94}$ American men who kill their wives, like Chen, often base their claim of reasonableness on the threat to masculine honor and identity posed by a wife's sexual infidelity. Recall Albert Joseph Berry's argument that he was reasonably provoked into a heat of passion by his wife Rachel's sexual infidelity. Like Chen, Berry's emotional upset was triggered by his wife's confession to adultery and her subsequent rejection of his sexual advances.

Consider another case in which an Asian immigrant man successfully invoked culture to support a claim of reasonable provocation. 
January 20,1998. 1:00 P.M. Chanh Van Duong, a former Vietnamese military officer, was waiting outside a divorce courtroom in Colorado when he saw his estranged wife, Huong "Rosie" Nguyen, with a man, Robert Jencks, whom Duong suspected was Rosie's lover and the reason she wanted to divorce him. Duong, who had brought a gun with him to the courthouse, fired at Jencks, hitting him in the wrist. Duong then fired at his wife, killing her. ${ }^{95}$

Duong was charged with murder in the death of his estranged wife and second-degree assault in the shooting of Jencks. At trial, Duong argued he should be found not guilty of murder or assault because he was provoked into a sudden heat of passion when he saw his estranged wife with the man he thought was her lover. According to Duong's attorney, the average or ordinary Vietnamese man would have been similarly provoked because divorce in Vietnam is a serious taboo.

Provocation ordinarily does not serve as a defense to any crime other than murder. Even in murder cases, it serves only as a partial, not a complete, defense. Nonetheless, the jury acquitted Duong of assault in the shooting of Robert Jencks, permitting Duong's provocation to be used as a complete defense to assault. The jury also returned a verdict of manslaughter, rather than murder, for Duong's killing of his estranged wife, even though Duong's claim that he was provoked into a sudden heat of passion was undermined by his having brought a loaded gun with him to the courthouse where he knew he would see his wife. ${ }^{96}$

Duong may not have needed to introduce cultural evidence to receive the mitigation to manslaughter. His argument was similar to that made by Jimmy Watkins, the Texan whose wife kicked him out of the family home after a female relative accused him of sexual assault, and then invited her boyfriend to live there with her. ${ }^{97}$ Watkins was so upset at his wife's flagrant rejection of him that he called her repeatedly from his cell phone the day he killed her. When he was just outside her house, he asked her which room she was in. When she told him that she was in the kitchen, he burst into that room and shot her once in the head in front of his ten-year-old son. He then turned on her boyfriend and shot him twice. When his gun jammed, Watkins left, fixed the jam, then came back and pumped five more bullets into his wife's head as she was on the telephone, pleading for help from 911. The only reason Watkins did not receive a manslaughter conviction is because Texas law no longer recognizes provocation as a partial defense to murder. The jury had no 
choice but to convict Watkins of murder in the death of his wife. The jurors, however, showed how they really felt about what Watkins did when they recommended that he be sentenced to probation and serve no jail time for murder. Duong, in contrast, was convicted of the lesser offense of manslaughter, but sentenced to sixteen years in prison.

When the claim of cultural reasonableness is far removed from American cultural norms, legal decision makers are more likely to disagree about the propriety of admitting such evidence at trial. In May Aphaylath's case, conflicting views about the relevance of cultural evidence and the propriety of admitting such evidence were reflected in the trial and appellate courts.

December 1982. Rochester, New York. May Aphaylath, a Laotian man in his twenties, came to the United States and settled in upstate New York in 1981. In November 1982, he and Lati Souvannavong, also from Laos, got married. Soon after the wedding, the couple began to quarrel over a man named Nunh, who was Lati's former boyfriend. Lati taunted May by using Nunh as an example of what a husband should be like. Lati even told May she wished she were married to Nunh. One day, May came into the kitchen and found his wife talking on the telephone with Nunh. Even though Lati's two sisters were in another room in the house at the time, May grabbed a kitchen knife and stabbed his wife sixteen times. ${ }^{98}$.

Charged with murder for the slaying of his wife, May Aphaylath maintained he was suffering from extreme emotional distress (the Model Penal Code equivalent to the provocation defense) caused by the stress of being a Laotian refugee, his shame over his wife's display of affection for another man, and her receiving telephone calls from this man. ${ }^{99}$ This shame, Aphaylath claimed, led to his loss of self-control. Aphaylath's attorney requested permission to call expert witnesses to the stand who would testify that in Laos the shame of having a wife receive calls from a single man is so great that a husband can be expected to lose his control. In other words, the Laotian husband who kills his wife for talking on the telephone with a single man acts reasonably or at least the way any ordinary Laotian husband would act. The judge, however, refused to allow this testimony and Aphaylath was convicted of murder.

Aphaylath appealed his conviction, arguing that the trial court erred in refusing to admit the expert witnesses who would have con- 
firmed his claim of cultural reasonableness. The Court of Appeals of New York (the highest court in New York) agreed with Aphaylath, and overturned his conviction on the ground that the trial court erred in refusing to allow the expert testimony on Laotian culture. Following his successful appeal, Aphaylath pled guilty to the less serious offense of first-degree manslaughter, and was sentenced to eight years in prison. Had his murder conviction been affirmed, Aphaylath would have served fifteen years to life in prison. ${ }^{100}$

\section{HMONG MARRIAGE-BY-CAPTURE}

The Asian immigrant female infidelity cases are the strongest evidence of interest convergence at work in cases involving claims of cultural reasonableness. A second example of interest convergence involves the Hmong practice of marriage-by-capture. ${ }^{101}$ Consider how a Hmong man's claim of reasonableness in a case involving nonconsensual sexual intercourse was treated by prosecutors and a judge in Fresno, California.

In 1985, Kong Moua, a twenty-three-year-old Hmong man from Laos, abducted Seng Xiong, a nineteen-year-old woman, also a Hmong from Laos, from her dormitory room at Fresno City College in Central California, brought her back to his family's home, and had sexual relations with her without her consent. When charged with rape and kidnapping, Moua defended his actions as part of the Hmong cultural practice of zij paj niam or "marriage by capture." Under this custom, a Hmong man will take a woman he wants to marry from her home, bring her to his family home, and then have sexual intercourse with her to consummate the marriage. The woman may scream, cry, and say no, but her protests will be understood by all involved as demonstrating her virtue. Moua argued that in light of his cultural background, he honestly and reasonably believed his female friend was consenting to sexual intercourse, and therefore he was not guilty of rape. Prosecutors allowed Moua to plead guilty to false imprisonment, a lesser offense than either rape or kidnapping. Moua was then sentenced to only one hundred and twenty days (approximately three months) in jail and a $\$ 1,000$ fine.

In an attempt to better understand what happened from both the defendant's and the victim's perspectives, Deirdre Evans-Pritchard and 
Alison Dundes Renteln reviewed statements Kong Moua and Seng Xiong gave to the police and court records. They first describe what happened from the defendant Kong Moua's perspective:

\section{A. Kong Moua's Version}

Kong first met Seng in 1982 while visiting relatives in Fresno, California. He then returned to Colorado to study, but came back to California in December 1983 to celebrate the Hmong New Year. At this time he reestablished contact with Seng:

Me and my friend Phong Yang went back to see Seng almost every day. Me and Seng have a commitment that we really love each other. So we were going to marry on February 12,1984. We make a statement that we were adult we should keep our commitment. This moment Seng gave me two pictures with her signature. I went back to Colorado. When I was in Colorado, I wrote a letter to Seng with some pictures of mine and Seng to her. We also talked on the phone three times. We were always saying that we were going to get married on February 12, 1984.

Kong subsequently moved to Stockton and visited Seng every weekend. During this period Kong felt that he had a strong relationship with Seng. She had shown all the signs of wanting to marry him. Indeed, he claimed that she had already indicated that she was prepared to elope with him. The first attempt had failed because her father intervened. They exchanged watches and Kong also gave her a necklace-" to prove that I'm going to marry her for sure."

On April 24, 1984 Seng asked him to pick her up at City College at noon. Taking a male friend, Yang Hue, with him, he met her and had a half-hour conversation about marriage. They left together in the car and, according to Kong, Seng was happy and fully aware that she was eloping with him. Kong took Seng to a close relative's home.

At the house, his male relatives collected four hundred and fifty dollars to give to Seng's father and uncle to finalize the marriage. "They took the money, that means they were agreed and give Seng to be my wife." Seng's father phoned Seng at Kong's home and she told him that she had married Kong and not to worry about her. At that point Kong's sister, Blay, helped Seng change into clothes Kong had bought her the week before. Kong returned, and they had sexual intercourse several times that night.

The next morning Seng talked to her mother on the phone. Following 
that conversation she informed Kong that her mother did not agree for her to marry Kong. "I asked her if that was so, why she came over to marry me and had sexual intercourse with me. Seng said because she loves me and she wants to make me happy." 102

Evans-Pritchard and Renteln then describe the facts from the victim Seng Xiong's perspective:

\section{B. Seng Xiong's Version}

Seng stated that she met Kong at the New Year's Festival in 1984 and that while they became friends, there was no romantic involvement. On the day in question, when she left work at City College, she met Kong and Yang Hue who told her they were kidnapping her. Yang informed her that she was to marry Kong, to which she replied that she never would. She was then physically forced into the car. "During the struggle getting into the vehicle she ... called out to Irene [an American college friend] who came up to the vehicle to look inside, but [Kong] Moua covered her mouth when she tried to ask for help."

While at Kong's house, she was prevented from communicating with her parents. She was convinced to change her clothes by Yang's wife who assured her that it was she who would be sleeping with her. Seng refused Kong's sexual advances, but he forced her onto the bed.

When the police met Seng outside [Kong] Moua's house the next day, she said that she had not been sexually molested and that she did not wish to report the kidnapping because she did not want to get the boys (Kong and Yang) into trouble. She also said that she did not report anything to the police because they "would not take her where she wanted to go." Thus, she chose to stay with [Kong] Moua instead of going with the police in order not to miss an important appointment with a lawyer concerning another matter.

Kong drove her to the appointment at the Lao Community Center where she implored her brother to rescue her from her kidnappers, saying she "wanted to come home and would die if she stayed." She subsequently returned with Kong to her family to resolve the situation in a Hmong fashion. The two families met to discuss how to settle the dispute but reached no agreement.

Seng eventually notified the police because Kong and Yang said they would kidnap her again. Her explanation for why she had not contacted 
the police previously was that her reputation in the Hmong community was at stake. If it became known that she was no longer a virgin, she might not be able to find a husband. ${ }^{103}$

The Moua case highlights the difficulty of ascertaining the facts when the defendant and victim's accounts differ dramatically. The prosecutors who allowed Moua to plead guilty to false imprisonment and the judge who sentenced him to one hundred and twenty days in jail apparently found credible and reasonable Moua's belief that Seng Xiong had consented to the sexual intercourse.

One way to understand the result in Moua is to compare the case to date rape cases involving American men charged with raping female friends or women they were dating. Prosecutors are often reluctant to prosecute date rape cases because they fear jurors will sympathize with the male defendant who claims he honestly and reasonably believed his female friend consented to having sexual intercourse. ${ }^{104}$ In America, an honest and reasonable belief in consent to sexual intercourse is a complete defense to a charge of rape. In he-said/she-said cases, prosecutors will often plea bargain with the defendant, permitting him to plead guilty to a lesser offense in order to secure some kind of conviction rather than risk a complete acquittal. In light of the way date rape cases involving American men and women are ofter handled, the result in the Moua case does not seem so extraordinary.

\section{BLACK RAGE}

A third example of interest convergence is the successful use of a Black Rage and mob contagion argument by attorneys representing Damian Williams and Henry Keith Watson, two of the young Black men charged with attempted murder in the beating of Reginald Denny. Since a description of this case appears earlier in this chapter, I will not repeat that discussion here.

At first glance, it is hard to understand how the use of a deviance defense like Black Rage or mob contagion supports Bell's interest convergence theory. Young White males charged with crimes of violence generally do not argue that their acts are a result of White rage or mob contagion. The result in the Williams and Watkins case, however, does serve the interests of the dominant culture, although in a different way 
than the Asian immigrant female infidelity and the Hmong marriageby-capture rape cases do. The dominant culture has an interest in perpetuating stereotypes about young Black males as deviant criminals. Such stereotypes keep the masses from questioning the large numbers of young Black men in prison and on death row. They keep the masses from questioning verdicts of acquittal and prosecutorial decisions not to charge police officers when they shoot and kill unarmed young Black men. The Black-as-Criminal stereotype reinforces the belief that Black men in prison are there because they committed a crime. It reinforces the belief that an officer who shoots a Black man reasonably believes the Black man poses an imminent threat of death or serious bodily injury.

\section{Oya-ko Shinju}

Interest convergence theory provides an explanation for the successful use of culture by Asian immigrant men who kill their female partners, Hmong men who have nonconsensual sexual intercourse with women they desire, and African American men who assert deviance defenses. Can it also explain the apparently successful use of culture in People $v$. Kimura, the case in which a Japanese woman walked into the Pacific Ocean from a beach in Santa Monica, California with her two young children, fully intending to kill them and then herself? Deborah Woo notes that Fumiko Kimura, a thirty-two-year-old immigrant from Japan, had lived in the United States for sixteen years, but had never really assimilated into American society. ${ }^{105}$ Even though she lived in Los Angeles, a city where most people drive because the public transportation there is so poor, Kimura did not drive and had few friends or interests outside the home. She was a very traditional Japanese wife, "waiting up each night to bathe her husband's feet upon his return home from work." 106 In November 1984, she learned that "her husband had been supporting a mistress during a good part of their marriage, a waitress at the restaurant where he worked."107 "Nine days before the drowning incident, the mistress had called [Kimura], herself distressed over the husband's being 'deceitful.'"108

On January 29, 1985, Kimura walked into the Pacific Ocean with her infant daughter and four-year-old son. ${ }^{109}$ Two college students spotted Kimura and pulled her and the two children out of the surf. ${ }^{110}$ Kimura survived, but her children did not. Kimura was charged with two 
counts of first-degree murder and two counts of felony child endangerment. The Japanese American community found out about her case, and gathered over twenty-five thousand signatures for a petition for leniency on her behalf. ${ }^{111}$ Kimura was permitted to plead guilty to manslaughter and was sentenced to five years of probation and one year in jail. Since Kimura had already served fifteen months in jail by the time she came up for sentencing, she received credit for time served and was released the same day. ${ }^{112}$

Kimura is often cited as an example of the successful use of culture by an immigrant defendant because her actions were in accord with the Japanese practice of oya-ko shinju (parent-child suicide). Alison Matsumoto explains that oya-ko means parent- child. ${ }^{113}$ Shinju means "any suicide involving more than one person."114 Oya-ko shinju may be committed for a number of reasons by either parent, but in most cases it is the mother who commits oya-ko shinju in response to the father's infidelity or neglect. ${ }^{115}$ Matsumoto notes that the wife/mother may commit oya-ko shinju for a number of reasons. First, she may wish to punish her husband, hoping that his social position will be destroyed and that he will lose his job. Second, she may feel obligated to kill her children so as not to leave them motherless and subject to social stigma and prejudice. ${ }^{116}$ Had Kimura done what she did in Japan, her acts would still have been criminal, but she would have been looked upon with extreme sympathy. Most likely, she would have received a short jail sentence or probation. ${ }^{117}$.

Deborah Woo notes that, contrary to popular belief, Kimura's attorneys actually sought to downplay the influence of culture. "[A]ny cultural factors, such as the custom of oyako-shinju, could have been useful as 'incriminating' evidence, helping to establish an intent to kill." 118 Instead of arguing that Kimura acted reasonably within her cultural upbringing, her attorneys argued she was temporarily insane when she walked into the Pacific Ocean. In other words, in order to achieve a favorable result for their client, the attorneys argued Kimura acted abnormally, not the way an ordinary Japanese woman would have acted.

Critics of the use of culture have compared Kimura to Susan Smith, the American woman who drowned her two young sons by strapping them into their car seats and then pushing her car into a lake. ${ }^{119}$ Smith initially claimed a Black carjacker had kidnapped her sons. When police discovered this was a lie, Smith was arrested and charged with two 
counts of first-degree murder. ${ }^{120}$ On July 23,1995 , Smith was convicted of first-degree murder. ${ }^{121}$ Six days later, she was sentenced to life in prison with the possibility of parole. ${ }^{122}$

Smith may have received some leniency as a result of her race and gender. Initially, when the public believed her claim that a Black man had kidnapped the children, there were loud cries for the death penalty. When the public found out that Smith herself had killed the two young boys, the cries for the death penalty subsided and were replaced with pleas to spare the life of the troubled young White mother.

The Smith case, while superficially similar, is not truly analogous to the Kimura case. First, Smith never intended nor tried to kill herself. She strapped her two young boys into their car seats and pushed the car they were in into a lake, never once putting herself in any danger. Second, the reason Smith killed her children was in order to please her boyfriend, who had made it clear that he was not interested in continuing a relationship with a single mother burdened with two young children. In contrast, Kimura not only intended to kill herself, but her primary intent was to kill herself. It was only because she thought she would be dead that she decided to kill her children. In Japan, the mother is primarily responsible for child rearing. Children who grow up without a mother are viewed with distrust. Kimura felt a tremendous responsibility not to leave her children in this world without a mother. Deborah Woo explains, "Without the natural mother, then, offspring are essentially subjected to the strong social prejudices against orphans: 'Orphans are regarded as unreliable because of a lack of parental protection, supervision, and disciplining. Banks usually do not hire them."123

The manslaughter conviction Kimura received is actually similar to the manslaughter convictions received by the bulk of women who kill their young children. Most women who kill their children are initially charged with murder, but end up pleading guilty to manslaughter. ${ }^{124}$ In most of these cases involving child homicide, the mother kills her children without also trying to kill herself, yet she still receives a manslaughter conviction. In the one case I was able to find involving a mother who shot and killed her daughter and also shot herself, the woman was found not guilty by reason of insanity and committed to a mental institution. ${ }^{125}$ Susan Smith and Andrea Yates, the woman who drowned her five young children in the bathtub of her home, are rather exceptional in the amount of attention their cases garnered and 
the results obtained. Both women were convicted of murder and received life sentences. ${ }^{126}$

\section{CONCLUSION}

In this chapter, I have sought to use the lens of the immigrant male defendant to demonstrate the false neutrality of our own objectivity. Opponents of the so-called cultural defense argue that admitting cultural evidence in the criminal courtroom gives immigrants and other minority defendants special treatment, which is unfair to majority defendants. These critics view the admission of cultural evidence as a kind of reverse discrimination against White American defendants. These critics, however, overlook the fact that majority culture defendants already receive the benefit of cultural norms, those of American culture, every time they walk into the courtroom. American defendants don't need to bring in experts to testify about why their beliefs and actions are reasonable in light of existing norms because judges and jurors are already familiar with those norms. Dominant social norms bolster these defendants' claims of reasonableness without any special effort on their part. 


\section{Race and Self-Defense}

ANOTHER CULTURAL NORM-the racial stereotype*-is pervasive in this society. Like masculinity and heterosexuality norms, racial stereotypes are a feature of contemporary American culture. Like other norms, race norms work beneath the surface, helping certain claims of reasonableness appear more credible than others. ${ }^{1}$

What is a stereotype? Jody Armour explains that stereotypes are well-learned sets of associations that result in automatic, gut-level responses. ${ }^{2}$ Stereotypes are correlational constructs based on an individual's membership in an identifiable group, such as the idea that most Blacks are good athletes, most Mexicans are poor, and most Asians are smart. All of us are influenced by stereotypes, even the most egalitarianminded of us.

In self-defense cases, racial stereotypes can influence the reasonableness determination in a myriad of ways. If the victim belongs to a racial group whose members are perceived as violent or hot-blooded, jurors may perceive ambiguous actions by the victim as more hostile than they actually are. Conversely, if the defendant belongs to a racial group whose members are perceived as violent and dangerous but the victim belongs to a racial group whose members are not marked by stereotypes of violence and dangerousness, jurors may be less willing to believe the defendant's claim of self-defense.

Race norms can also affect the reasonableness determination in other, less obvious, ways. According to social cognition theory, people tend to emphasize the positive attributes of those who are perceived to be like them and the negative traits of those who are perceived to be different or other. ${ }^{3}$ We have all seen examples of this in real life. If you types.

* When I use the term "racial stereotype," I refer to both racial and ethnic stereo- 
meet a person for the first time, you are more likely to think positively of that person if you find you have common interests and mutual friends. In a homicide case in which the victim belongs to a racial or ethnic minority group whose members are perceived as foreigners or immigrants, jurors may subconsciously minimize the harm suffered by the victim and be more willing to view the defendant's use of force as reasonable.

\section{THE BLACK-AS-CRIMINAL STEREOTYPE}

Despite the abolition of slavery, passage of the Civil Rights Act, and other positive changes in the law, Blacks in America today still suffer from race-based discrimination. While overt racial prejudice appears to have declined, negative stereotypes about African Americans still persist. One stereotype about African Americans in general, and young Black men in particular, is that they are more likely to be dangerous, prone to violence, and involved in criminal activity than other members of society. ${ }^{4}$ When people talk about high-crime neighborhoods, it is understood that these neighborhoods are predominantly Black. When a young Black male is seen in a predominantly White ${ }^{5}$ neighborhood, residents often call the police, worried that the youth is going to commit a burglary or some other crime. According to Adeno Addis, crime has "become a metaphor to describe young black men." 6

Leonard Baynes reports that media images reinforce the Black-asCriminal stereotype by "emphasizing black-on-white crime even though it is a small percentage of the actual crimes reported. ${ }^{\prime 7}$ One study found that Blacks and Latinos "are twice as likely to be shown in local crime stories than in human interest stories." 8 The same study also found that persons of color "are more often shown as perpetrators than as victims" and that "stories with non-white offenders and white vic"tims are given more emphasis than stories with same-race perpetrators and victims."

The fear of Black-on-White violence is reinforced by incidents such as the beating of Reginald Denny, a White truck driver who was pulled from his truck and brutally beaten by several Black men during the 1992 Los Angeles riots following the acquittal of the four police officers who brutally beat Rodney King. 
April 29, 1992. Los Angeles, California. About 6:30 P.M. Reginald Denny, a $\$ 16.70$ per hour White truck driver, was in the process of delivering twentyseven tons of sand to an Inglewood cement-mixing plant. He drove west down the San Bernadino Freeway, then took the Harbor Freeway south, and got off at Florence. Hours earlier, the jury in the state trial of the four White Los Angeles police officers who brutally beat African American Rodney King had announced not guilty verdicts on all but one count. Unbeknownst to Denny, who rarely watched television and did not even subscribe to a newspaper, people in the neighborhood he was about to enter had reacted violently to the verdicts, overturning trash cans, throwing rocks and bottles at cars and buildings, and looting stores. Denny pulled up to the intersection of Florence and Normandie streets where an angry mob filled the streets. As Denny slowed his truck to accommodate the crowd, five Black men surrounded his truck. One man yanked open the door of Denny's truck and dragged Denny out into the street. Several Black men began beating and kicking Denny, knocking him down to the ground. They continued to kick and beat Denny after he was on the ground. One man grabbed a fire extinguisher from Denny's truck and smashed it against Denny's head. Another hit Denny on the head with a brick. While Denny lay bleeding and helpless, another man rifled through his pockets and ran away after he found Denny's wallet. ${ }^{10}$

Many people saw the beating of Reginald Denny, rather than the beating of Rodney King, as a typical criminal event. Young Black males kicking and beating an innocent White man reinforced the already present White fear of the violent young Black male criminal. The incident, however, was atypical in terms of offenders and victims. As Samuel Walker points out, racial minorities are more likely than Whites to be the victims of crime. ${ }^{11}$ Moreover, if typical means average, the typical criminal offender is actually White. In 1999, over two-thirds (69 percent) of those arrested were White, while less than one-third (28.6 percent) were Black. ${ }^{12}$

In self-defense cases, the Black-as-Criminal stereotype can influence the jury in several ways. When the accused is African American, jurors may discount his claim of self-defense, believing that the defendant provoked the confrontation. When the victim is African American, jurors may more readily believe the defendant's claim that he honestly and reasonably believed he needed to act in self-defense. 
It is important to remember that the Black-as-Criminal stereotype is not simply a manifestation of White racism. White taxicab drivers are not the only ones who drive past waiting Black men. Non-White taxi$\mathrm{cab}$ drivers also refuse to pick up Black men. White police officers are not the only ones who engage in racial profiling. ${ }^{13}$ Black, Latino, and Asian American police officers also stop and harass Black and Brown drivers. Whites are not the only ones who fear Black men. Even Black men fear other Black men. The Reverend Jesse Jackson, a leader in the African American community, once admitted, "There is nothing more painful to me at this stage in my life than to walk down the street and hear footsteps and start thinking about robbery ... [t]hen look around and see somebody white and feel relieved." ${ }^{14}$ All individuals in this society, including African Americans, Asian Americans, Latinos, and other racial minorities, are influenced by the Black-as-Criminal stereotype.

According to the General Social Science Survey, an institution associated with the University of Chicago, 52.8 percent of individuals representing all different races polled in 1990 viewed violence as a trait characteristic of African Americans and 42.8 percent viewed violence as a trait characteristic of Latinos. ${ }^{15}$ In contrast, only 18.8 percent of the individuals polled attributed violence to Whites. ${ }^{16}$

Negative stereotypes about Blacks and fear of Black-on-White crime may be one reason for the disproportionate number of Black men on death row. Numerous studies have found that prosecutors are more likely to seek the death penalty and juries are more likely to recommend a death sentence over life in prison without the possibility of parole when the defendant is Black and the victim is White. ${ }^{17}$ David Baldus, for example, examined over two thousand capital murder cases and found that juries imposed the death penalty in 22 percent of the cases involving Black defendants and White victims; 8 percent of the cases involving White defendants and White victims; 3 percent of the cases involving White defendants and Black victims; and only 1 percent of the cases involving Black defendants and Black victims. ${ }^{18}$ In recent years, DNA tests have proven that many Black men sentenced to death did not commit the crimes which put them on death row. ${ }^{19}$

Social science studies verify the existence and influence of the Black-as-Criminal stereotype. Birt Duncan found that White undergraduate students at the University of California (U.C.) at Irvine perceived ambiguously hostile acts (acts that could be perceived as either 
violent or nonviolent) as violent when a Black person engaged in these acts and as nonviolent when a White person engaged in the same behavior. ${ }^{20}$ Students participating in Duncan's study observed two people involved in a heated argument that ended with one party shoving the other. Immediately after observing the shove, the subjects were asked to characterize the behavior of the person who shoved the other person. Duncan found that when the person shoving was Black and the person being shoved was White, 75 percent of the students tested characterized the Black person's behavior as "violent." Only 6 percent of the students characterized the Black person's behavior as "playing around." When the person shoving was White and the person being shoved was Black, only 17 percent of the students characterized the White person's act as "violent," while 42 percent characterized the White's person's act as "playing around."21

H. Andrew Sagar and Janet Ward Schofield conducted a similar study on forty Black and forty White male sixth graders, and found that both the Black and the White sixth graders tended to perceive ambiguously hostile behavior by Blacks as more threatening than similar behavior by Whites. ${ }^{22}$ The students also perceived clearly nonaggressive behavior by Blacks as more hostile than similar behavior by Whites. ${ }^{23}$

Charles Bond, Clarisse DiCandia, and John MacKinnon found similar patterns at the Altobello Youth Center in Connecticut. ${ }^{24}$ Bond, DiCandia, and MacKinnon studied 453 incidents involving juvenile patients who engaged in violent behavior at a Connecticut state youth psychiatric facility. Patients who acted violently could receive one of two negative sanctions. A patient could either be secluded (a nonphysical restraint) or forcibly restrained by being placed in a straitjacket or tied to a bed with sheets. A patient who was forcibly restrained would then be injected with a strong tranquilizer that would induce unconsciousness.

Bond, DiCandia, and MacKinnon found no difference in the mean number of violent offenses by Black and White patients. In other words, Black and White patients acted violently at about the same rate. However, the researchers found a substantial racial difference in the sanctions given to violent patients by the predominantly White staff workers. Black patients who acted up were forcibly restrained four times as often as White patients who committed similar transgressions.

The Black-as-Criminal stereotype is so deeply entrenched in our culture that Whites are able to use the stereotype to manufacture 
believable, but patently false, claims of Black criminal activity. In The Color of Crime, Katheryn Russell discusses the prevalence of "racial hoaxes," false claims of criminality by an individual of one race who blames someone of another race for his or her own crimes. ${ }^{25}$ For example, in 1994, Susan Smith told police that a Black man had kidnapped her two sons at gunpoint and taken her car. Initially, many voiced the belief that the wrongdoer, whoever he was, should be punished with the death penalty. Later, Smith confessed to pushing her car into a lake and watching it sink with her two sons inside. Once it was discovered that a Black man was not responsible for the disappearance of the two boys, calls for the death penalty subsided. By the time Smith was tried and convicted of first-degree murder, pleas for sympathy and mercy had replaced the initial public outcry for the death penalty. Smith was sentenced to life imprisonment. ${ }^{26}$

In 1989, Carol Stuart was shot and killed in an inner-city neighborhood in Boston, Massachusetts. Charles Stuart, Carol's husband, told police that a Black man had abducted the two of them at gunpoint, robbed the couple, then shot both of them. Police combed the city of Boston, stopping and searching more than one hundred and fifty young Black men each day. Finally, police arrested William Bennett, a Black man who had been in trouble with the law and served two terms in prison for threatening and shooting police officers. It was not until Charles Stuart's brother came forward and admitted that he helped Charles hide the murder weapon that Charles confessed to killing his wife. Joe Feagin and Hernan Vera note, "Charles Stuart counted on the strong presumption among powerful Whites that a White businessperson would be telling the truth in his account of a black male attacking a White woman, even though his story was full of obvious inconsistencies. ${ }^{27}$ Had police been more skeptical of Charles Stuart's claim, they might have found out earlier that Charles was having an affair with another woman, had taken out several large life insurance policies on his wife, and had previously plotted to kill her.

The Black-as-Criminal stereotype can also influence prosecutorial charging decisions.

August 23, 1995. San Francisco, California. Patrick Hourican, a thirty-threeyear-old Irish-American construction worker, rode his bicycle past a car driven by Louis Waldron, a twenty-two-year-old Black college student. For no apparent reason, Hourican hit and then broke the side view mirror of 
Waldron's car, then sped off on his bicycle. Angered by the unprovoked vandalism of his car, Waldron drove after Hourican. When Waldron caught up with Hourican, he got out of his car. Hourican, ready for a confrontation, punched Waldron, then got back on his bike and rode away. Waldron gave chase again. When he caught up with Hourican the second time, Waldron demanded that Hourican pay for the side view car mirror. Hourican refused. Waldron then punched Hourican in the face. Hourican fell, hit his head on the pavement, and died two days later. ${ }^{28}$

Former San Francisco District Attorney Arlo Smith charged Waldron, never before arrested or convicted, with first-degree murder, a crime for which the punishment in California is twenty-five years to life imprisonment. First-degree murder generally requires proof of premeditation and deliberation. In this case, there was little evidence that Waldron had thought about killing Hourican in advance. Indeed, there was evidence of provocation, since Hourican, a man with twenty-eight prior misdemeanor convictions and three felony contacts with police, ${ }^{29}$ was the one who initiated the confrontation by breaking Waldron's car side view mirror and throwing the first punch. Many believed race influenced the decision to charge Waldron with the most serious type of homicide apart from capital murder. There was some support for this view. Just two months before Hourican's death, a White man punched another White man outside a bar. Even though the second man died as a result of the punch, the same District Attorney who filed first-degree murder charges against Waldron declined to file any charges against this White man. ${ }^{30}$

While the Black-as-Criminal stereotype is triggered most often by the sight of a young Black male in baggy pants worn low around the hips, even Black men who do not fit this profile are treated as suspect. In Race Matters, Harvard professor Cornel West describes the all-toocommon experience for Black men of not being able to hail a taxicab.

This past September my wife, Elleni, and I made our biweekly trek to New York City from Princeton. I was in good spirits. My morning lecture on the first half of Plato's Republic in my European Cultural Studies course had gone well. And my afternoon lecture on W. E. B. Du Bois's The Souls of Black Folk in my Afro-American Cultural Studies course had left me exhausted yet exhilarated....

I dropped my wife off for an appointment on $60^{\text {th }}$ Street between Lexington and Park avenues. I left my car-a rather elegant one-in a safe 
parking lot and stood on the corner of $60^{\text {th }}$ Street and Park Avenue to catch a taxi. I felt quite relaxed since I had an hour until my next engagement. At 5:00 P.M. I had to meet a photographer who would take the picture for the cover of this book on the roof of an apartment building in East Harlem on 115th Street and $1^{\text {st }}$ Avenue. I waited and waited and waited. After the ninth taxi refused me, my blood began to boil. The tenth taxi refused me and stopped for a kind, well-dressed, smiling female fellow citizen of European descent. As she stepped in the cab, she said, "This is really ridiculous, is it not?"

Ugly racial memories of the past flashed through my mind. Years ago, while driving from New York to teach at Williams College, I was stopped on fake charges of trafficking cocaine. When I told the police officer I was a professor of religion, he replied "Yeh, and I'm the Flying Nun. Let's go, nigger!" I was stopped three times in my first ten days in Princeton for driving too slowly on a residential street with a speed limit of twenty-five miles per hour. (And my son, Clifton, already has similar memories at the tender age of fifteen.) Needless to say, these incidents are dwarfed by those like Rodney King's beating or the abuse of black targets of the FBI's COINTELPRO efforts in the 1960s and 1970s. Yet the memories cut like a merciless knife at my soul as I waited on the godforsaken corner. Finally I decided to take the subway. I walked three long avenues, arrived late, and had to catch my moral breath as I approached the white male photographer and white female cover designer. I chose not to dwell on this everyday experience of black New Yorkers. ${ }^{31}$

Black women are also subject to the Black-as-Criminal stereotype. Poor Black women on the street are often seen as potential thieves or con artists scamming for a free dollar. Sometimes, even Black women dressed in business suits inspire racialized fear. Taunya Banks, a law professor at the University of Maryland, recounts one incident in which several White women refused to get on an elevator in a luxury condominium with her and four other well-dressed Black women law professors in Philadelphia.

One Saturday afternoon I entered an elevator in a luxury condominium in downtown Philadelphia with four other Black women law professors. We were leaving the apartment of another Black woman law professor. The elevator was large and spacious. A few minutes later, the door opened and a White woman in her late fifties peered in, let out a muffled cry of surprise, 
stepped back and let the door close without getting on. Several floors later the elevator stopped again, and the doors opened to reveal yet another White middle-aged woman, who also decided not to get on.

Following the first incident we looked at each other somewhat puzzled. After the second incident we laughed in disbelief, belatedly realizing that the two women seemed afraid to get on an elevator in a luxury condominium with five well-dressed Black women in their thirties and forties. Our laughter, the nervous laugh Blacks often express when faced with the blatant or unconscious racism of White America, masked our shock and hurt.

The elevator incident is yet another reminder that no matter how welleducated, well-dressed, or financially secure, we are Black first and thus still undesirable "others" to many White Americans. It reminds me that no matter what my accomplishments, I am still perceived as less than equal and even dangerous! ${ }^{32}$

Patricia Williams, a Black female law professor who teaches at Columbia University, recounts the humiliating experience of not being buzzed into a Benetton store in New York City while other White patrons were happily shopping within:

Buzzers are big in New York City. Favored particularly by smaller stores and boutiques, merchants throughout the city have installed them as screening devices to reduce the incidence of robbery. When the buzzer sounds, if the face at the door looks "desirable," the door is unlocked. If the face is that of an "undesirable," the door stays locked. Predictably, the issue of undesirability has revealed itself to be primarily a racial determination. Although the buzzer system was controversial at first, even civil rights organizations have backed down in the face of arguments that the system is a "necessary evil," that it is a "mere inconvenience" compared to the risks of being murdered, that discrimination is not as bad as assault, and that in any event, it is not all blacks who are barred, just "seventeen-year-old black males wearing running shoes and hooded sweatshirts."

Two Saturdays before Christmas, I saw a sweater that I wanted to purchase for my mother. I pressed my brown face to the store window and my finger to the buzzer, seeking admittance. A narrow-eyed white youth who looked barely seventeen, wearing tennis sneakers and feasting on bubble gum, glared at me, evaluating me for signs that would pit me against the limits of his social understanding. After about five seconds, he mouthed, 
"We're closed," and blew pink rubber at me. It was one o'clock in the afternoon. There were several white people in the store who appeared to be shopping for things for their mothers.... [That salesperson] saw me only as one who would take his money and therefore could not conceive that I was there to give him money. ${ }^{33}$

These incidents happened to Black professors who, by all accounts, have been successful in their careers. Yet, despite their professional successes, they still were viewed by others-who knew nothing about them other than the way they looked-with race-based suspicion and fear.

\section{STATISTICAL ARGUMENTS SUPPORTING RACIALIZED FEAR OF BLACK MEN}

In self-defense cases, a defendant's claim that he feared his Black victim may be perceived as more credible because of statistics that show that Blacks are arrested and convicted of crimes far more often than Whites. ${ }^{34}$ In 1990, Marc Mauer with the Sentencing Project published a report entitled Young Black Men and the Criminal Justice System: A Growing National Problem. ${ }^{35}$ In this report, Mauer reported that on any given day in 1989, 23 percent of Black men between the ages of twenty to twenty-nine were in prison, on probation, on parole, or in some way connected with the criminal justice system. ${ }^{36}$ Five years later, Mauer updated his study with a new report entitled The Sentencing Project, Young Black Americans and the Criminal Justice System: Five Years Later. ${ }^{37}$. This time, Mauer and coauthor Tracy Huling reported that " $30.2 \%$ of African American males in the age group 20-29 were under criminal justice control-prison, jail, probation, or parole-on any given day." 38

At first glance, these statistics seem powerful evidence that it is eminently reasonable to fear a Black man even if one would not fear a White man under the same circumstances. The Mauer and Huling report, however, cautions its readers not to jump to such conclusions. As Mauer and Huling are careful to note, "The typical African American male in the criminal justice system is not a violent offender." 39 The vast majority of Black men in prison are convicted of nonviolent drug offenses. ${ }^{40}$ 
Mauer and Huling also report that contrary to common expectations, "the majority of arrestees for violent offenses are white." Federal Bureau of Investigation's Uniform Crime Reports confirms this. In 2000, 59.9 percent of those arrested for violent crime were White. ${ }^{42}$ Only 37.8 percent were Black. ${ }^{43}$

Because Whites constitute approximately 83 percent of the population in the United States, it is not surprising that Whites would constitute a majority of those arrested for violent crime. Blacks, in contrast, constitute only 12 percent of the population, yet account for almost 45 percent of those arrested for violent crime. Some would argue that these statistics therefore support the position that it is reasonable to fear Blacks in general because Blacks constitute a disproportionate number of persons arrested for violent crime.

The problem with saying it is reasonable to fear Blacks because they constitute a disproportionate number of violent crime arrestees is that this attributes the criminality of some Blacks to the entire Black population. When the total number of Blacks arrested for violent offenses is compared to the total number of Blacks in the United States, those arrested make up only a small percentage of the total Black population. In 2000 , for example, Blacks arrested for violent crime comprised less than 1 percent of the total Black population. ${ }^{44}$ Even this figure could be of doubtful reliability if racial stereotypes influenced those police decisions to arrest. ${ }^{45}$

Ellis Cose points out that if we relied upon statistics to justify everything, it would be reasonable to fear all men. Men are arrested for violent crime far more often than women, ${ }^{46}$ yet no one argues that it is reasonable to fear all men because of their propensity for violence. Cose elaborates:

According to the FBI Uniform Crime Report, in 1990, men, regardless of age, were arrested for violent crimes at levels that dwarfed the numbers for women. Men twenty-five to thirty-four years old were seven times as likely as women in the same age bracket to be arrested for murder, forcible rape, robbery, and aggravated assault. Those from thirty-five to forty-four were seven to eight times more likely to land in jail, and those over sixty-five were nearly fifteen times as likely.

If one applies [the argument that it is reasonable to fear Blacks over Whites because Blacks are arrested for violent crimes at rates greater than Whites] to those statistics, one would expect discrimination 
against men to be much more prevalent than discrimination against women. One would expect that until such time as the male crime rate is made to equal the female crime rate, society would treat men as objects of fear and terror. ${ }^{47}$

It is dangerous to rely heavily upon statistics because statistics can be used to support almost any proposition. For example, according to government statistics, a White person is more than four times as likely to be killed by another White person than by a Black person. ${ }^{48}$ Approximately 80 percent of all crimes of violence occur between and among persons of the same race. ${ }^{49}$ If one relied upon these statistics, one could argue that it is reasonable for Whites to fear other Whites. Statistics, however, are not used to support race-based fear of Whites because no White-as-Criminal stereotype exists to give social legitimacy to such fear. The average person on the street who finds himself or herself in a situation of perceived danger probably does not know what percentage of crimes of violence are committed by Whites and what percentage are committed by Blacks. Statistics or no statistics, Whites fear being attacked by a Black person much more than they fear being attacked by a fellow White person.

Ultimately, the use of statistics to justify race-based fear is unhelpful. Fear inspired by race will exist with or without statistics. The question in self-defense cases is usually not whether that fear is genuine, but whether that fear is reasonable. And whether or not that fear is considered reasonable depends in large part upon who is making that determination. Consider a well-known case involving a claim of self-defense by a White man who shot four Black youths on a New York subway.

\section{BERNHARD GOETZ: RACIST VIGILANTE OR SUBWAY HERO?}

December 22, 1984.1:00 P.M. Troy-Ganty, DarrylEabey,James-Ramseur $r$ and Bârry Allen, four Black youths, boarded an express subway train in the Bronx. The four-teenagers-rede-together in the rear portion of one of the cars of the train. Bernhard Goetz, a White man, boarded the same car a litthe later and sat down on a bench in the rear section. Goetz was carrying an unlicensed .38 caliber pistol loaded with five rounds of ammunition, concealed in a waistband holster. Canty and Allen walked up to Goetz. Canty smiled at Goetz and said, "Give me five dollars." Without a word, Goetz 
stood up, pulled out his gun, and started firing rapidly at Canty, Allen, Cabey, and Ramseur. The youths scattered, trying to avoid the bullets. Noticing that Cabey appeared to be unhurt, Goetz walked up to him and said, "You seem to be all right, here's another." He then fired his last bullet into Cabey's spinal cord.

After the shooting, Goetz fled. Even though flight is usually considered evidence of a guilty conscience, Goetz's flight did not affect his popularity. Complete strangers called Goetz a subway hero and applauded his actions.

Subsequently, Goetz surrendered himself to police. He admitted that when he shot his gun, he was certain none of the Black youths had a gun. Nonetheless, he told police, "My intention was to do anything I could do to hurt them. My intention ... I know this sounds horrible, but my intention was to murder them, to hurt them, to make them suffer as much as possible." 50

Goetz was charged with assault, attempted murder, reckless endangerment, and illegal possession of a weapon. At trial, Goetz claimed he shot at the youths in self-defense. His jury ${ }^{51}$ returned a verdict of not guilty on all the charges except Goetz's illegal possession of a weapon.

As a textbook criminal law hypothetical, Goetz's claim of self-defense should have been rejected out of hand. First, under New York law, a defendant is justified in using defensive physical force if and only if he honestly and reasonably believes two things: (1) that his assailant is attacking or about to attack him, and (2) that the use of physical force is necessary to defend himself. Moreover, deadly force can only be used if one is protecting oneself against an imminent threat of death or serious bodily injury. ${ }^{52}$ Even if Goetz honestly believed the Black youths were about to attack him, it is a stretch to say this belief was reasonable. Neither of the two youths who approached Goetz displayed a weapon; neither made any menacing movement toward Goetz suggesting an imminent threat of death or grievous bodily injury. ${ }^{53}$

Second, it was not necessary for Goetz to shoot the youths. Goetz could have simply responded to the youths' demand for money with a polite "no." He could have moved to another section of the subway. He could have warned the youths not to bother him by showing them his gun and then walking away. Instead, Goetz's immediate response was to fire upon the youths, endangering their lives and the lives of everyone else in that subway car. 
Some may think it unreasonable to expect Goetz, an "innocent" citizen minding his own business in the subway car, to move to another section of the subway car. The law of self-defense recognizes this sentiment in its "no duty to retreat" rule. The necessity requirement of selfdefense doctrine means one should not use force, particularly deadly force, unless it is reasonably necessary to do so. If one can avoid using deadly force, but chooses to use such force anyway, then one is responsible for the often fatal consequences of one's actions. Most jurisdictions, however, do not require individuals to retreat before using deadly force even though the no duty to retreat rule is contrary to the necessity requirement. Even if Goetz had no duty to retreat to another subway car, several less lethal alternatives were available to him and should have been pursued prior to his shooting a deadly weapon in a crowded subway. The availability of these alternatives suggest it was not necessary for Goetz to have acted the way he did.

Calling Goetz an "'innecent"-stiggests that the young-Black-men who were shot at were "wrongdoers" who deserved whatever they got. When a White defendant is charged with killing or assaulting a Black victim, defense attorneys and commentators often refer to the victim as the attacker and call the actual wrongdoer (the defendant) the victim. This is problematic because it shifts the focus of attention away from the appropriateness of the defendant's use of deadly force to the conduct of the victim.

One might also object to requiring Goetz to warn the youths by showing them his gun because such action could have been interpreted by the Black youths as a challenge and might have encouraged them to attack Goetz. Perhaps this is true, but the law is clear that one should not use deadly force unless it is reasonably necessary to do so. If one of the youths had actually started to attack, Goetz might have had a legitimate reason to fear imminent death or serious bodily injury. Until that time, Goetz should have held his fire.

Goetz's self-defense claim should have been rejected for a third reason. His use of a loaded gun was not proportionate to the threatened harm. Deadly force generally is not an appropriate response to nondeadly force. Goetz responded with deadly force to a verbal request ("give me five dollars"), one unaccompanied by any show of force, movement, or other indication of an imminent attack. Goetz admitted that he was certain none of the youths had a gun, yet he chose to shoot them. 
Some scholars, known as rights-based deontologists, object to the proportionality requirement on the ground that one whose rights are threatened by another has an unqualified right to fight back. George Fletcher, for example, argues that the right of self-defense is based on the right to protect one's autonomy. ${ }^{54}$ Under this view, a homeowner would have the right to use deadly force even if he were merely threatened with loss of property. ${ }^{55}$

The proportionality requirement exists for a good reason. As a society, we value human life over property. Therefore, if a person is only threatened with loss of property, the property owner should not be entitled to use deadly force to defend his property. If a person is threatened with nondeadly force (e.g., a kiss or unwanted sexual touching), that person is expected to resist the advance with nondeadly force. One cannot claim self- defense if one shoots another person to stop an unwanted kiss.

Fourth, one who introduces deadly force into a situation of conflict can be viewed as a deadly aggressor. A deadly aggressor is unable to assert the defense of self-defense unless he first withdraws from the encounter and effectively communicates his withdrawal to the other person. ${ }^{56}$ When Goetz pulled out his loaded gun in response to the boys' verbal demand for money, he became a deadly aggressor and lost his right to claim self- defense. Since Goetz never withdrew from the conflict, he did not have a right to act in self-defense.

Finally, Goetz admitted to police that his intention was to murder the youths, to hurt them, and make them suffer as much as possible. Far from constituting self-defense, Goetz's act of shooting the youths with an intent to kill them fits the textbook definition of attempted murder. Goetz had the specific intent to kill the youths and took a substantial step toward accomplishing this objective by pulling the trigger of his gun more than once.

If Goetz's claim of self-defense was so patently unreasonable, why did the jury acquit him of all but the illegal possession of a firearm charge? After the trial was over, some of the jurors explained that they didn't feel the prosecution had met its burden of proving its case beyond a reasonable doubt. ${ }^{57}$ One of the jurors opined, "We felt that Mr. Goetz had no chance to retreat in that situation." 58 Another juror insisted that race had no effect on the jury's decision to acquit, stating, "It didn't matter if he was a white man or a black man. Crime doesn't know color." 59 
The appeal to racial stereotypes in self-defense cases is less obvious than the appeal to norms of masculinity and heterosexuality in female infidelity killings and gay panic killings. An overt race-based appeal is likely to meet with objection from all but those with a White supremacist mentality. Therefore, the clever attorney who wants jurors to rely on racial stereotypes rarely addresses the racial component of a case directly. Instead he uses the jurors' own fears to create a backdrop of sympathy for his client's situation.

Goetz's attorney knew that a jury of New Yorkers would likely sympathize with a lone White subway rider confronted by a group of Black teens not merely asking for spare change, but demanding five dollars. Nonetheless, Barry Slotnick never once explicitly mentioned race as a factor contributing to Goetz's fear of the youths. Instead, his appeal to race norms was more subtle. Slotnick referred to the Black teens as "savages," "predators," and "vultures," language that conveyed the message that these Black youths were not law-abiding citizens, but gang members or criminals who preyed on innocent law-abiding New York subway riders. ${ }^{60}$ In other words, these boys were wrongdoers and predators who had to be shot before they harmed Goetz.

George Fletcher, who observed Goetz's criminal trial explains-how Goetz's attorney cleverly played the race card by using four young Black-men-from the Guardian Angels to re-create the subway-shooting scene:

The covert appeal to racial bias came out most dramatically in the recreation of the shooting, played out while Joseph Quirk was testifying. The defendant called in four props to stand in for the four victims Canty, Allen, Ramseur, and Cabey. The nominal purpose of the demonstration was to show the way in which each bullet entered the body of each victim. The defense's real purpose, however, was to recreate for the jury, as dramatically as possible, the scene that Goetz encountered when four young black passengers began to surround him. For that reason (defense attorney) Barry Slotnick asked the Guardian Angels to send him the four young black men to act as the props in the demonstration. In came the four young black Guardian Angels, fit and muscular, dressed in T-shirts, to play the parts of the four victims in a courtroom minidrama. ${ }^{61}$

A study by Paul Robinson and John Darley provides a nonracial expla- 
nation for the outcome in Goetz. In 1995, Robinson and Darley published the results of a study comparing community views regarding the assignment of criminal liability and punishment in various cases to the legal rules expressed in criminal codes such as the Model Penal Code. ${ }^{62}$ Robinson and Darley found that the average person tends to have considerably looser standards regarding what constitutes acceptable use of force in self-defense than the criminal law normally permits. For example, subjects were asked to consider the criminal culpability of a person who shoots and kills a beggar who persists in requesting money even after the person turns the beggar down. Most subjects felt the person who used deadly force against the unarmed beggar deserved some punishment, but they also thought the person who used deadly force against an unarmed beggar was not as culpable as the individual who used deadly force in a no threat situation. ${ }^{63}$ Lay intuitions about the culpability of the person who kills an unarmed beggar are at odds with modern self-defense doctrine and the Model Penal Code, both of which assign murder liability to an individual who uses deadly force against another individual who does not threaten death or serious bodily injury.

Theorizing about the reasons for the discrepancy between community views and the criminal codes, Robinson and Darley suggest that criminal codes are drafted with the presupposition that people who commit crimes have a high likelihood of being caught, convicted, and punished. The average person, not involved in the drafting of such legislation, may believe the criminal justice system inadequately protects innocent citizens. If the system is perceived as ineffective at providing protection, the average person may be more willing to let individuals take the law into their own hands even if this means permitting the use of deadly force against a nondeadly threat, in violation of the proportionality principle.

In the 1980s, when the Goetz shooting took place, New York subways were places where gang members terrorized riders by demanding money, covering cars with graffiti, and stealing tokens. These crimes often went unpunished. Perhaps the members of Goetz's criminal jury (six of whom had been victimized by crime; three by subway crime) ${ }^{64}$ felt Goetz had a right to use deadly force against the four Black youths who demanded that he give them five dollars, because the New York City police and Transit police were not adequately protecting New Yorkers who rode the subway. As James Levine explains: 
In New York, the subway symbolizes the perilous state of the city. It is on the subways that people often find themselves shoulder to shoulder and eye to eye with unsavory characters whom they can often avoid in the normal course of their lives. And it is in the subway that they feel at the mercy of the criminal element, with nowhere to flee and usually with no help around. The subway situation is so unnerving that many would rather endure the enormous cost and aggravation of commuting by bus or car than expose themselves to that terrifying situation. ${ }^{65}$

While it is tempting to write off the Goetz case as not involving race, the racial dimensions of the case should not be ignored. Reconsider the reasonableness of Goetz's actions if we imagine Goetz as a Black man and the four youths as White teenagers.

Four White teens board an express subway train in the Bronx at around 1:00 P.M. A Black man, carrying a concealed unlicensed pistol loaded with five rounds of ammunition, boards the same car a little later and sits down. Moments later, two of the White youths approach the Black man and one says, "Give me five dollars." Without any warning, the Black man stands up, pulls out his gun, and starts to fire it at the youths. The youths scramble to get out of the way. The Black man corners one of the youths and says, "You seem to be all right, here's another." Then he fires his last bullet into the youth's spinal cord. ${ }^{66}$

It is hard to imagine anyone thinking that shooting a loaded gun in a crowded subway is a reasonable response to a request for money. Yet the predominantly White jury that acquitted Goetz of all but the illegal possession charge obviously felt he acted reasonably when he shot the youths in response to a request for money. If Goetz had been a Black man and the four youths had been White, the jury might have seen things differently. ${ }^{67}$ Likewise, if the jury had been constituted differently, they might have reached a different verdict. ${ }^{68}$ Nine years later, an all-minority six-person civil jury, composed of four Blacks and two Hispanics, found Goetz liable to Darryl Cabey, the boy who was paralyzed after Goetz shot him in the spine, and ordered him to pay Cabey $\$ 43$ million in damages. ${ }^{69}$ 


\section{STEREOTYPES ABOUT MEXICAN AMERICANS}

\section{AND OTHER LATINOS}

Stereotypes about Mexican Americans and Latinos are varied and complex. Not all persons with Mexican or Latin American ancestry suffer from the same stereotypes because not all Latinos look alike. Some Latinos are fair and can pass as non-Latino Whites, while others are darker skinned.

Stereotypes about Mexican Americans and Latinos have received relatively little attention in legal scholarship. ${ }^{70}$ Moreover, very little social science research has been conducted on Latino stereotypes. Despite the dearth of scholarship in this area, it is commonly known that Mexican Americans and other Latinos are often perceived as foreigners or immigrants. Particularly in states bordering Mexico, such as California, New Mexico, and Texas, Mexican Americans are more often seen as Mexican than American. Even outside these southwestern states, the stereotype persists.

The foreigner stereotype may have influenced a Capitol Police security aide in Washington, D.C., who stopped U.S. Congressman Luis Gutierrez, a Puerto Rican American, and accused him of presenting false congressional credentials. ${ }^{71}$ Gutierrez was passing through a metal detector security checkpoint in one of the Capitol buildings with his daughter and niece who were carrying two small Puerto Rican flags. The security aide stopped Congressman Gutierrez, and began screaming at him for allowing the flags to slightly unfurl. According to the Congressman, "She said she didn't want to see those flags, and I told her I would take care of them. Then she said, 'Who do you think you are?' When I told her I was Congressman Gutierrez, she said, 'I don't think so."'72 The aide then added insult to injury, telling the Congressman, who was born in Chicago, to go back to his country. ${ }^{73}$ The confrontation lasted until a Capitol Police sergeant noticed what was happening, recognized the Congressman, and took the security aide away.

The Latino-as-Foreigner stereotype is particularly troublesome when it slides into the Latino-as-Illegal Immigrant stereotype because of negative associations linked to illegal immigration. ${ }^{74}$ Immigrants from Mexico and other countries in Latin America are viewed by many as lawbreakers who sneak across the border and take jobs from more deserving Americans, even though not all immigrants from Mexico are 
here unlawfully and many of the jobs they hold are low-paying positions that most Americans are unwilling to perform, such as janitorial services, housecleaning, and gardening. Hostility against immigrants who illegally enter this country sparked a popular movement in California in the 1990s to deny publicly funded nonemergency medical care, public schooling; and other social services to undocumented immigrants and their children. ${ }^{75}$ Major parts of Proposition 187 were later ruled unconstitutional. ${ }^{76}$

Linked to the image of poor, unemployed Mexicans crossing the border illegally to steal jobs from law-abiding American citizens is the idea that persons of Mexican descent are involved in criminal drug activity, either as distributors or as carriers. Mexican Americans are often stereotyped as drug users and drug dealers, ${ }^{77}$ even though drug use is lower among Latinos than it is among Whites or Blacks. ${ }^{78}$

Stereotypes about the inherent criminality of Mexican Americans have a long history in this country. Former Chief of the Foreign Relations Bureau of the Los Angeles County Sheriff's Office, Captain Ed Duran Ayres, once presented a report to a grand jury in which he asserted that Mexican youths, unlike their Caucasian counterparts, were more inclined to use lethal force during fights because of their "desire to kill." ${ }^{\prime 79}$ Mexican Americans have also been stereotyped as sly, treacherous, wily, and undependable knife carriers. ${ }^{80}$ Embracing this stereotype, former FBI director J. Edgar Hoover once said, "You never have to bother about a President being shot by Puerto Ricans or Mexicans. They don't shoot very straight. But if they come at you with a knife, beware." 81

Today, young Latino males who live in low-income high-crime neighborhoods and wear baggy pants and T-shirts are often seen as dangerous gang members. ${ }^{82}$ The belief that young Latino men dressed in a certain way are likely to be gang members may have encouraged prosecutors to believe William Masters's claim that he acted reasonably in self-defense when he shot and killed Cesar Rene Arce, a young Mexican American teenager, after catching him spray painting with a friend under a freeway in Los Angeles.

January 31, 1995. Around 1:00 A.M. Hollywood (Los Angeles), California. William Masters II, a White man, was out for a late-night walk. He spotted Cesar Rene Arce and David Hillo, two Mexican American teenagers, spray painting columns under a freeway. Masters was carrying a loaded gun in 
his fanny pack. Masters picked up a piece of paper from the ground and wrote down the license plate number of the only car parked in the area, assuming the car belonged to the boys. He planned to report the boys to the proper authorities. He was tired of seeing gang-type graffiti all over the city.

One of the teens spotted Masters as he was writing. Cesar Arce approached Masters and demanded that he hand over the piece of paper. A scuffle ensued. Arce tried to rip the paper from Masters's hand while Masters tried to jam the paper into his pocket. Then Hillo came over and held up a screwdriver in a threatening manner. Masters gave up the paper and began walking away. Suddenly, Masters pulled his gun out of his fanny pack, swung around, and began firing at the teenagers. Masters hit Arce in the back and Hillo in the buttocks. Arce died as a result of this shooting. ${ }^{83}$

Masters told the first officers to arrive on the scene, "I shot him because he was spray painting." Later, Masters claimed he shot the boys in selfdefense. In yet another explanation, Masters said he shot the boys because they tried to rob him. Hillo, the teen who survived the shooting, denied that the two had tried to rob Masters. Hillo told police that after Masters shot him in the buttocks, Masters walked up to Hillo, held the gun to Hillo's head while Hillo was lying on the ground, and said, "This all happened because you were tagging."

Although Masters was initially arrested and jailed on suspicion of murder, the Los Angeles County District Attorney's Office ultimately declined to prosecute Masters on the ground that he acted in self-defense when he shot the boys. ${ }^{84}$ The determination that Masters reasonably believed he was about to be attacked by Arce is surprising in light of the fact that Masters shot Arce in the back. It is hard to believe that one is protecting oneself against an imminent threat of death or grievous bodily injury when one shoots one's victim as he is trying to run away.

Indeed, this was the primary reason why a claim of self-defense in another high-profile case that occurred two years earlier was rejected by the same Los Angeles District Attorney's Office that declined to file murder charges against William Masters. That office filed murder and manslaughter charges against two Black men, one of whom was the rap singer known as Snoop Doggy Dogg, rejecting the defendants' claim of self-defense primarily on the ground that the victim was shot in the back. The prosecutor in charge of the case summed up his view of the 
case when he remarked, "If the famous rapper and his bodyguard acted in self-defense, why was the victim shot in the back?"85

The decision not to file criminal homicide charges against Masters was probably motivated by the belief that the government would have a difficult time convincing a jury to return a guilty verdict. The local community voiced loud support for Masters. Telephone calls flooded into the police station where Masters was being held, offering Masters money and legal assistance. Sandi Webb, a Simi Valley councilwoman, expressed her support for Masters by declaring, "Kudos to William Masters for his vigilant anti-graffiti efforts and for his foresight in carrying a gun for self-protection. If [Los Angeles] refuses to honor Masters as a crime-fighting hero, then I invite him to relocate to our town." 86

Masters's supporters were likely reacting to the fear of crime and gang violence. In Southern California, graffiti on freeway overpasses, public buildings, and even private property serves as a reminder that the threat of violent gang-related crime, including carjackings and drive-by shootings, is never too far away. One individual reflected these sentiments when he stated, "Whatever [Masters] did doesn't bother me. I'm not saying shooting people is the way to do it. ... But [the graffiti is] just disgusting. It doesn't seem like anyone's doing anything about it." 87

However legitimate the generalized fear of gang violence, such fear does not satisfy the requirement in self-defense doctrine that a person using deadly force in self-defense must have a reasonable belief that another individual poses an imminent threat of death or serious bodily injury. Moreover, defacing property through graffiti is not a capital offense. If the state is not permitted to execute a graffiti offender after a trial and conviction, a private citizen should not be permitted to kill such an offender.

Stereotypes about young Mexican Americans as gang bangers might also have influenced the lack of public concern for the victims in this case. Little research has been published on whether and to what extent presumptions about young Mexican American males as gang bangers influence perceptions of dangerousness, but such presumptions are common in cities like San Diego, which have large concentrations of lower-class and dark-complexioned Mexican Americans and Mexican nationals and in other cities close to the Mexican border.

The support generated in favor of William Masters for shooting two Mexican American teenagers engaged in spray painting is striking 
when compared to the condemnation of the Singapore government in response to its decision to cane Michael Fay, a non-Latino White teenager who was caught spray painting cars in Singapore less than a year earlier. In 1994, Fay pleaded guilty to two counts of mischief, admitting that he and others spray painted eighteen cars, threw eggs at other cars, and switched license plates on other cars.

A Singapore judge sentenced Fay to four months in prison, a $\$ 2,230$ fine, and six lashes with a rattan cane. The outrage in America was immediate. Describing her son as "a typical teenager," Fay's mother appealed to U.S. government officials to intervene and insist on clemency for her son, explaining, "Caning is not something the American public would want an American to go through. It's barbaric." 88 U.S. Embassy officials and members of the American Chamber of Commerce responded by condemning the severity of the sentence. Even President Bill Clinton asked the Singapore government to reconsider the sentence.

When a White American shoots two Mexican Americans for spray painting columns supporting a freeway, killing one of the youths, he is called a crime-fighting hero. When a foreign government canes a White American youth for spray painting and egging cars, that punishment is denounced as inhumane and cruel. If a Singapore citizen had shot and killed Fay after catching him in the act of spray painting his car, then claimed that he acted in self-defense because he thought Fay was going to hurt him, it is unlikely that people in this country would believe that Singapore citizen's claim of self-defense. Yet many in this country saw Masters as a crime-fighting hero and were sympathetic to his claim of self-defense.

\section{STEREOTYPES ABOUT ASIAN AMERICANS}

In 1995, David Magdael, President of the Asian American Advertising and Public Relations Alliance remarked, "Gone, it seems, are the days when Asian males were solely represented in the media as martial arts fighters, butlers, and laundry owners. ${ }^{189}$ While Magdael's statement may be true, racialized and gendered stereotypes about Asian Americans in general and Asian American men in particular persist even today.

The ways in which Asian Americans have been socially constructed 
in American society are varied and contradictory. Some stereotypes about Asian Americans are considered "positive" stereotypes, or stereotypes that project a favorable image of Asian Americans, while other stereotypes are considered "negative." At least three stereotypes about Asian Americans may influence perceptions about the reasonableness of a violent act when the defendant or victim is Asian: (1) the Asian-asModel-Minority stereotype, (2) the Asian-as-Foreigner stereotype, and (3) the Asian-as-Martial-Artist stereotype.

\section{THE ASIAN-AS-MODEL MINORITY}

One of the most common stereotypes about Asian Americans is the model minority stereotype..$^{90}$ This stereotype depicts Asians as smart, hard-working, law-abiding, and respectful of authority. ${ }^{91}$ Such positive images likely benefited a Korean American woman who claimed she acted in self-defense after she killed a fifteen-year-old African American girl by shooting her in the back of the head.

March 16, 1991. Los Angeles. Soon Ja Du, a Korean American woman who owned and operated a liquor store was alone at the cash register. Latasha Harlins, a fifteen-year-old African American teenager came into the store, went to the section of the store where the orange juice was shelved, selected a bottle of orange juice and placed it in her backpack. Harlins approached the cash register with two dollars visible in her hand. The bottle of orange juice, which cost only $\$ 1.79$, was also visible from Harlins's backpack. Du confronted Harlins and accused her of trying to steal the bottle of orange juice. Du called Harlins a "bitch" and pulled on Harlins's sweater. Harlins responded by hitting $\mathrm{Du}$ in the eye twice. Harlins put the orange juice down on the counter and turned to leave. Du reached under the counter and pulled out a .38 caliber revolver. From a distance of about three feet, Du shot Harlins in the back of the head, killing Harlins instantly. ${ }^{92}$

Du was charged with first-degree murder. At trial, Du argued that she should be acquitted of murder because she shot Harlins in self-defense. Alternatively, Du argued that she should be convicted of manslaughter rather than murder because she had an honest but unreasonable belief in the need to act in self-defense and acted in the heat 
of passion. Although the jury rejected Du's claim of perfect self-defense, it found her guilty of voluntary manslaughter rather than murder.

The sentencing judge was even more sympathetic to Du than the jury, and imposed an extraordinarily lenient sentence. Because Du used a firearm, she was presumptively ineligible for probation under California Penal Code section 1203(e)(2). ${ }^{93}$ Nonetheless, Judge Joyce Karlin suspended execution of Du's prison sentence and placed Du on probation for five years. Du was not required to serve any jail time as a condition of probation.

In an insightful analysis of Judge Karlin's sentencing decision, Neil Gotanda notes that Judge Karlin relied upon positive stereotypes about Korean Americans and negative stereotypes about African Americans in deciding Du's sentence. ${ }^{94}$ Judge Karlin described $\mathrm{Du}$ as a dutiful mother who was watching the store that day "to shield her son from repeated robberies." ${ }^{195}$ In referencing repeated robberies, Judge Karlin's sympathy for the Korean storeowner defendant was clear. In contrast, Judge Karlin ignored several positive facts about Latasha Harlins. The court of appeals noted:

The probation report also reveals that Latasha had suffered many painful experiences during her life, including the violent death of her mother. Latasha lived with her extended family (her grandmother, younger brother and sister, aunt, uncle and niece) in what the probation officer described as "a clean, attractively furnished three-bedroom apartment" in South Central Los Angeles. Latasha had been an honor student at Bret Hart Junior High School, from which she had graduated the previous spring. Although she was making only average grades in high school, she had promised that she would bring her grades up to her former standard. Latasha was involved in activities at a youth center as an assistant cheerleader, a member of the drill team and a summer junior camp counselor. She was a good athlete and an active church member. ${ }^{96}$

The Soon Ja $D u$ case illustrates how the model minority stereotype can benefit Asian Americans. The stereotype, however, can also be harmful to Asian Americans. As Frank Wu observes, every positive attribute of the model minority stereotype is linked to a corresponding negative characteristic: 
In the [model minority] stereotype, every positive element is matched to a negative counterpart. To be intelligent is to lack personality. To be hard-working is to be unfairly competitive. To be family-oriented is to be clannish, "too ethnic," and unwilling to assimilate. To be law-abiding is to be rigidly rule-bound, tied to traditions in the homeland, unappreciative of democracy and free expression. ${ }^{97}$

For example, public reaction to the chaos and looting in Los Angeles that followed the acquittal of four police officers who brutally beat Rodney King reflected conflicting feelings of sympathy for, as well as resentment against, the Korean Americans whose lives were caught up in the destruction. Just as Asian Americans in general are often held up as the "good" minority compared to the other "bad" minorities, Korean American store owners were sympathetically portrayed as the unfortunate victims of "bad" African American and Latino looters. At the same time, Korean Americans were negatively portrayed as property-loving, gun-toting store owners who valued their material possessions over human life. ${ }^{98}$

The model minority stereotype may have another harmful effect. Rhoda Yen argues that it "may lead to an increased likelihood of criminal acquittals in cases involving Asian American victims." cause the stereotype encourages the belief that "Asian Americans are unlikely targets for racially-motivated crimes." ${ }^{100}$ Crimes involving Asian American victims are rarely viewed as hate crimes. Instead they are considered "crimes that merely happen to involve minority victims."101 For example, the brutal beating of Vincent Chin, while perceived as a crime of hate by most in the Asian American community, was largely seen by White Americans as "a drunken brawl between two men, one of whom happened to be Asian."102

\section{Vincent Chin}

Petroit, Michigan. June 19, 1982. Vincent Chin, a Chinese-American man, and several of his friends had gone to the Fancy Pants strip bar to celebrate Chin's upcoming marriage. Ronald Ebens and Michael Nitz, two White men, were sitting directly across from Chin's group of friends. Ebens and Nitz started calling Chin a "Nip," a derogatory name for a person of Japanese descent, derived from the word "Nippon" which is the Japanese word for Japan. Referring to the growth of foreign car imports and rising unem- 
ployment, Ebens yelled, "It's because of you little mother fuckers that we're out of work." ${ }^{103}$ Chin got out of his chair and walked up to Ebens. Chin threw a punch, a scuffle ensued, and Chin, Ebens, and their friends vere asked to leave the bar. Chin challenged Ebens to finish the fight outjide. Ebens went to Nitz's car and retrieved a baseball bat. When Chin saw Ebens with a baseball bat, he fled. Ebens and Nitz chased Chin. When Hbens and Nitz finally caught up with Chin, Ebens struck Chin repeatedly with the baseball bat. Witnesses told investigators that Ebens swung the baseball bat at Chin's head as if he were hitting a home run. Chin's skull was fractured in several places and police officers on the scene said pieces $\oint f$ Chin's brain were splattered all over the sidewalk. Chin died four days later. $^{104}$

Ebens and Nitz were charged with second-degree murder. They each pled no contest to manslaughter and were sentenced to three years of probation and a fine of $\$ 3,780$. When asked why he did not impose any jail time on Ebens and Nitz, Judge Charles Kaufman responded, "Had it been a brutal murder, those fellows would be in jail now." 105 Judge Kaufman did not see the killing of Vincent Chin as a brutal murder, even though Ebens struck Chin's head so hard that pieces of his brain were splattered all over the sidewalk. Judge Kaufman explained further why he thought Ebens and Nitz did not deserve any jail time:

These [aren't] the kind of men you send to jail. We're talking here about a man who's held down a responsible job with the same company for seventeen or eighteen years and his son who is employed and is a part-time student... These men are not going to go out and harm somebody else. I just [don't] think that putting them in prison [will] do any good for them or for society. ${ }^{106}$

Expressing the sentiments of many Asian Americans, Chin's mother decried the judge's sentence, asking, "What kind of law is this? What kind of justice? This happened because my son is Chinese. If two Chinese killed a white person, they must go to jail, maybe for their whole lives."107

Most people who are familiar with the Vincent Chin story know it as a case of racial prejudice. Robert Chang explains how race, class, and gender converged to make the Vincent Chin story more complicated than it appeared in the press: 
In order for Vincent Chin to become the focal point of organizing and politicizing people about anti-Asian violence, the unsavory parts of the narrative were suppressed. The standard narrative does not include the fact that the encounter between Vincent Chin and the two white autoworkers took place in a strip club where Chin was having a bachelor's party. In the standard narrative where Chin is a victim of racial violence, we are uncomfortable with Chin's participation in the objectification of women. The standard narrative also does not include the fact that it was Chin who threw the first punch, or the fact that ... Chin said, "Come on, you chickenshits, let's fight some more." This is not to say that Chin was not a victim of racial violence-my point is that this is not a simple case of an aggressor and victim and mistaken racial/ethnic identification. Bringing in the suppressed details provides a richer story involving race, nation, class, and sexuality. ${ }^{108}$

Chang explains how Chin participated in the objectification of women.

There may have been other showgirls, but one stripper was black, the other white. Chin gave a large tip to the white dancer and a small tip to the black dancer. The black dancer didn't like the way Chin wanted to give her the tip, which we might presume was in her G-string, so she only received a small tip. We can imagine, then, that the white dancer permitted this way and got a larger tip. Furthermore, Ebens and Nitz were unhappy that Chin was enjoying the show. Why did Chin's enjoyment make them unhappy? ${ }^{109}$

Chang answers this question by explaining that Ebens and Nitz felt doubly displaced by Chin. First, they felt Chin and others like him were displacing them from their jobs. Second, because of Chin's economic security, they felt displaced by Chin as consumers of (the white dancer's) sexual attention. Chang explains:

My thesis is that Ebens and Nitz were suffering a double displacement. People like Chin were making people like Ebens and Nitz lose their jobs. Even though Ebens was still employed as a foreman in an automobile plant, he clearly identified with laid-off autoworkers. But there was more. Chin was displacing them as (the rightful) consumers of sexual attention. Here we have economics, race, gender, and sexuality coming together in interesting ways. Loss of jobs entails a loss of 
masculinity. The loss of masculinity was caused by a racial and foreign Other, an Asian man who in many ways was just like them. The bonding that might normally take place between men in a strip club is disrupted by Chin's Asianness. Further, the Asian man may be improperly consuming the sexual attention of a white woman, which, in part, he is able to do because he is doing well, economically, by displacing people like Ebens and Nitz from their jobs. We have, then, a double displacement along with a threat to racial purity, a threat to the very whiteness that provides their sense of place and entitlement in America. ${ }^{110}$

\section{THE ASIAN-AS-FOREIGNER STEREOTYPE}

Fear of the foreigner is sometimes a black streak that runs through America's political culture. We see instances of [this] when it involves hate crimes, not necessarily directed at black Americans, but at foreign Americans.

-Mike McCurry, Former White House Press Secretary to President Bill Clinton

Even though it is oxymoronic to speak of "foreign" "Americans," the term "foreign Americans" conveys meaning. Asians and Latinos are usually considered foreign Americans. A person who asks an Asian American, "So, where are you from?" usually expects to hear, "I'm from Japan," or "I'm from China," or "I'm from Vietnam." If one answers, "I'm from Houston," or "I'm from New York," one is likely to be asked, "No, I mean, where are your parents from?" Even if true, it won't do to say, "My parents were also born in Houston," because the speaker is interested in finding out which foreign country the Asian person is from, even if she isn't from a foreign country.

The focus on the Asian in Asian American is deep-rooted. During World War II, when the United States was at war with Japan, hostility toward Japan extended to all persons of Japanese ancestry, even Japanese Americans born and raised in the United States for several generations. From 1942 to 1945 , all persons of Japanese descent were forced to leave their homes and were incarcerated in internment camps because the American government viewed them as a potential threat. ${ }^{111}$

In times of economic uncertainty, resentment and violence against 
Asian Americans seem to increase as individuals vent their frustrations on model-minority Asian Americans who are perceived as stealing valuable job opportunities from "real" Americans. Because many individuals can't tell Americans of Asian descent apart from Asian nationals, Asian Americans are mistaken for Asian nationals and then blamed for foreign imports that threaten domestic goods, such as American cars. In the film, Who Killed Vincent Chin? filmmakers Renee Tajima and Christine Choy illustrate the association between Asians and foreign car imports by juxtaposing the image of angry White American autoworkers and their friends taking turns swinging a baseball bat as hard as possible at a Japanese economy car with the actual baseball bat beating of Vincent Chin, a Chinese American man who was mistaken for a Japanese. ${ }^{112}$ Around the time of Chin's death, a Detroit radio station hosted "Toyota parties," encouraging people to demolish Japanese autos with a sledgehammer, and a car dealership in Detroit ran television commercials that showed a battle tank crushing a Japanese car. ${ }^{113}$

The Asian-as-Foreigner stereotype continues today, although it often takes more subtle forms. During the O. J. Simpson trial, for example, much of the racial joking that arose in connection with the case was directed at two prominent Asian Americans, the presiding judge, Lance Ito, and the criminalist, Dennis Fung. Ito and Fung, both of whom speak English without a noticeable accent, were portrayed by radio station disk jockeys, publishing houses, and even a United States senator as bumbling, heavily accented Asians who could barely speak English. ${ }^{114}$ The 1996 campaign finance scandal involving Johnny Huang and the Democratic National Party and the December 1999 arrest of scientist Wen Ho Lee on charges of illegally downloading nuclear secrets raised the specter of the evil Asian foreigner again, prompting Neil Gotanda to opine that "The Wen Ho Lee case and the campaign finance scandals are the most serious threat to Asian Pacific Americans since the end of the Vietnam war."115

Another example of the Asian-as-Foreigner stereotype at work is reflected in crimes of violence against Asians and Asian Americans. Jerry Kang has noted that Asians and Asian Americans are often targeted by muggers who assume that all Asians carry a lot of cash. ${ }^{116}$ The fact that some individuals from certain Asian countries do carry a lot of cash contributes to this type of targeting. A mugger who sees someone who looks Asian is not likely to know whether the person was born and raised in the United States or is from another country, and is not likely 
to ask. The problem is compounded by stereotypes about Asians as "physically weak and culturally adverse to defending themselves."117

The Asian-as-Foreigner stereotype is complicated by the fact that approximately two-thirds of all Asians in the United States are foreignborn. Frank Wu cautions us not to use this statistical information to "justify the assumption that everyone with an Asian name is a guest or a tourist," because such an assumption "leads to implications that the Asians are enjoying their sojourn and will ultimately return elsewhere." ${ }^{118}$

Because of the constant conflation of Asian nationals and Asian Americans, symptomatic of the Asian-as-Foreigner stereotype, the tragic shooting of Yoshihiro Hattori, a Japanese foreign exchange student, has special significance for Asian Americans. Hattori died after being shot by a Louisiana homeowner who claimed he shot the unarmed Japanese teenager in self- defense.

October 17, 1992. Two sixteen-year-old high school students, Webb Haymaker and Yoshihiro Hattori, were looking for a Halloween party in the suburbs of Baton Rouge, Louisiana, when they came across the home of Rodney and Bonnie Peairs. The home was decorated for Halloween, and was just a few doors away from the correct house. Hattori was a Japanese foreign exchange student, and Haymaker was a member of his host family. Haymaker was dressed as a car accident victim. Hattori was dressed as the character played by John Travolta in the movie "Saturday Night Fever." He wore a white tuxedo jacket and carried a small black camera. The boys rang the front doorbell. No one answered the door, but the boys heard the clinking of window blinds coming from the carport area. The boys walked around the house towards the carport, Haymaker leading the way. A moment later, Bonnie Peairs opened the back door leading out to the carport. She saw Haymaker, who started to say, "We're here for the party." Then Hattori came around the corner. When Bonnie Peairs saw Hattori, she emitted a scream, slammed the door, and called for her husband to "get the gun." Without asking any questions, Rodney Peairs ran to the bedroom and grabbed a laser-scoped .44-magnum Smith and Wesson, one of a number of guns he owned.

The two boys had walked away from the house and were on the sidewalk about ten yards from the house when Peairs rushed out of the house from the back door and into the carport area. The carport light and a street light in front of the house illuminated the carport and the sidewalk area. 
Hattori turned and approached Peairs, smiling and explaining in his broken English, "We are here for the party." Rather than telling Hattori that he had the wrong house, Peairs pointed his laser-scoped gun at Hattori and shouted, "Freeze." Hattori, who was from Japan, a country where firearms are prohibited, had never learned the English word "Freeze," so he continued to approach Peairs. Without waiting a second longer, Peairs fired one shot at Hattori's chest. Hattori collapsed and died on the spot. The entire incident-from the time Peairs opened his back door to the time he fired his gun-took place in approximately three seconds..$^{119}$

Peairs was charged with manslaughter. At trial, Peairs asserted that he shot Hattori in self-defense. He claimed that Hattori was skipping or walking very fast toward him and looked very scary. Peairs said Hattori, the slight teenage boy, looked like a crazy man. When Hattori did not stop after Peairs shouted at him to freeze, Peairs claimed he was terrified and thought his life was in danger. Although Hattori was carrying a camera, Peairs did not claim that he thought the camera was a gun. In fact, Peairs later admitted, during the course of the civil wrongful death action filed by Hattori's parents, that he did not see a gun, knife, stick, or club in Hattori's hand that night. ${ }^{120}$

The judge instructed the jury that in order to acquit Peairs, they had to find that Peairs reasonably believed he was in imminent danger of losing his life or receiving great bodily harm and that the killing was necessary to save Peairs from that danger. After little more than three hours of deliberation, the jury found Peairs not guilty of manslaughter. Spectators in the courtroom applauded the verdict. In contrast to the public outrage over the short deliberation process in the O.J. Simpson case, in which jurors reached a verdict of acquittal in less than four hours, ${ }^{121}$ there was little public outrage over the shortness of deliberation time leading to Peairs's acquittal. In fact, residents of the town of Baton Rouge felt so strongly that Peairs was justified in shooting Hattori that they loudly objected to plans to erect a memorial in honor of Hattori.

The key question in the Peairs case was whether it was reasonable for Peairs to believe (1) that he was in imminent danger of death or great bodily harm, and (2) that it was necessary to shoot Hattori to protect himself from such imminent death or great bodily harm. Reasonable minds can certainly disagree on this question. On the one hand, Peairs had pointed a gun at Hattori and shouted at him to freeze. Hattori kept approaching. Arguably, the average Louisiana homeowner in Peairs's 
situation could have thought Hattori posed a very real threat of death or great bodily injury. If Hattori wouldn't stop after being warned to stop, there was nothing left to do but shoot. Additionally, this shooting took place in Louisiana. As discussed in chapter 1, place (i.e., geographic location) has some influence over whether the use of deadly force is seen as reasonable. Studies have shown that men in Southern states are more prone to perceive nonthreatening insults as a threat to their honor and more prone to respond violently to threats of a nondeadly nature. ${ }^{122}$

On the other hand, Peairs could have completely avoided the shooting tragedy by retreating into his house and locking the door. Once inside, Peairs could have called the police. There was little reason to think Hattori would try to follow Peairs inside the house and force the door open. Recall that by the time Peairs came outside with his gun, the two boys were already on the sidewalk, leaving the premises. They were not hanging around near the back door, waiting for someone to open it so they could enter. Moreover, Peairs did not have to go outside in the first place. When his wife screamed at him to get the gun, Peairs could have asked her why she was screaming. He could have quickly locked the doors and called the police. In fact, if Hattori and Haymaker had been robbers, it would have been much safer for Peairs to lock the doors right away (to prevent entry into the home), rather than rushing to get a gun. Any of these less fatal measures would have avoided the imagined danger posed by Hattori.

How did the Asian-as-Foreigner stereotype influence the verdict in this case? The fact that Hattori was in fact a foreigner, a Japanese citizen and not an American, simply made it easier for the Baton Rouge jury to empathize with Peairs. They could picture themselves in Peairs's shoes. If an Asian teenager came onto their property and refused to freeze even with a gun pointed at his chest, that teenager was asking to be shot. Bonnie Peairs's trial testimony is very revealing in this regard. When asked to describe Hattori, she responded, "I guess he appeared Oriental. He could have been Mexican or whatever."123 Mrs. Peairs was unable to tell whether Hattori was Asian or Mexican or neither. All she knew was that Hattori was different. He wasn't White like her.

Because of Hattori's nationality, the jurors couldn't see Hattori as one of their own sons. If Webb Haymaker, the boy from the neighborhood, had been the victim in this case, Peairs would have found it difficult to persuade the jury that he was terrified for his life and thought the 
boy looked like a crazy man. It would have been difficult for the defense to paint a credible picture of the victim as the bad guy. If Haymaker had been shot and killed, it is unlikely that the spectators in the courtroom would have applauded the not guilty verdict. Haymaker's parents and his siblings would have been in the courtroom, reminding the other members of that Baton Rouge community that the dead boy could have been their son. But it was a teenager from Japan who was shot and killed, and the sight of his grieving parents in the courtroom only served to remind the jurors that the victim was not one of the community's own.

\section{THE ASIAN-AS-MARTIAL-ARTIST STEREOTYPE}

Another stereotype that affects mostly the male half of the Asian population is what I call the Asian-as-Martial-Artist stereotype. ${ }^{124}$ This stereotype seems to surface only when convenient. Not all Asian men are assumed to know kung-fu or karate. As far as Asian male stereotypes go, Asian men are either thought of as nerdy computer scientists or engineer types who lack basic social skills or martial arts jocks like Bruce Lee. ${ }^{125}$

The Asian-as-Martial-Artist stereotype links Asians to proficiency in karate, kung-fu, Tae-kwan-do, or some other martial art form from Asia. The image of the Asian male as martial artist became popular in the 1970s with a series of kung-fu films featuring the legendary Bruce Lee. The image has continued with a number of high-profile Asian martial arts actors such as Jackie Chan, Chow Yun Fat, and Jet Li. Even older Asian men such as Pat Morita (the elderly Japanese man in The Karate Kid who teaches his young pupil how to block, kick, and punch), are portrayed as possessing almost magical ability to defend themselves from attack and disable opponents.

The Asian-as-Martial-Artist stereotype has influenced some individuals to use deadly force against an Asian American they thought knew martial arts. Take, for example, Anthony Simon, who shot his next-door neighbor because he thought the Chinese American knew martial arts.

Anthony Simon, an elderly White man, was afraid of his next-door neighbor, Steffen Wong, because Wong was Chinese and Simon assumed Wong 
was an expert in the martial arts. The two men each owned half of the same duplex and had exchanged heated words in the past. The elderly Simon was also afraid of the changing demographics in the neighborhood. Many Asians were moving into the neighborhood. An Asian had even expressed interest in buying Simon's home. Simon was afraid of being surrounded by "Orientals." One day, as Wong was entering his own home, Simon pulled out a gun and, for no apparent reason, shot Wong. ${ }^{126}$

Simon was charged with two counts of aggravated assault. At trial, Simon argued that he shot Wong in self-defense. Simon explained that he thought Wong knew martial arts and posed an imminent threat of danger to Simon. The judge instructed the jury that "A person is justified in the use of force to defend himself against an aggressor's imminent use of unlawful force to the extent it appears reasonable to him under the circumstances then existing." Finding Simon's claim of selfdefense credible, the jury acquitted Simon on both counts.

Although the verdict of acquittal can be explained by reference to the subjective standard of reasonableness used in the jury instruction, ${ }^{127}$ it is shocking that a jury could conclude that Simon acted in self-defense when Wong did nothing to provoke the attack. It is all the more disturbing because Simon's self- defense claim was explicitly based on an incorrect assumption about Wong's proficiency in the martial arts.

The Asian-as-Martial-Artist stereotype may have also encouraged a police officer in Rohnert Park, California, to shoot and kill Kuan Chung Kao, a drunk Taiwanese American man who had no martial arts experience:

April 29, 1997. Kuan Chung Kao, a thirty-three-year-old Taiwan-born engineer, lived in Rohnert Park with his wife and three children. One evening, Kao went to the Cotati Yacht Club to celebrate a new job. Kao came to the club about twice a week, always in a suit and tie. Normally, he did not get drunk or act aggressively towards other patrons. That night, however, Kao did get drunk and also got into an altercation with another customer who referred to Kao as a Japanese person. Kao corrected him, saying that he was Chinese. The other customer responded, "You all look alike to me." The bartender separated the two men, seating them at opposite ends of the bar. A couple of hours later, the same customer who had upset Kao earlier said something else (which the bartender couldn't hear) that provoked Kao. According to customers, Kao became livid and began 
kicking and shouting, "I'm sick and tired of being put down because I'm Chinese. If you want to challenge me, now's the time to do it." A scuffle broke out and the Cotati police were called. By the time the police arrived, Kao had calmed down. The bartender talked the police out of taking Kao in. Kao was sent home in a taxi. There, Kao continued to shout from the driveway of his home. Neighbors called the police around 2:00 A.M., complaining that Kao was screaming and yelling in the street. By this time, Kao had taken off his shirt and was lying in the middle of the street, crying, "Oh my neighbors, help me." Kao then retrieved a six-foot long wooden stick from a motor home parked in his driveway and began waving it around.

Minutes later, Officer Mike Lynch arrived on the scene. Officer Lynch tried to scare Kao by shining the headlights of his patrol car on Kao, driving his car quickly towards Kao, then braking about three or four feet from Kao to avoid hitting him. Kao continued to yell and banged his stick on Officer Lynch's car.

Next, Officer Jack Shields pulled up to the scene. Officer Mike Lynch radioed to Officer Shields and advised him to stay in his car and wait for back-up. Instead, Shields got out of his patrol car and, without identifying himself as a police officer, ordered Kao to drop the stick. Kao, with a blood alcohol level of 0.23 , kept hold of the stick, jabbing it towards Officer Shields and his patrol car. Kao's wife, Ayling Wu, came out of the house and tried to approach her husband to take the stick away from him, but Officer Shields ordered her to back off. Wu retreated and the next thing she knew, Shields had shot her husband in the chest. A mere thirty seconds had elapsed between the time Officer Shields got out of his car and his decision to shoot Kao. After Kao was shot, the officers handcuffed him and left him lying face down on the ground. $\mathrm{Wu}$, a registered nurse, tried to give first aid to her husband, but the officers restrained her and threatened her with arrest. By the time paramedics arrived, it was too late to save Kao. ${ }^{128}$

After the shooting, the Sonoma County Sheriff's Office conducted an investigation into the homicide. The Office interviewed the two officers who were on the scene, neighbors, and others, and concluded that Officer Jack Shields shot Kao in self-defense. ${ }^{129}$ Relying largely on the Sheriff's Office's report, the Sonoma County District Attorney's Office declined to press charges against Officer Shields, explaining that "the death of Kuan-Chung Kao was the result of Officer Shields' use of deadly force to protect himself from serious bodily harm or death." ${ }^{\prime 30}$ 
The U.S. Attorney's Office also declined to prosecute Officer Shields for lack of sufficient evidence. ${ }^{131}$

Officer Shields could have chosen less fatal means of resolving the situation. He could have either stayed in his police car as his partner advised or retreated there once he surveyed the situation. He could have called for backup or fired a warning shot. Instead, the officer fired within thirty seconds of getting out of his car. Despite these less deadly alternatives, Officer Shields's belief that he had to shoot Kao, an obviously drunk and overweight middle-aged man, ${ }^{132}$ in order to protect himself from death or serious bodily injury, was considered reasonable.

In this case, like the Simon case, the shooting was precipitated by a false belief that the target, an Asian male, knew martial arts. In his interview with the Sheriff's Office, Officer Shields stated, "He was flipping it [in] what I would refer to as a martial arts-type of uh, moves. Things that $I$ have seen in demonstrations and on T.V. . . . flipping it around, over, around his head . . . and around his back." 133 Officer Lynch told investigators that when he arrived on the scene, he saw an Asian male, about thirty to forty years old, carrying a pole which looked like a closet rod. ${ }^{134}$ Lynch continued, "He was running around in a little circle and started spinning the pole around in his hands like you see a Ninja fighter do."135 "I was real concerned about this guy on top of the fact that I didn't know if the guy had any other weapons aside from this staff he's, he's playing with, um, and you know, the, the thoughts that went in my mind when I saw him spinning the thing around, it was like the, the, um, the movies you see with martial arts guys, the, you know, the Ninja and stuff." ${ }^{\prime 36}$ Some of Kao's neighbors also thought the drunk Asian man was acting "in a manner consistent with a Ninja fighter" and standing in a "Samurai warrior-type stance." 137

In an effort to substantiate Officer Shields's claim of self-defense, the police obtained a search warrant immediately after the shooting to look for martial arts equipment and any evidence that Kao was a martial arts expert. ${ }^{138}$ Normally, search warrants are sought to aid police in gathering evidence of a crime against a suspect. In this case, however, a search warrant was sought to search the home of a dead man who could not be charged with any crime relating to the incident. The search warrant, like the rest of the investigation into the shooting, seemed designed to help exonerate the officers. ${ }^{139}$ 
No evidence of martial arts equipment was found because Kao had no martial arts experience. ${ }^{140}$ The lack of evidence to support Officer Shields's belief that Kao knew martial arts, however, did not preclude the Sheriff's Office from finding that his belief was reasonable. According to both the Sheriff's Office and the District Attorney, a drunk, overweight Asian man waving a stick posed a sufficient threat to justify shooting him to death. 